\title{
ANALYSIS OF THE EFFECTS OF ADAPTIVE RAMP METERING \\ ON MEASURES OF EFFICIENCY WITH A PROPOSED \\ FRAMEWORK FOR SAFETY EVALUATION
}

\author{
A Thesis \\ presented to \\ the Faculty of California Polytechnic State University, \\ San Luis Obispo
}

\author{
In Partial Fulfillment \\ of the Requirements for the Degree \\ Master of Science in Civil and Environmental Engineering
}

by

Jacky Loh

June 2019 
(C) 2019

Jacky Loh

ALL RIGHTS RESERVED 


\section{COMMITTEE MEMBERSHIP}

TITLE: Analysis of Effects of Adaptive Ramp Metering on Measures of Efficiency with a Proposed Framework for Safety Evaluation

AUTHOR: Jacky Loh

DATE SUBMITTED: June 2019

COMMITTEE CHAIR: $\quad$ Anurag Pande, Ph.D.

Associate Professor, Civil and Environmental

Engineering

COMMITTEE MEMBER: Kimberley Mastako, Ph.D.

Lecturer, Civil and Environmental Engineering

COMMITTEE MEMBER: Carole Turley Voulgaris, Ph.D.

Assistant Professor, Civil and Environmental Engineering 


\begin{abstract}
Analysis of Effects of Adaptive Ramp Metering on Measures of Efficiency with a Proposed Framework for Safety Evaluation

Jacky Loh
\end{abstract}

Adaptive ramp metering (ARM) is a widely popular intelligent transportation system (ITS) tool that boasts the ability to reduce congestion and streamline traffic flow during peak hour periods while maintaining a lower implementation cost than traditional methods such as freeway widening. This thesis explores the effectiveness of ARM implementation on an 18 mile segment of the Interstate 80 (I-80) corridor in the Bay Area residing in northern California. Smaller segments of this particular segment were analyzed to determine the effective length of ARM on efficiency at various lengths originating from a known bottleneck location. Efficiency values were also compared against a control segment of the Interstate 280 (I-280) in San Jose to provide a test site experiencing similar traffic congestion but without any ARM implementation. An Empirical Bayes analysis was conducted to provide the foundation of a safety evaluation of the ramp metering implementation and determine a counterfactual estimate of expected collisions had ARM implementation not occurred.

It was found that the installation of the ramp meters did allow for some marginal increases in efficiency but may not be entirely associated with ARM implementation due to a variety of external factors as well as showing inconsistent behavior between analyzed segments. Regarding safety, the predictive model estimates 32.8 collisions to occur along a 0.5 mile segment within a three-year timeframe if ARM were not installed, which implies substantial improvements in safety conditions. However additional efficiency and safety data within the "after" period may be necessary to provide a more robust and conclusive evaluation as the ARM system is still relatively new. 
Keywords: Adaptive Ramp Metering, Intelligent Transportation System (ITS), Efficiency, Safety, Performance Measurement System (PeMS), Transportation Injury Mapping System (TIMS), Interstate 80 (I-80), SMART Corridor Project 


\section{ACKNOWLEDGMENTS}

This research was supported by the Metropolitan Transportation Commission (MTC) and funded via grant from the Center for Transportation Equity, Decisions and Dollars (CTEDD) and the Mineta Transportation Institute (MTI). Your continued support and funding in the development of this research was invaluable - this project would not have been possible without you. I'd like to thank Caltrans for providing access to their Performance Measurement System (PeMS) and, by extent, to the necessary VMT and VHT data for efficiency analysis. Much thanks is also owed to UC Berkeley and their Safe Transportation Research and Education Center (SafeTREC) for providing access to their Transportation Injury Mapping System (TIMS) vehicle collision data.

Additional Acknowledgements Include:

To Dr. Pande: Your endless dedication to research and knowledge are truly inspirational. I am grateful that you took me under your wing to develop as a researcher and graduate student and hope that I can one day become as important to someone else's success as you have been to mine.

To Dr. Mastako and Dr. Voulgaris: Thank you both for taking the time to review my work and for providing guidance, mentorship, and encouragement throughout the development of this research (as well as throughout my academic career).

To Travis Low: Thank you for providing the foundation and beginnings of this thesis as well as providing answers to any questions I had.

To Faridur Rahman and Bernice Liu: Thank you both for embarking on this graduate journey with me together under Dr. Pande's tutelage. I cannot imagine how working through the 
seemingly endless challenges of this thesis would have ended if I did not have either of you to share in the experience.

To my family: Thank you for providing encouragement and support when needed most, and for being a source of peace and logic throughout this entire process.

And to my friends, most notably Kyle Aube, Steffi Chao, Brandon Friedman, Ally Woo, and Yingyi Xu: Thank you for offering the encouragement, advice, and listening ear I've come to truly appreciate throughout our time here at Cal Poly. Thank you as well for taking the time to at least try and be interested in topics you didn't completely understand just so I might let off some steam. And last of all, thank you for the timely reminders to go sleep at a decent time, which I soundly ignored but nevertheless found solace and comfort in hearing. 


\section{TABLE OF CONTENTS}

Page

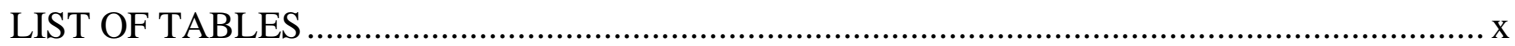

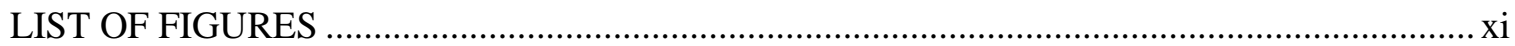

\section{CHAPTER}

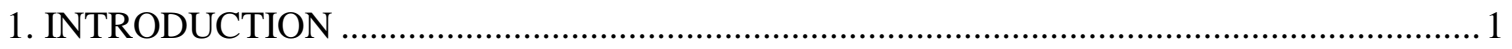

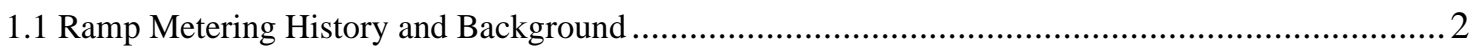

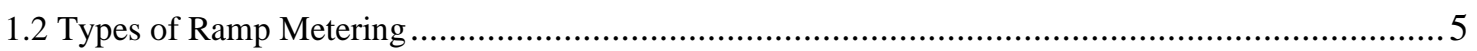

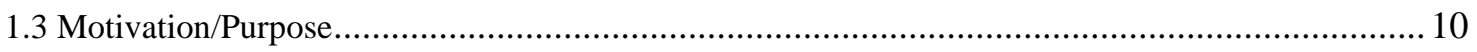

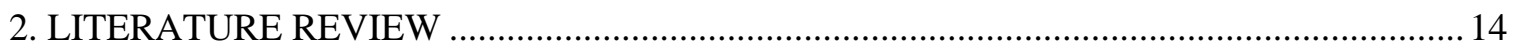

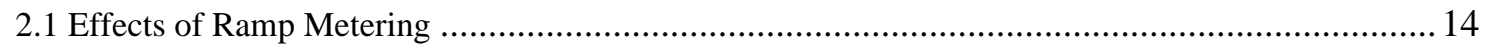

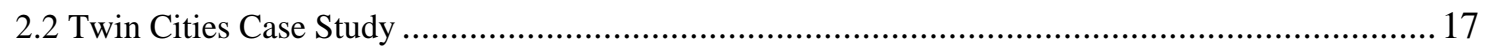

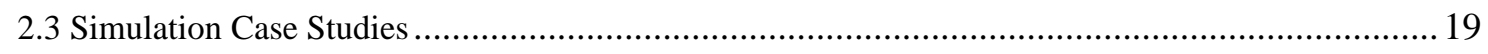

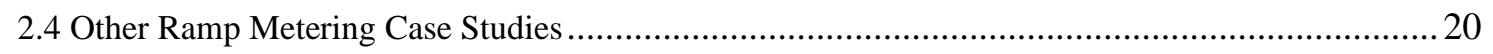

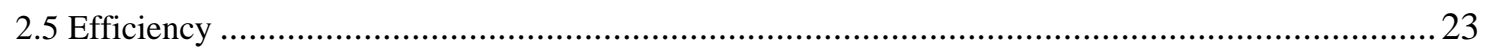

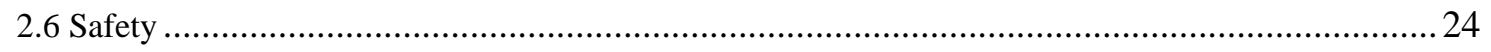

2.6.1 Safety Case Study on Variable Speed Limit Systems .......................................................2

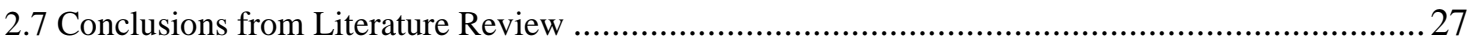

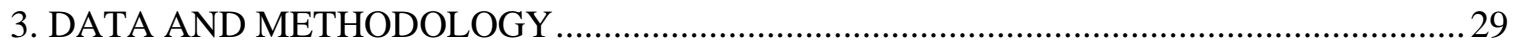

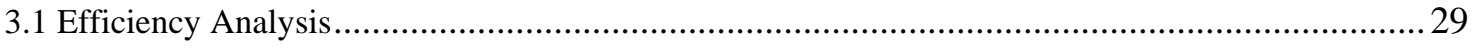

3.1.1 Data Source - Performance Measurement System (PeMS) ................................................2 29 


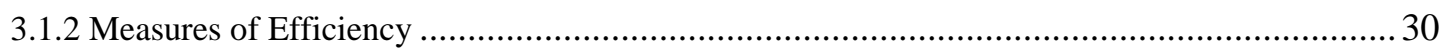

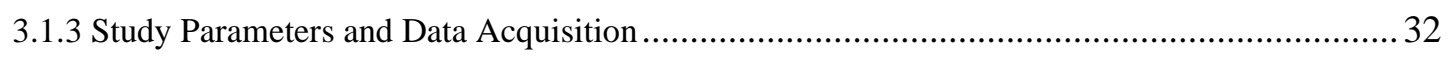

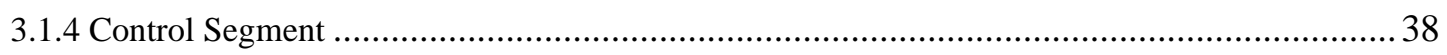

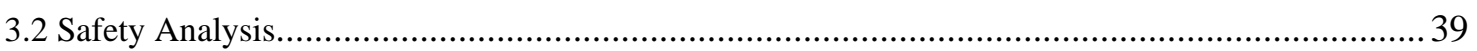

3.2.1 Data Source - Transportation Injury Mapping System (TIMS) …...................................... 39

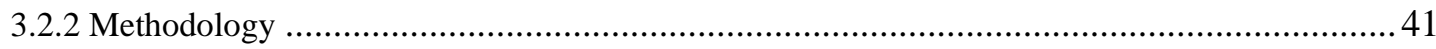

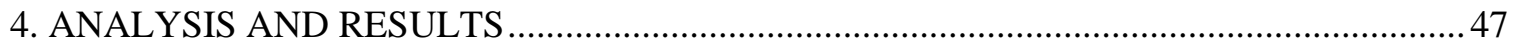

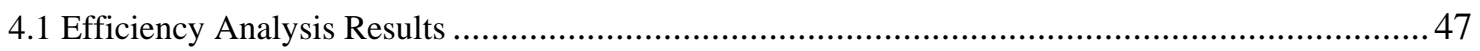

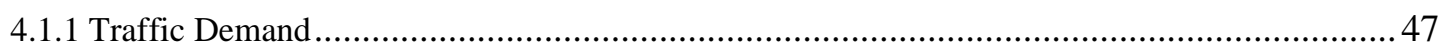

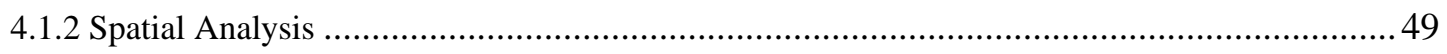

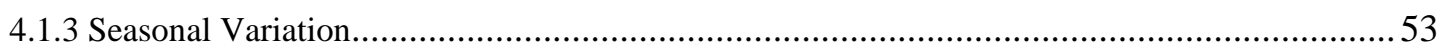

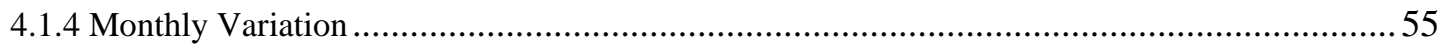

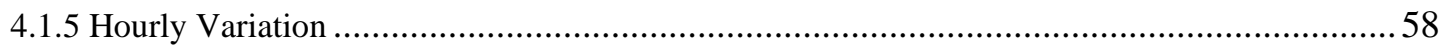

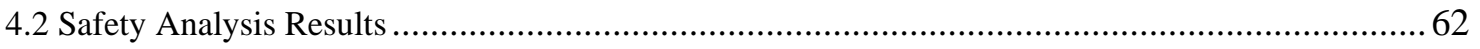

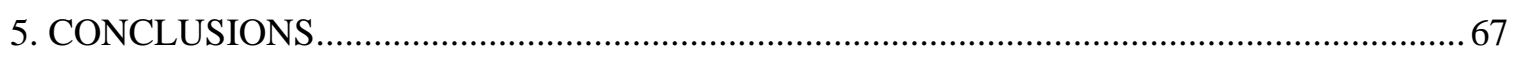

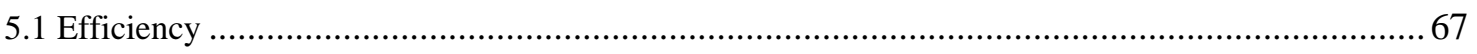

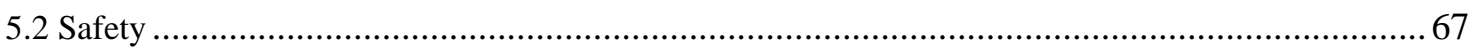

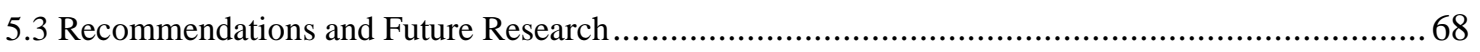

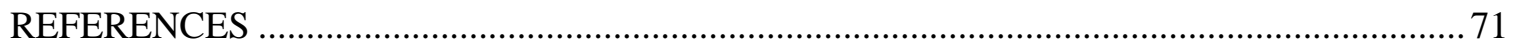

APPENDICES

A. Detailed Graphs Showing Spatial Analysis and Monthly Variations............................................. 74

B. Step-by-Step Guide Acquiring Data from PeMS Database ................................................. 77 
C. ISATe Spreadsheet Data Inputs

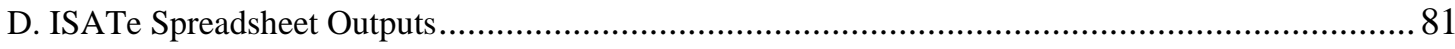




\section{LIST OF TABLES}

Table

Page

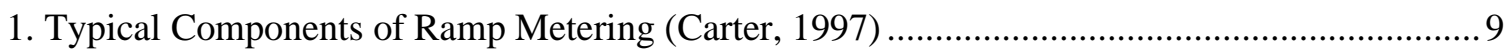

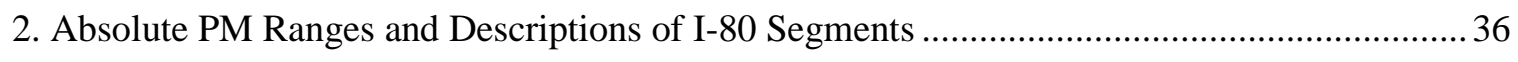

3. Label of Year and Corresponding Duration of Analysis ...................................................... 37

4. Absolute PM Range and Description of I-280 Control Segment............................................. 39

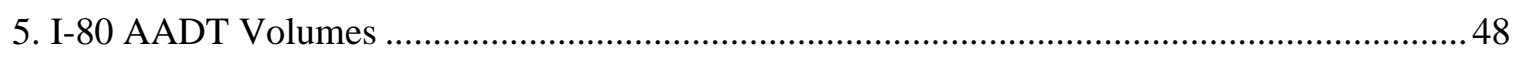

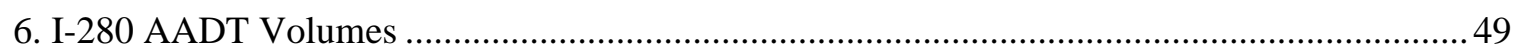




\section{LIST OF FIGURES}

Figure

Page

1. Typical Layout of Ramp Metering System (Carter, 1997) ................................................... 9

2. Local Traffic Operations Stalled Due to Queue Spillback (D. Kan, 2017) .............................. 15

3. Bottleneck Forming as a Result of Queue Override (D. Kan, 2017) ...................................... 16

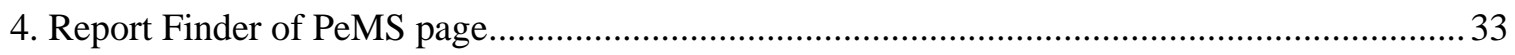

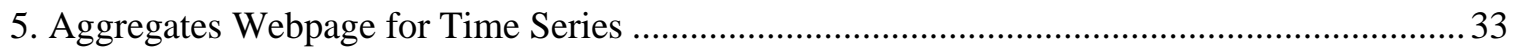

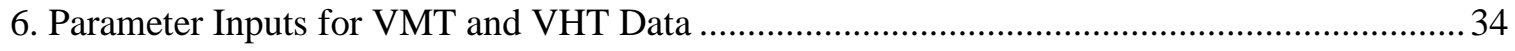

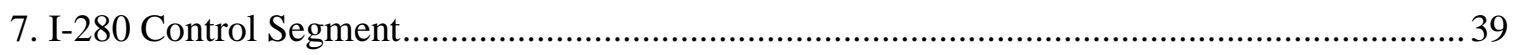

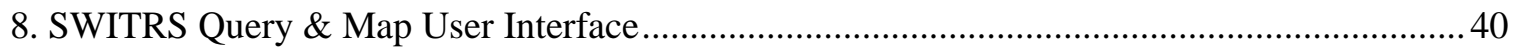

9. I-80 Segment from Cutting to Macdonald Split into Four Subsections ...................................42

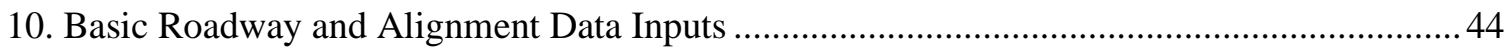

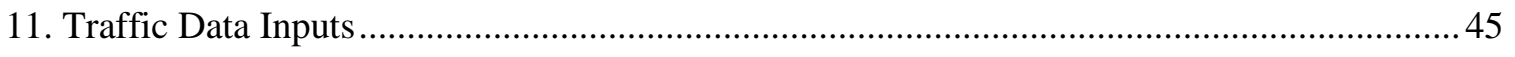

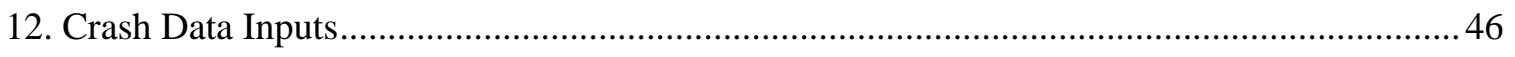

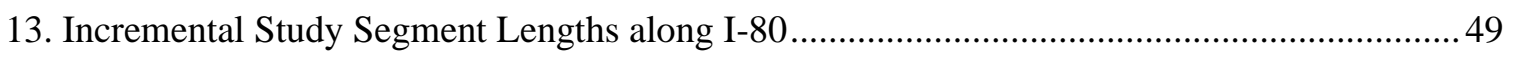

14. Average Efficiency Comparing I-80 EB PM and I-280 SB PM........................................51

15. Average Efficiency Comparing I-80 WB AM and I-280 SB PM ....................................... 51

16. Average Efficiency for Various Segment Lengths along I-80 EB PM ................................52

17. Average Efficiency for Various Segment Lengths along I-80 WB AM ...............................53

18. Seasonal Variation in Efficiency between I-80 EB PM and WB AM Directions.....................54

19. Seasonal Variation in Efficiency between I-80 Critical Segment and I-280 Control

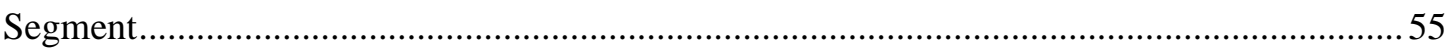

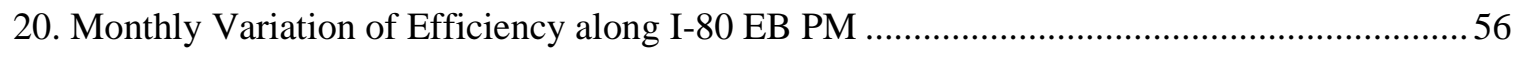

21. Monthly Variation of Efficiency along I-80 EB PM Segment 1 .........................................56

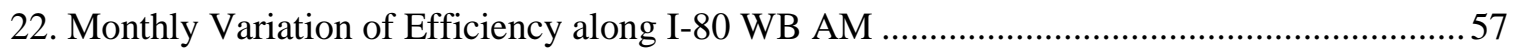


23. Monthly Variation of Efficiency along I-280 SB PM.

24. Average Efficiency by PM Peak Hour for Major Segments.

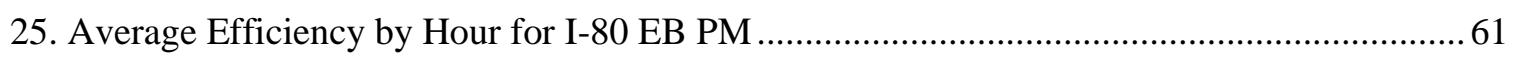

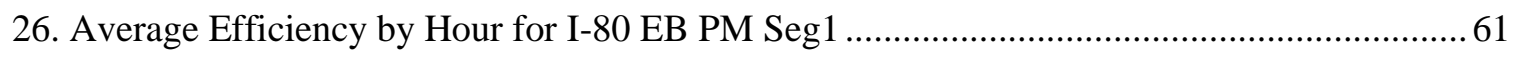

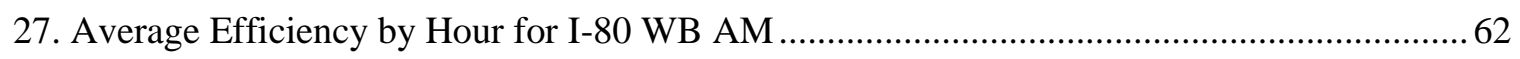

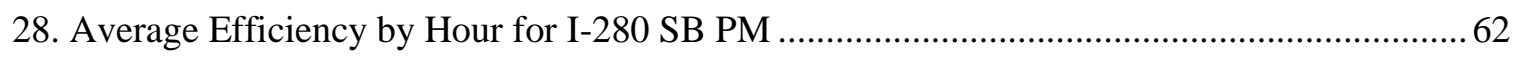

29. Summary of Calculated Crash Modification Factors (CMFs) ............................................. 63

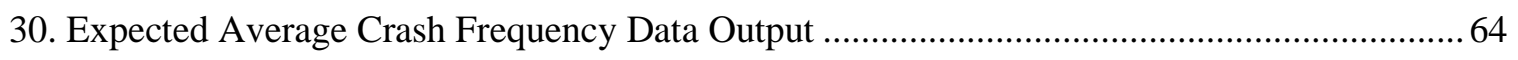

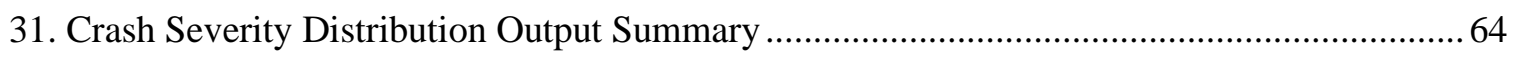

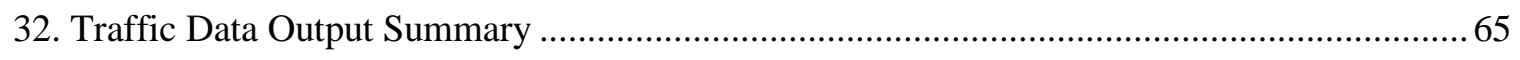

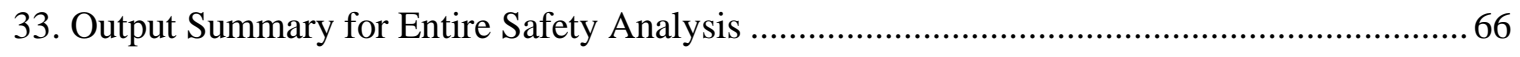




\section{CHAPTER 1 - INTRODUCTION}

As the technological age continues to modify our culture and methodologies, the emergence of intelligent transportation systems (ITS) have made a debut as an advanced application capable of enhancing the coordination, operation, and safety of transportation. Ramp metering has emerged as one of the more popular ITS tools in the everlasting battle against freeway traffic congestion. The system, characterized by signal heads installed on entrance ramps just prior to the merging area, is widely considered as a cost-effective and functional freeway management tool to mitigate congestion and improve safety.

Due to the growth of urban metropolitan areas and recent constraints on project costs, the need for effective and financially viable freeway management tools is unprecedented. This study explores one such example - the Bay Area in northern California. Residents in the Bay Area have historically faced the daily frustrating challenge of traffic congestion and prolonged commuting trips throughout the day. Interstate 80 (I-80), in particular, is one of the most congested corridors in the region, with drivers experiencing weekday and weekend traffic delays in both directions.

Interstate 80 (I-80) is a transcontinental freeway that extends from San Francisco, CA, to Teaneck, NJ. A 19-mile section of the highway between the Carquinez and Bay Bridge is regularly plagued with high volumes of commuting traffic and is considered one of the most congested corridors in the region with over 270,000 vehicles per day. Congestion on I-80 is a result of existing demand being higher than the capacity of the freeway meant to serve that demand. This scenario creates stop-and-go conditions, which involves vehicles inching forward throughout their commute rather than be allowed to travel at higher speeds or in free-flow conditions. In addition to the overflow in capacity, the situation is compounded in the event of vehicles merging onto the freeway and collisions. These collisions create more congestion, which causes vehicles travelling at high speeds to encounter unexpected slowdowns and could 
potentially result in secondary accidents. These secondary accidents then lead to more congestion in a cycle that repeats itself as vehicles continue to queue up behind the initial accident.

Traditional methods of congestion relief have delved into the addition of travel lanes and improving the interchanges to create higher capacity and thus increase throughput. However, many of these improvements have already been implemented along the corridor; at this point, there is no longer additional physical space for these methods. While these solutions provide some congestion relief, they also cause significant environmental and financial impacts without accounting for the added right-of-way. Even if given enough space, freeway widening would cost several million dollars per lane-mile and require years to construct. Other traditional demand management strategies, such as HOV lanes and park and ride lots, have also already been implemented along the corridor. The HOV lanes, for example, currently require three or more occupants per vehicles as opposed to the standard two occupants (Caltrans, n.d., p. 80). New technologies, however, can yield similar benefits compared to traditional solutions but with less environmental impacts and faster implementation.

This thesis analyzes the effectiveness of an ARM system in the 19-mile segment by looking at measures of efficiency, which directly correlates with the overall traffic conditions of the freeway. A secondary focus for this research is to provide a preliminary framework for a safety analysis utilizing the Empirical Bayes approach. This analysis produces a counterfactual estimate of conditions that may appear had the ramp metering implementation not occurred. It is anticipated that this study will guide other researchers and analysts to a greater understanding of ramp metering operations and ultimately contribute to a reduction in freeway congestion one day.

\subsection{Ramp Metering History and Background}

With the onset of increasing traffic demands and reduced funding and physical space for new roads, transportation engineers are motivated to focus on developing innovative traffic management strategies such as ITS tools. These systems apply current and emerging technologies 
in communications, electronics, and information processing to mitigate various transportation problems, including congestion and safety. Congestion can generally be classified into two broad categories - recurrent and non-recurrent (Carter, 1997). Recurrent congestion is expected to occur at a predictable location and on a predictable basis, usually daily. This type of congestion is often caused by the normal traffic scenario where demand exceeds the capacity of the freeway segment. Non-recurrent congestion, on the other hand, occurs when the freeway capacity is reduced to a level under the current traffic demand. These scenarios are usually caused by random or unpredictable events, such as collisions, random obstructions along the roadway, and special events.

There are two main categories of ITS tools utilized in congestion-related issues on the roadway. The first group is known as Advanced Traveler Information Systems (ATIS). These tools assist in informing users of current traffic conditions and enable them to make more informed routing choices and better use of the existing roadway capacity (Carter, 1997).

The second group is known as Advanced Traffic Management Systems (ATMS). ATMSs involve the application of information and control infrastructure to effectively manage traffic demands. These systems have historically been applied at both the freeway and local arterial level, although there have been efforts to apply a system to both and coordinate both the freeway network and the underlying local street network (Carter, 1997). Two distinct types of ATMS related to freeway management have emerged within the past couple decades. The first type is the detection and management of traffic incidents in the hopes of reducing delays caused by collisions or any other atypical incidents. The second, which is the main focus of this thesis, is the management of freeway-bound traffic entering the freeway via ramp metering.

Ramp metering was first implemented in the 1960s on the Eisenhower Expressway in Chicago, Illinois. At this time, ramp metering strategies were a far cry from today's more advanced methodologies. Stand-alone ramp metering was mostly used in the 1960 s to 70 s. This strategy involves a pre-determined operation as it was unable to adjust to the traffic flow 
automatically within the field. In the 1970 s to 80 s, local control ramp metering was developed to "utilize a set of freeway facility performance measures to verify the success of implementation" but was still unable to respond to real-time traffic patterns (Aghdashi, Khazraeian, Trask, Hadi, \& Rouphail, 2016).

Coordinated ramp metering realized this advancement in the 1980s to 90 s by installing an algorithm within the system that calculated the optimal metering rate for a given traffic level. In the 2000s, traffic responsive, or adaptive, ramp metering evolved to take on traffic demands and patterns during real-time conditions. In other words, ramp meters at this stage were capable of sensing changes in traffic flow throughout the entire freeway network, locate any bottlenecks, and adjust its metering rate accordingly. The ITS tool gained popularity throughout time in metropolitan areas such as Detroit, Los Angeles, and Minneapolis/St. Paul and is now deployed in varying degrees of sophistication and scale across the United States (Mizuta, Roberts, Jacobsen, \& Thompson, 2014).

Ramp metering installations have typically been integrated with other improvements within the freeway network as a collective effort of various strategies to improve the freeway operations. This allows agencies to optimize the incident and traffic management of freeways without needing to add a large area of physical space and can potentially lead to a system with enhanced mobility, reliability, safety, and environmental impacts with no drop in capacity or drastic increase in project expenses. The I-80 Integrated Corridor Mobility (ICM) project is a prime example.

Ramp metering has historically faced its fair share of challenges when being advertised as a new and innovative smart technology. One of the most critical factors in the implementation of ramp metering is the public opinion of the ITS tool itself. Negative misconceptions about the treatment can impact any progress towards their deployment. Proper advertisement and feedback should be conducted to ensure a realistic outlook of the tool is shown. Users and local agencies alike may also be concerned about other transportation systems being negatively affected by the 
appearance of ramp metering. Local agency and lack of support from related stakeholders can impact any installation progress as well.

Project funding and costs also play a critical role in both public opinion and the overall success of ramp metering. Without sufficient funds, maintain and capital costs cannot be fulfilled, which can lead to only part of the system being installed. However, without the entire system operating and collaborating with each other, the full benefits are unlikely to be achieved. On a similar note, if the cost of implementation is viewed as too high by the general public, the system's public outlook will also be affected.

Existing conditions also pose a potential challenge to ramp metering. With the installation of new infrastructure, the project site requires adequate space for the technology to function as designed. In this case, ramp metering is installed on entrance ramps just prior to the merge area of the mainline freeway. The technology requires the length of the entrance ramp after the meters be long enough for adequate acceleration to avoid large travel speed differences at the merge area. In addition, if there exists heavy ramp volumes entering the freeway at any certain entrance ramp, the ramp must either be capable of holding the maximum queue within the physical space of the entrance ramp or be able to release the vehicles into the freeway network before the queue extends into the local street network. This strategy, also known as queue override, is typically applied as a function within the ramp metering algorithm to allow a faster metering rate or suspension of it. Queue override will be further discussed in the literature review section of this thesis, or Chapter 2.

\subsection{Types of Ramp Metering}

Multiple types of ramp metering algorithms have been developed over time with three broad categories emerging - fixed rate/pre-timed, local traffic responsive, and system-wide traffic responsive/adaptive. Each strategy possesses its own unique infrastructure requirements. The first is a fixed rate ramp metering strategy and is also known as pre-timed ramp metering. The 
metering rate in this case is based on historical traffic flow data and processed to reflect local conditions for each ramp meter. It is considered the most appropriate metering strategy for localized problems and requires only periodic manual updates. This strategy may also be chosen when budget limitations restrict more costly options. Since it uses inputted traffic data, fixed rate ramp metering does not require any detection within the field. The metering can be improved to adjust to conditions varying throughout the time of day given that adequate traffic flow data is available and can be processed correctly. However, this ramp metering strategy is unable to account for any atypical scenarios such as special events or accidents. The strategy may be further developed so that the installed algorithm can determine the metering rate based on traffic flow of the entire freeway system rather than traffic flow within the vicinity of each ramp meter. Regardless, this improvement is unable to address the issues concerning accident scenarios, which is one of the main reasons ramp metering is typically implemented for.

With local traffic responsive control, ramp meters become capable of adapting to traffic conditions within their vicinity and adjust the ramp metering rate as necessary. This strategy does require loop detectors to be installed on the mainline in order to analyze the local traffic conditions, which implies higher capital and maintenance costs relative to fixed rate systems. However, this system is considered more robust and capable of responding to a larger variety of scenarios, including those involving collisions. The system operates by detecting traffic speed and volume immediately upstream and downstream of the ramp as well as entrance ramp volumes. Metering rates are adjusted based off the local conditions of each ramp meter's entrance ramp and the upstream freeway segment.

An example of local traffic responsive control ramp metering algorithm is ALINEA. Metering rates under this algorithm are calculated via occupancy data collected from loop detectors located downstream from the meter. The algorithm's primary objective is to maximize the throughput of the mainline segment without crossing the target threshold. Doing so will result in traffic congestion and a weaker performance. 
System-wide Traffic Responsive Control ramp metering is arguably the most robust and adaptable ramp metering strategy. Ramp meters are actuated to system-wide conditions and therefore can optimize flow along an entire facility, corridor, or freeway system given enough detection within the field. While similar to local traffic responsive metering, this system-wide variant takes an additional step after detecting local ramp conditions. Each ramp meter communicates with one another and collaborates through the installed algorithm to prevent capacity loss of the freeway. The entire system is controlled from a traffic operations center where the controllers can be remotely overridden or reprogrammed by traffic operators. ARM is considered the most appropriate for widespread congestion issues and corridor- or entire systemwide applications but does also demand the highest capital and maintenance costs. Infrastructure requirements include detectors upstream and downstream of the ramps, a communication medium, and a central computer linked to the ramps. The detector measures traffic volumes, freeway occupancy, and travel speeds. A downstream detector for a ramp meter may be used as the upstream detector for the next meter if entrance ramps are placed relatively close together. The typical layout for an ARM system is shown below (Figure 1). Typical components and their uses are also listed out in Table 1. ARM is capable of providing more options in optimizing mainline capacity and reducing the amount of overall system delay by using multiple ramps to control traffic at any given bottleneck or congested location. Some examples of system-wide traffic responsive control algorithms are listed below:

- Corridor Adaptive Ramp Metering Program (CARMA) - the metering rate is determined via mainline speeds and prevailing local controller conditions. This strategy assumes that when speeds are high, maximum throughput should be allowed through the meters. If speeds are slower or near optimal, then the minimum throughput should be allowed through the meters. This strategy has been used in Kansas City, Missouri.

- Heuristic Ramp Metering Coordination (HERO) - this algorithm uses ALINEA to establish a baseline for managing local conditions. When ramp queues meet or near their 
thresholds, the control algorithm is activated and assigns slower metering rates to upstream meters to balance out downstream conditions. This strategy has been used in Melbourne, Australia.

- Fuzzy Logic - ramp queues are integral to managing the freeway network via this strategy. The algorithm controls multiple ramps and uses more comprehensive mainline and ramp inputs as well as different heuristics to maintain the most dexterity in determining the optimal metering rate for local conditions. This strategy has been used in Seattle, Washington and Miami, Florida.

- Stratified Zone Metering (SZM) - this algorithm primarily uses density measurements collected from upstream merge zones, exit ramps, and the mainline itself. The overall objective of the algorithm is to ensure the total traffic volume exiting a zone exceeds the volume entering it. When the algorithm detects an increase in density along the mainline freeway, it will restrict the metering rates of the congested zone to slow down the entering rate of traffic. Ramp queue wait times are managed by an independent algorithm. This strategy has been used in Minneapolis, Minnesota.

- $\quad$ System-Wide Adaptive Ramp Metering (SWARM) - the metering rate is calculated based on the current density, required density, and number of vehicles that should be added or removed from the mainline segment. When a ramp queue reaches capacity and queue spillback is imminent, upstream ramps will activate to lower the entering rate of traffic traveling down the mainline freeway. This algorithm also provides advantages to mixed ramp controls so that ramp meters may be applied locally, manually, or via a different algorithm. Regardless of the control type, SWARM will adapt to distribute wait times equally among all entrance ramps. This strategy has been used in Orange County, California and Portland, Oregon. 


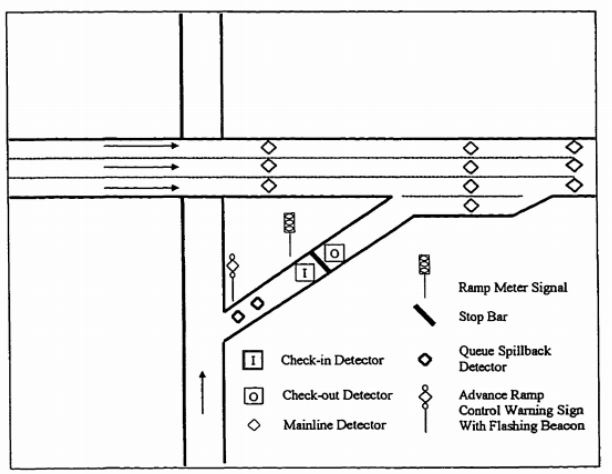

Figure 1. Typical Layout of Ramp Metering System (Carter, 1997)

Table 1. Typical Components of Ramp Metering (Carter, 1997)

\begin{tabular}{|c|c|}
\hline Component & Description \\
\hline Ramp Meter Signal & $\begin{array}{l}\text { A standard red-yellow-green or red-green signal head } \\
\text { used to control entrance ramp traffic }\end{array}$ \\
\hline $\begin{array}{l}\text { Advance Ramp Control } \\
\text { Warning Sign }\end{array}$ & $\begin{array}{l}\text { A sign which indicates to approaching traffic that the } \\
\text { ramp is being metered }\end{array}$ \\
\hline Stop Bar & Painted line similar to surface street intersection \\
\hline Check-in Detector & $\begin{array}{l}\text { A detector that may be used if the ramp signal is used as } \\
\text { an actuated signal. In such cases, the light will remain } \\
\text { red until the detector is activated }\end{array}$ \\
\hline Check-out Detector & $\begin{array}{l}\text { Used to ensure single-vehicle entry. The light is kept } \\
\text { green until this detector is activated, and then turned red } \\
\text { upon activation }\end{array}$ \\
\hline $\begin{array}{l}\text { Queue Spillback } \\
\text { Detector }\end{array}$ & $\begin{array}{l}\text { Used to detect the presence of a queue spilling back } \\
\text { down the entrance ramp onto the adjacent surface street }\end{array}$ \\
\hline Mainline Detector & $\begin{array}{l}\text { May be used to provide real-time traffic information for } \\
\text { use by adaptive signal control strategies }\end{array}$ \\
\hline
\end{tabular}




\subsection{Motivation/Purpose}

The ICM project was activated in 2016 and represents one of the most comprehensive ITS projects in California. Also known as the I-80 SMART Corridor project, the entire project is composed of several technologies and strategies that work together to manage traffic flow on the I-80 and underlying local arterials such as San Pablo Avenue. There are five main aspects to the project:

1) Incident Management - use of signs to provide information for motorists of downstream incidents and lane closures. Signs include Variable Advisory Speed signs, lane use signal signs, variable message signs (VMS), and information display boards (IDB). Incident management on the freeway involves providing drivers with real-time information, such as downstream lane closures of reduced speeds, to decide which route or transportation mode to use. Variable speed signs will be installed on both direction of the I-80 corridor displaying advisory speeds during an incident to slow down during an incident, thus resulting in a fewer rear end collisions and overall smoother traffic flow.

2) Adaptive Ramp Metering - installation of ramp meters on approximately 40 westbound and eastbound entrance ramps. Four additional ramp meters were constructed as a part of a high-occupancy vehicle (HOV) lane widening project. The signals were activated in April 2017 as part of a coordinated system capable of communicating with each other in real-time to reduce the merging conflicts that appear near bottlenecks and potentially mitigate accidents and improve travel time reliability and efficiency.

3) Traffic and Transit Information - use of VMS and IDB signs to provide information about traffic conditions, travel time and parking availability at transit centers.

4) Improvement to SR-123 and other arterials - San Pablo Avenue will have its signal timing altered to allow for more green time for freeway-bound traffic. In addition, 
traffic signal hardware/software will be updated to current technologies along with closed-circuits television (CCTV) cameras, information message signs (IMS), VMS and communication detection equipment. These installments allow related agencies to both provide real-time information to users while also effectively monitoring and managing traffic during any incidents.

5) Integration of I-80, SR-123, and other arterial systems - different agencies relating to I-80, San Pablo Avenue, and other major arterials collaborated to integrate operation coordination and optimize the sharing of corridor traffic and transit information. All of these pieces were integrated into the California Department of Transportation's (Caltrans) central communications network, allowing for real-time monitoring and coordination amongst various involved entities from a single system. This will result in a region-wide cooperative and coordinated traffic management system capable of reducing congestion and improving safety along the corridor.

The ultimate project was a collaboration of various agencies to create an integrated network of technologies to enhance safety and improve travel time reliability and efficiency of the I- 80 freeway. The funding originated primarily from Proposition $1 \mathrm{~B}$ and the California Medical Instrumentation Association (CMIA) funds, which were approved by California in 2006 for transportation needs. Local funds from Measure B and $\mathrm{J}$ were also pooled into the total budget of $\$ 79$ million (Caltrans, n.d., p. 20). Other partners involved in the project included: the Federal Highway Administration (FHWA), Caltrans, Contra Costa Transportation Authority, Alameda County Transportation Commission, West Contra Costa Transportation Advisory Committee (WCCTAC), AC Transit, Western Contra Costa Authority, as well as all cities within range of the I-80 segment - Albany, Berkeley, San Pablo, Emeryville, El Cerrito, Hercules, Pinole, Richmond, and Oakland.

Although ramp metering has been a popular ITS tool in California and the Bay Area for decades, political and institutional concerns have prevented the installation of a ramp metering 
system along this particular corridor. Alternative strategies were discussed during the implementation of the I-80 SMART Corridor projects; however, many of them, such as HOV lanes and park and ride lots, had already been implemented along the corridor. As previously mentioned, freeway widening was not an option either - potential freeway right-of-way along the corridor is physical constrained by the presence of fully developed residential communities and environmentally sensitive areas. In addition, freeway widening would likely have been ineffective over time, as any relief measures implemented to the corridor would likely incur even more demand from choice transit users or off-peak commuters and result in the same situation in the near future. Regardless of these hurdles, it has now become the first Bay Area corridor to utilized ARM rather than local traffic responsive ramp metering (Low, 2017).

The motivation of this study stems from past research of ramp metering. It is extremely difficult to replicate an isolated experiment of ramp metering on freeways in the real world. As a result, most case studies have opted for a simulation approach in favor of the limitations of infield evaluations. A large proportion of these studies have formed an optimistic outlook on ramp metering and have endorsed in the benefits in travel time reliability, efficiency, and safety that ramp metering can cause. However, many of these studies' conclusions can arguably be unfounded due to slight bias and/or non-isolated variables within the study. This is not meant to unseat or disprove any of the studies' findings; however, it is worth noting that simulated approaches cannot reflect the real world as well as an in-field evaluation can despite the complications of isolating an entire freeway segment, let alone network. The contrast between empirical and simulated studies will be further discussed in literature review section of this thesis, or Chapter 2.

As a result, MTC has requested that a study be conducted to ascertain if the I- 80 actually benefited since the implementation of ramp metering in April 2017. A former graduate student, Travis Charles Low, initiated this research using measures of travel time reliability; another graduate student, Faridur Rahman, continued Low's research by contributing additional travel 
time data, introducing new measures of travel time reliability, and studying a similar segment serving as a control for comparison. This thesis parallels the scope of the travel time reliability study but instead evaluates the I-80 freeway based on measures of efficiency and safety. Together, these studies provide a comprehensive before-and-after analysis of the freeway and hopes to contribute insight on the effects of ARM implementation on the I- 80 corridor.

A secondary focus of the research includes determining the ideal travel distance in which ARM would function effectively. Ramp metering has been shown to be less beneficial for users who utilize the corridor for short lengths but tends to benefit those with longer trips. Thus, segmental analysis of multiple, shorter lengths of the I-80 study segment was conducted. The segment lengths originated at a designated entrance ramp and was incrementally increased to the immediate downstream entrance ramp. To better contrast the implementation of ARM on I-80 and its potential benefits, similar freeway segments in the Bay Area were selected for analysis to serve as a control segment for comparison. The analysis on the control allows one to explore how a typical freeway behaves relative to a freeway recently renovated with new ITS technologies.

For the safety evaluation, a preliminary analysis was conducted comparing collision data from the "before" and "after" periods. However, a more accurate and comprehensive methodology known as Empirical Bayes analysis was utilized to reliably predict future crash frequencies based on various freeway characteristics and compare them with historical collision data. The result of the comparison will determine if ARM has improved or worsened safety conditions on the corridor. 


\section{CHAPTER 2 - LITERATURE REVIEW}

Due to urbanization trends and growing transportation demands, traffic congestion is occurring more frequently near and on urban freeway networks. Due to logistical, environmental, and economic concerns, it is not always practical to consider infrastructure expansions. Traffic management strategies have begun to play more important roles in improving traffic operations, with ramp metering being a leading treatment. This section explores the various benefits and effects on performance measures that ramp metering, when properly implemented, can have as an active traffic and demand management (ATDM) ITS tool.

\subsection{Effects of Ramp Metering}

Ramp metering has been shown to help reduce congestion by managing traffic demand and reducing accidents throughout the entire corridor. This is found to be particularly helpful within the merging zones of freeway networks. By smoothing out the entering traffic flow rate and reducing entry speeds, ramp metering is capable of increasing the likelihood of efficient and safe merging maneuvers (Kang \& Gillen, 1999). This can ultimately reduce traffic congestion and lead to lowered travel times, increased freeway capacity and throughout, and reduced fuel consumption and emissions (Kang \& Gillen, 1999).

One of the key components of ramp metering is its ability to transfer delay from the mainline freeway to the entrance ramps. The purpose here is to maintain uninterrupted, noncongested freeway traffic flow as long as possible to maximize the capacity of the corridor. However, the nature of the treatment may work against itself given enough traffic demand.

A simulation study based in the cities of Minneapolis and St. Paul revealed positive effects on effectiveness, but also showed the appearance of delays at certain ramps (Ahn, Bertini, Auffray, \& Ross, 2007). These delays were caused by the ramp metering itself - by increasing delay at the ramp, the metering was able to decrease delays on the mainline freeway. However, this ramp metering operation may cause long queues at the entrance ramp that may exceed the 
queue storage and interfere with the operation of the adjacent surface street network (Figure 2). This is a common issue on freeways in California as most entrance ramps do not provide sufficient queue storage (X. (David) Kan, Lu, \& Skabardonis, 2019). With high enough traffic demand, this queue builds up and leads to extended delays at the ramp and queue spillback onto the local street network.

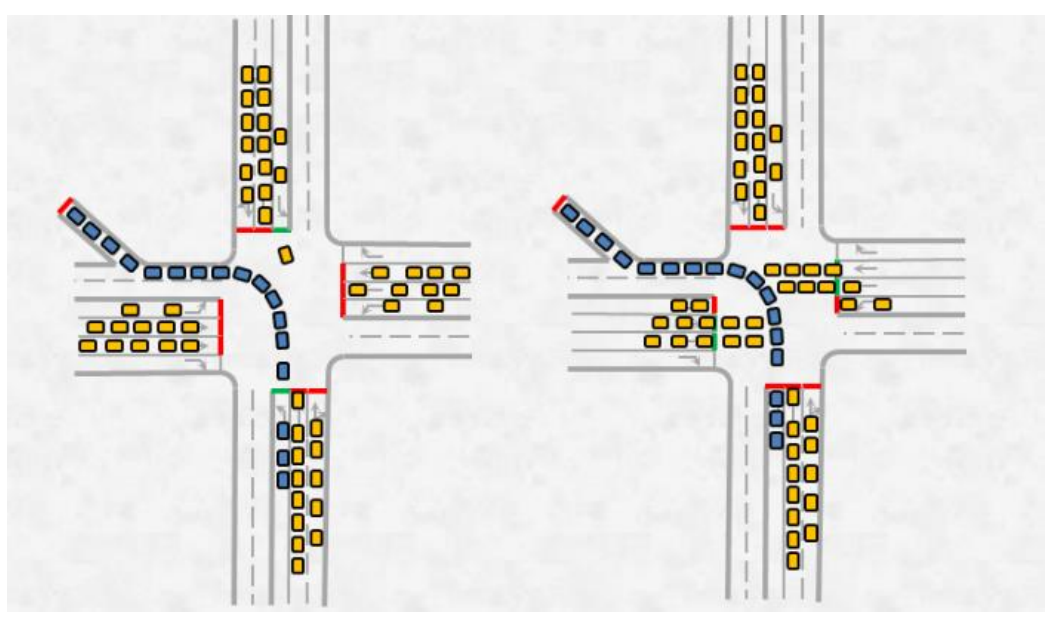

Figure 2. Local Traffic Operations Stalled Due to Queue Spillback (D. Kan, 2017)

In order to counteract these two issues, ramp metering was installed with a "queue override" function that can suspend ramp metering or increase the release rate for a short period of time to dissipate the entrance ramp queues (X. (David) Kan et al., 2019). A sensor installed near the entrance to the ramp detects the potential queue spillover and communicates with the ramp meters accordingly. While this can relieve congestion at the entrance ramp, this feature ultimately reduces the effectiveness of ramp metering during peak hours, ironically when it is most needed.

When queue override is activated too long, a bottleneck can appear near the entrance ramps, typically shortly downstream of the merging zone (Figure 3). A bottleneck is defined as a point on the road where the traffic demand exceeds the normal freeway capacity, resulting in 
queues forming upstream and free-flowing traffic some distance downstream of the point. High volumes of traffic at entrances ramps will result in flow breakdown, thus reducing the discharge rate of the bottleneck. This leads to lower throughput, slower average travel speed, and less efficient overall performance (X. (David) Kan et al., 2019).

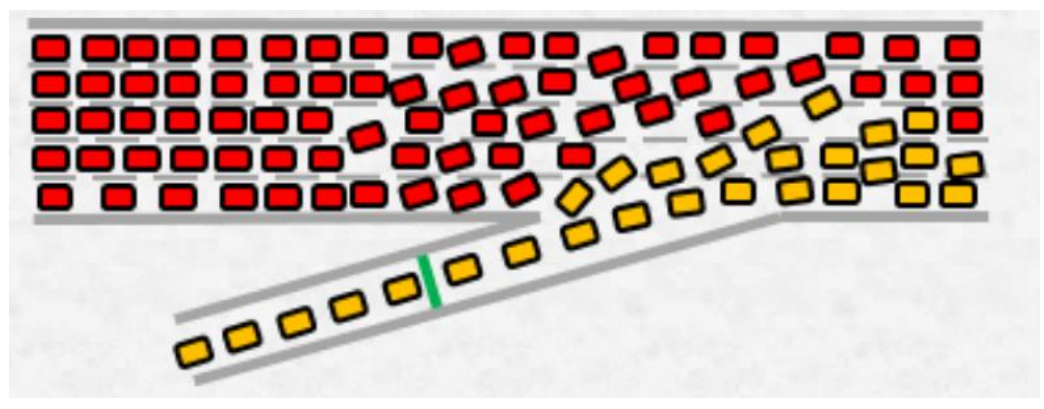

Figure 3. Bottleneck Forming as a Result of Queue Override (D. Kan, 2017)

This event, known as "capacity drop", typically leads to a 5-15\% reduction in capacity. The queue discharge rate is greatly influenced by the speed of the upstream congestion. Depending on the average travel speed of the congestion area, freeway capacity could drop even further - up to $25 \%$. However, it is worth nothing that local traffic conditions, such as the percentage of trucks present and weather, could also affect the result (K. Yuan, Knoop, \& Hoogendoorn, 2015). A two-week field study was conducted at a metered freeway entrance ramp in San Jose, California. The aforementioned findings were verified through a reduction in queue discharge rate of $10 \%$ while queue override was active (X. (David) Kan et al., 2019).

Currently, arterial traffic signals adjacent to freeway entrance ramps tend to operate independently of freeway ramp metering. During peak hours, the nearby intersections employ long signals cycles to maximize the intersection capacity. This often results in large platoons of freeway-bound traffic entering within a short duration of time and thus queue spillback. In order to prevent vehicles from flooding the bottleneck region on the freeway network and from queuing too far on the entrance ramps, it is important to balance the arrival of freeway-bound traffic from 
the local street network with the traffic operations of the ramp meters and local intersections. The study recommends reducing the arterial signal cycle length while maintaining the same green time distribution such that only a small platoon of vehicles feeds the ramp queue each cycle. This can help to prevent queue spillback by allowing for smaller but more frequent groups of freewaybound traffic (X. (David) Kan, Lu, \& Skabardonis, n.d.). The proposed signal control was implemented on the northbound Interstate 680 freeway in San Jose, California, to test its effectiveness. The applied system successfully eliminated the queue spillback at entrance ramps capable of queue override, this reducing delay and increasing capacity of the freeway segment.

The effectiveness of ramp metering is also potentially impacted by socio-environmental factors as well. For instance, if public opinion is generally "opposed to" rather than "in support of", it is possible that the ITS tool implementation will be met with a negative attitude regardless if the results. This is especially true when results are only marginally positive rather than significantly so. In Milwaukee, for example, equity proved to be a delicate subject among the general community. Certain members felt as if they and others were being left out of the benefits of newly-implemented ramp metering in the area because the metering was installed mostly in the highly congested zones rather than spread throughout the city. As a result, metering rates were adjusted so that delay to the average motorists was the same on nearby and outlying ramps (Kang \& Gillen, 1999).

\subsection{Twin Cities Case Study}

As mentioned previously, the cities of Minneapolis and St. Paul, Minnesota possess an extensive ramp metering system managing approximately 210 miles of freeway access within the Twin Cities metropolitan area. After the ramp metering was first installed in 1969 to improve safety and efficiency, the network has grown to nearly 430 ramp meters being utilized to help direct traffic through bottlenecks and merging zones (Cambridge Systematics, Inc., SRF Consulting Group, Inc., \& N.K. Friedrichs Consulting, Inc., 2001). 
One study explored travel time variation and the effective ramp metering length as performance measures (Levinson, Zhang, Das, \& Sheikh, 2001). The study showed that ramp metering may be generally beneficial to freeway segments but may not necessarily improve overall trip travel times when including ramp delays. In addition, ramp metering is likely more helpful and effective for users who are taking long trips as opposed to short trips. This study shows that trips more than three exits in length holds benefits while trips that last three exits or less are typically hurt by the metering. This is likely due to the fact that users embarking on short trips are more likely to optimize their travel time by using the local street network and/or parallel arterials instead of utilizing the freeway where delays can form immediately after the merging zone.

The effectiveness of the strategy was questioned by the public after recent congestion issues appeared at certain entrance ramps, leading to a movement to shut down the metering system. In an attempt to prevent this outcome, the Department of Transportation simulated a model of two freeway sections for detailed analysis on the effects of the ITS tool. While they did discover the congested entrance ramps to be a valid concern, a few positive outcomes did emerge. For example, even though there was a lack of accident data to be used in the simulated ramp metering shutoff, it can be inferred that with a noticeable reduction in braking and increased smoothness of flow, ramp metering should result in lower accident rates (Hourdakis \& Michalopoulos, 2002).

Another study was conducted on four corridors representative of the corridors within the Twin Cities region comparing "with ramp metering" and "without ramp metering” scenarios from September $11^{\text {th }}$ to October $15^{\text {th }}, 2000$ and from October $16^{\text {th }}$ to December $8^{\text {th }}, 2000$, respectively (Cambridge Systematics, Inc. et al., 2001). While this may be subject to some seasonal or monthly variation in data, data collection was able to conclude before the advent of holiday shopping season. Traffic data was only collected from the second week onward to allow traffic 
patterns to adjust to the change, thereby somewhat limiting the range of the data but also improving its quality.

The "with ramp metering" scenario was found to reduce the average traffic volume by 9\% and no substantial changes on parallel local arterials. During peak hours in the "without ramp metering" scenario, throughput was reduced by $14 \%$. Travel speeds were also substantially reduced during this time, leading to delays being higher than those measured on entrance ramps during the "with ramp metering" scenario. When ramp metering is active, the entire freeway system was estimated to save over 25,000 hours of travel time per year. Travel time reliability analysis revealed that travel times become twice as unreliable without ramp metering than with it and can save up to 2.6 million hours of unexpected delay yearly. In terms of safety, an increase of $26 \%$ was observed during peak hours and resulted in 1,041 crashes being avoided per year, or about four crashes per day. The ramp metering also allowed for emissions savings of 1,160 tons, but does show increases in fuel consumption (Cambridge Systematics, Inc. et al., 2001). In addition, the general public that was initially opposed to the idea of ramp metering implementation became more appreciative of the ITS tool following the shutdown.

\subsection{Simulation Case Studies}

There have been a variety of simulated case studies conducted on various ramp metering strategies that have given insight on the effectiveness of ramp metering.

A coordinated ramp metering algorithm was implemented on a 26-kilometer segment of northbound Autobahn No.9 (A9) in Munich, Germany. The algorithm produced substantial reductions in both vehicles emissions and fuel consumption (Bogenberger, Vukanovic, \& Keller, 2002).

Another algorithm called HERO/RWS (Heuristic Ramp metering coordination/RWS is the commissioning organization) was developed for the current Dutch ramp metering system and applied to the Amsterdam A10 freeway network. The study noted that freeways nowadays tend to 
be plagued by increasing total travel times, economic losses, environmental pollution and reduced traffic safety (Y. Yuan, Daamen, Hoogendoorn, \& Vrancken, 2009). Some of these issues may be caused by underutilization of the existing infrastructure. The algorithm was tested in VISSIM simulations and offered promising results in individual ramp metering control. On the freeway network, congestion and travel times were reduced while the average travel speed increased. However, the control strategy was also shown to induce greater delay on the local street network compared to individual ramps with active ramp metering.

A 6-mile stretch of the northbound freeway Interstate 405 (I-405) was simulated in a study involving notable coordinated ramp metering algorithms - ALINEA, a local-feedback type; BOTTLENECK, an algorithm involving both local and coordination metering strategies; and ZONE, an area-wide coordinated type (Chu, Liu, Recker, \& Zhang, 2004). ALINEA was able to achieve reductions of freeway travel time under both recurrent and non-recurrent congestion scenarios while maintaining modest delay for entering vehicles. BOTTLENECK and ZONE, on the other hand, were unable to show superior performances despite having a larger area-of-effect. However, once the local occupancy control algorithms for each were replaced with ALINEA's, both BOTTLENECK and ZONE performed more efficiently than any of the original three. The revised BOTTLENECK algorithm produced a robust performance across both typical and incident scenarios. (Chu et al., 2004).

\subsection{Other Ramp Metering Case Studies}

It is considered ideal to conduct in-field evaluations for ramp metering, as the real-word data would likely be perceived as the most credible. Computer simulations, while growing rapidly in both scale and complexity in today's technological era, cannot completely model the real world perfectly. In addition, the real world captures the multitude of combinations of traffic demands, roadway sections, traffic flow patterns, etc., that can change in unforeseen ways. These erratic changes would be relatively difficult to account for within a simulation model. Human behavior, 
in particular, is somewhat unpredictable - especially in accident-related scenarios - and can also be difficult to reflect accurately in simulation evaluations (Carter, 1997). Case studies of ramp metering strategies within the field can arguably provide the most accurate data given proper data acquisition methods.

On the other hand, one of the aforementioned challenges ramp metering has faced is the potential difficulty and impracticality of an in-field empirical study. Capital and maintenance costs for sensor equipment can easily scale higher than that of a simulation model evaluation. In addition, the coverage area would likely require a substantial amount of said equipment for accurate and reliable data (Carter, 1997). However, ramp metering has historically been recognized as an effective strategy for traffic management. The potential benefits are typically satisfactory justification for many agencies and transportation departments to pursue ramp metering implementation regardless of the costs.

One such study was conducted in Portland, Oregon along a 6-mile segment on Interstate 5 (Ahn et al., 2007). The initial ramp metering used a pre-timed algorithm that determined both active periods as well as the metering using historical flow data. However, the algorithm was found to only be sufficient for typical patterns rather than adaptable to real-time changes. A more sophisticated algorithm - in this case, SWARM - was developed with the use of enhanced sensing and communication technology. Two modes were developed into a "combined" metering strategy. A "global" mode accounted for the entire system and calculated the predicted densities at bottleneck locations using recent traffic data. After any outlying factors are filtered out, the program predicts the next forecasted congestion time period and density. The excess density that was predicted is converted into the "current density" is input into the algorithm as the "required density" needed to avoid congestion at the bottleneck. The "local" mode, on the other hand, adapts the metering system based on real-time traffic conditions near each entrance ramp. The new SWARM approach was also implemented on freeways in Los Angeles and Ventura Counties with successful results - the "combined" metering resulted in an increase in average freeway 
speed and reduction in delay. However, this lower VHT value on the mainline freeway also led to the increase in VHT near the busiest entrance ramps due to the higher metering rates (Ahn et al., 2007).

A study conducted in Jinan City, China, shows that the time duration of the spillback and travel time of the entrance ramp was reduced by the ramp metering. While the field test results are based off a fixed time ramp metering control strategy rather than an adaptive one, it is worth noting that system-wide implementations of ramp metering typically yield more beneficial outcomes than local applications. In addition, the study also notes that an ARM strategy is expected to further improve the freeway's performance (Han, Meng, Zheng, \& Liu, 2019). This improvement also implies the optimistic potential expansion of ramp metering systems - most ramp metering systems remain at the fixed rate level mainly due to lack of project funding. Given time, with systems transitioning from fixed rate to more adaptive strategies and potentially showing optimistic results, agencies and funding partners may be convinced to allocate more monetary resources towards ramp metering projects.

The aforementioned HERO algorithm, a heuristic feedback control strategy, was applied to local ramp metering on the Monash Freeway in Australia. It was found to help increase the throughput on the mainline freeway and reduce travel times.

Another ramp metering study was conducted in Paris on Corridor Périphérique between May $2^{\text {nd }}$ and June $16^{\text {th }}, 1992$. The study drew only short-term conclusions from the field results, although long-term results are likely to be similar given the only change over time would be the drivers further adapting to the new ramp metering system. Drivers were found to travel along the corridor for typically medium to long trips and experienced up to 50\% higher travel speeds relative to the local arterial. Some users appeared to favor the local street network, but were likely traveling a shorter distance than those on the freeway. The ramp metering system was able to reduce the recurrent congested traffic - increased average travel speed, increased capacity, and amelioration of the total time spend in the freeway network were reported. Average speed also 
showed a significant increase even during incidents and/or crashes on the freeway (Haj-Salem \& Papageorgiou, 1995).

\subsection{Efficiency}

Coordinated ramp metering (CRM) was applied to the northbound California State Route 99 on a 9-mile segment lying between Calvine Road and the SR 50 interchange after $12^{\text {th }}$ Avenue. All 11 entrance ramps were installed with the CRM algorithm while five entrance ramps upstream of the test site were left to continue using local responsive ramp metering. This consideration was made for three reasons: the traffic demands on the other 11 ramps were relatively higher, the overall finalized system was shorter and simpler to analyze, and most importantly, the improvement of downstream traffic would naturally lead to improved upstream traffic.

The results of the study were drawn using VMT and VHT data collected in the Caltrans Performance Measurement System (PeMS) for five weeks. Q, known by PeMS as the efficiency of the freeway, is equal to VMT/VHT, which can be interpreted as the average speed or space mean sped. The values VMT and VHT are both collected via sensors along the corridor at various points in the segments, rendering the values as a representation of the entire segment rather than simply a spot speed measured at a single point in the corridor. This ratio is considered to be more objective and could reasonably accommodate traffic demand fluctuations (Shladover \& Lu, 2017).

The evaluation on the SR 99 revealed an improvement of approximately $7.25 \%$ during the AM peak period in efficiency but no substantial change in the PM peak. The lack of change during the PM peak period was attributed towards free-flow traffic conditions at the time.

Therefore, CRM is not necessarily beneficial to non-congested traffic, but can improve congested conditions (Shladover \& Lu, 2017). 
This analysis methodology helps the analyst to determine the efficiency of the freeway's performance and is also the basis for this thesis's efficiency analysis on the I- 80 corridor. It should be noted that no control corridor was used in that study. The data acquisition procedure will be later discussed in Chapter 3, while the results and analysis will be elaborated on in Chapter 4.

2.6 Safety

Roadway safety is also an important factor to consider during ITS implementation. Ramp metering has been increasingly utilized to enhance the performance of freeway facilities by improving traffic entry flow. However, ramp metering is also capable of improving safety on the freeway network (Aghdashi et al., 2016).

Ramp metering helps to split up platoons of vehicles so that a large number of vehicles do not have to compete for the same limited gaps into traffic (Mizuta et al., 2014). When the meters are active, smoother merging maneuvers and less stop-and-go movements can be expected, which can ultimately reduce the probability of a collision.

Collision data was collected for 10 operating ramp meters along multiple freeways in northern California. The study explores the influence of the installed ramp metering strategy on freeway safety by looking at the vehicular collision data near entrance ramps before and after the meters' activation. Results show that the ramp metering reduced freeway collisions by $36 \%$. The reduction also adds the benefit of reducing both accident-related congestion and typical congestion (Liu \& Wang, 2013).

In Hayward, California, a $14.8 \mathrm{~km}$ segment of the Interstate 880 (I-880) is described as a relatively isolated freeway network, allowing researchers the freedom to conduct a microsimulation study quantifying the reduced crash potential. The results revealed that ALINEA ramp metering strategy was capable of reducing the crash potential by $5-37 \%$ depending on the no-control scenario. It was shown that is a queue already exists downstream of the ramp, the ramp 
metering would have minimal effects due to the high level of congestion already present and the increased likelihood of large speed drops in the vicinity. The safety benefits were restricted to the vicinity of the entrance ramp and also influenced by existing traffic conditions and the area in which the evaluation was conducted (Lee, Hellinga, \& Ozbay, 2006).

\subsubsection{Safety Case Study on Variable Speed Limit Systems}

Alex Chambers, a former Cal Poly graduate student, developed a thesis in 2016 on the effects of a variable speed limit (VSL) system on freeway safety. Chambers' work on his thesis provided the basis for this thesis's proposed safety assessment of the I-80 corridor using both a naïve before-after study methodology and an Empirical Bayes analysis.

Chambers (2016) conducted the "naïve before-after" study on the Oregon Route 217 (OR 217) after a VSL system was installed on the highway in the summer of 2014 (Chambers, 2016). The objective of the study was to determine if the VSL system had any measurable impacts on traffic safety and, if so, what the scale of the impact was. This preliminary analysis relied on crash data prior to the ITS implementation to predict an expected number of crashes in an "after" scenario in which the VSL system had not been installed. The method utilizes simple statistical processes to compare the predicted crash rates with the recorded collisions (Chambers, 2016). The "before" period took place from July 2011 to July 2014, while the "after" period took place from July 2014 to April 2016. While the ideal situation would be to use the same amount of data - in this case, three years' worth - for both the "before" and "after" scenarios, the study was conducted too recently after the ITS implementation for adequate collision data to be available. The necessary collision data was gathered from the Washington County Consolidated Communications Agency (WCCCA) and categorized by injury type.

The naïve before-after study allows for a basic understanding of the impacts of a treatment in a "before" and "after" scenario. However, this methodology faces an issue by 
assuming that system conditions are constant throughout the entire study period. This is unlikely to be true in reality - system conditions that affect safety, such as traffic volumes, are extremely likely to change from the "before" period to the "after" period due to the implemented treatment. In addition, if one were to use only collision counts to characterize the safety of a corridor, it may be considered biased to do so, as accidents are not the only cause of a safety issue (Hagen, 2014). As a result, the study also incorporated the use of an Empirical Bayes method for a more comprehensive analysis.

The Empirical Bayes analysis is a more complex method relative to the Naïve BeforeAfter study and is noted for combating regression to the mean bias while also considering the changes in system conditions after the treatment is implemented (Hauer, et al., 1997). Regression to the mean is described as the phenomenon that occurs when a random variable is extreme in its first measurement but closer to the mean on its second measurement, or vice versa. The Empirical Bayes analysis may be used for to increase the precision of estimation and consider other factors besides collision counts, such as traffic volumes and geometric characteristics, in order to estimate the safety of the corridor. In addition, the method helps to account for limited sample sizes when data availability might be limited.

As Chambers' noted in his thesis, the OR 217 is considered an outlier with above average crash rates. However, these higher rates could merely reflect a period in which the roadway happens to experience an above average number of crashes or could reflect a fundamental issue with the freeway itself. Likewise, any treatments that have taken place may simply coincide with a period of lower than average crash rate or could be a direct result of the treatment(s).

The Empirical Bayes before-after procedure is also capable of normalizing any traffic volume differences from the before and after periods. The method utilizes a regression model to first estimate the annual number of crashes in the "before" period that would have occurred given a typical site with similar geometry and traffic volumes. When compared with the recorded number of crashes in the "before" period at the actual test site, the model can then use said data to 
predict the number of crashes occurring in the "after" period (Hauer, 1997). Comparing this value against the recorded "after" period crashes reveals if the implementation actually reduced the crash rate.

This analysis requires a baseline crash estimate of the study site known as the Safety Performance Function (SPF). The SPF is influenced by site characteristics, such as traffic volumes and the general geometry of the freeway, that are used to predict the number of crashes that typically occur at the site. After applying crash modification factors (CMFs), which account for other various site conditions such as historical traffic volumes or lane widths, the site is split into smaller "zones" that represent homogenous segments. The split between these segments is the point along the site at which the freeway differentiates into a different segment with different site characteristics. Once CMFs are applied and an SPF is calculated for each homogenous segment, the values are combined to form a counterfactual estimate of future expected number of collisions on the freeway network as a result of the ramp metering implementation (Chambers, 2016).

\subsection{Conclusions from Literature Review}

The above literature review yields a number of findings that relate to ramp metering effects on freeway performance. One of the key components of ramp metering is its ability to transfer the delay from the mainline of the freeway to the entrance ramp. While having the potential benefit of increased average travel speed along the mainline freeway, the delay at the entrance ramp can prove to be higher and lead to negative perception of the ITS tool, as was the case in the Twin Cities case study. Queue override functions and signal timing alterations are both useful tools in mitigating the delay experienced on the entrance ramp but require careful optimization to avoid exacerbating the situation rather than improving it. In addition, ramp 
metering was also shown to reduce collisions by reducing the severity of congestion at bottleneck locations.

There have historically been two main types of ramp metering case studies - simulationbased and in-field evaluations. Simulation approaches allow researchers to perform large-scale isolated treatments on a simulated freeway network without having to use project funding for the installation and maintenance of the ITS infrastructure. However, it is worth noting that simulation-based models are unable to reflect the real world and human behaviors accurately, while in-field evaluations inherently account for these factors. While a number of in-field evaluations have been noted and discussed in this chapter, part of the motivation behind this study stems from the increased need to evaluate ARM treatments that are both recent and utilize more modern performance measures. In-field evaluations in particular can be influenced by external factors outside of the researchers' ability to control and can therefore lead to confusing or improper results. 


\section{CHAPTER 3 - DATA AND METHODOLOGY}

This chapter of the thesis covers the various databases and the methodologies used in the efficiency and safety evaluations. The efficiency analysis utilized Caltrans' Performance Measurement System (PeMS) to gather VMT and VHT to estimate the efficiency, Q. The safety analysis required both collision data and geometric characteristics of the study site, which were obtained via the Transportation Injury Mapping System (TIMS), Google Earth, and Google Maps. The last two programs are capable of rendering accurate satellite images for remote measurements. The safety analysis initially included a naïve before-after analysis to compare before and after collision data. However, this methodology conveys a relatively simple comparison between collision rates and was considered unnecessary to pursue as the Empirical Bayes analysis would lead to a more robust safety evaluation. The Empirical Bayes approach has been utilized within this thesis to develop a framework for a safety analysis that enables researchers to explore the effects of ramp metering implementation on safety. This framework focused on providing a counterfactual estimate of the crash counts, which can be compared with the "after" period collision data to verify any improvements.

\subsection{Efficiency Analysis}

\subsubsection{Data Source - Performance Measurement System (PeMS)}

Data for the efficiency analysis was obtained from Caltrans' Performance Measurement System (PeMS), which is a centralized traffic database first initiated as a Partners for Advances Transit and Highways (PATH) research project at the University of California, Berkeley. The database provides over ten years of data for historical analysis, which enables planners, engineers and policy makers to accurately track system performance across most urban freeways in California and make informed suggestions for potential improvements. PeMS supports system management objectives as envisioned in Caltrans' Traffic Operations Strategies (TOPS): reducing 
highway congestion, increasing trip reliability, enhancing customer safety, utilizing the freeway infrastructure fully, and being demand sensitive. PeMS served as an adequate decision support tool that can be utilized to monitor highway performance using the appropriate measures.

Detection on the road is performed by a vehicle detector station (VDS), which is a set of detectors that cover all lanes across one direction of travel for one facility (e.g. entrance ramp, exit ramp, mainline freeway lanes, or HOV lane). Freeway performance is monitored via over 40,000 installed detectors that measure the number of vehicles that pass over the detector as well as the duration of time in which they remain over the detector. The data is then processed through a communications line to be compiled in the database.

\subsubsection{Measures of Efficiency}

The goal of the ARM implementation was to improve the freeway system efficiency by regulating the number of vehicles entering the mainline freeway. The two measures used to define that efficiency are known as vehicle miles travelled (VMT) and vehicle hours travelled (VHT). VMT and VHT are defined for any given time period and for any number of segments, such as a freeway.

The VMT term refers to the sum of distance, in miles, traveled by each vehicle on the given section of freeway over a given time period. It follows a similar concept to the total travel distance. If a freeway were segregated into $n$ segments with length $L_{i}$ for the $i$-th segment and each with at least one loop detector, the VMT term can be computed as

$$
V M T(t)=\sum_{i=1}^{n} V M T_{i}(t)
$$

where

$$
\operatorname{VMT}_{i}(t)=f_{i}(t) L_{i}
$$

and $f_{i}(t)$ is the flow, or volume, at the $i$-th segment. 
Similar to VMT, the VHT term pertains to the sum of all trip times, in hours, spent by each vehicle on the given section of freeway over a given period of time. VHT follows the same concept as total travel time and can be computed as

$$
\operatorname{VHT}(t)=\sum_{i=1}^{n} V H T_{i}(t)
$$

where

$$
\operatorname{VHT}_{i}(t)=\frac{f_{i}(t) L_{i}}{v_{i}(t)}
$$

and $v_{i}(t)$ is the average speed at the $i$-th segment. For example, if 1,000 people used the freeway system to travel 100 miles each in one year, the total annual VMT for the system would be 100,000 vehicle-miles. If all of these miles were traveled at a speed of 60 miles per hour, then the annual VHT would be 1,666.67 vehicles-hours. This value represents the cost, in units of time, of traveling those miles. The additive property of VMT and VHT allows researchers to compute hourly, daily, monthly, and annual measures of their performance and observe data trends. In addition, as these are the direct output and input of the system, they are considered as some of the most useful quantities to know for performance evaluation.

The performance measure used for this study's efficiency analysis was the ratio of total Vehicle Miles Traveled (VMT) and total Vehicle Hours Traveled (VHT). This ratio can be interpreted as the efficiency of the highway, Q, or the average speed. It is important to note that this average speed also represents the "space mean speed", or the mean travel speed across the entire segment, rather than a simple "spot average speed". While the two measures are closely related, Q is a better representation of efficiency of the entire corridor, as the average speed can vary greatly depending on whether a bottleneck is present at the location if a "spot" speed was measured. The efficiency of the freeway, Q, can be computed as

$$
Q(t)=\frac{\operatorname{VMT}(t)}{\operatorname{VHT}(t)}
$$


From the definition of Q, increasing VMT or decreasing VHT allows Q to increase, which indicates the freeway efficiency is better. Higher Q values imply that users of the freeway are experiencing higher average travel speeds and/or lower average travel times for their trips, which leads to greater freeway usage by more drivers.

The comparison of the value is relatively straightforward - if the efficiency of the "after" scenario is found to be higher than that of the "before" scenario, then the treatment of the ARM is considered to have a positive effect on the freeway. This implies that the freeway is capable of accommodating more traffic demand and/or users are spending less travel time on the freeway than before the treatment. On the other hand, if the "before" scenario shows a higher Q value, then the ramp metering worsened conditions on the freeway and may require reconfiguration or removal.

It is also worth noting that the Caltrans PeMS database recommends utilizing delay, D, as another performance measure to characterize freeway performance. D can be computed as

$$
D=\max \left\{V H T-\frac{V M T}{v_{r}}, 0\right\}
$$

where $\mathrm{v}_{\mathrm{r}}$ is the reference speed of the freeway and is equal to $35 \mathrm{mph}$, according to Caltrans. The measure is useful because it separates the total VHT into the minimum travel time and extra travel time above the minimum. The PeMS database proposes using $\mathrm{v}_{\mathrm{r}}=60 \mathrm{mph}$, or the free-flow speed of the freeway. By using this $v_{r}$, the delay is equal to the cost of congestion in extra travel time (Chen, 2003). However, the scope of the study does not extend to utilizing D as a performance measure and will therefore be mentioned only as a recommendation for future research.

\subsubsection{Study Parameters and Data Acquisition}

Figures 4 and 5 show the PeMS interfaces for users to acquire VMT and VHT data. The eastbound and westbound directions, along with the appropriate peak hour ranges, were chosen to 
comprehensively analyze the freeway performance. Figure 6 shows the adjustable parameters of the dataset. A more comprehensive guide may be found in Appendix B.

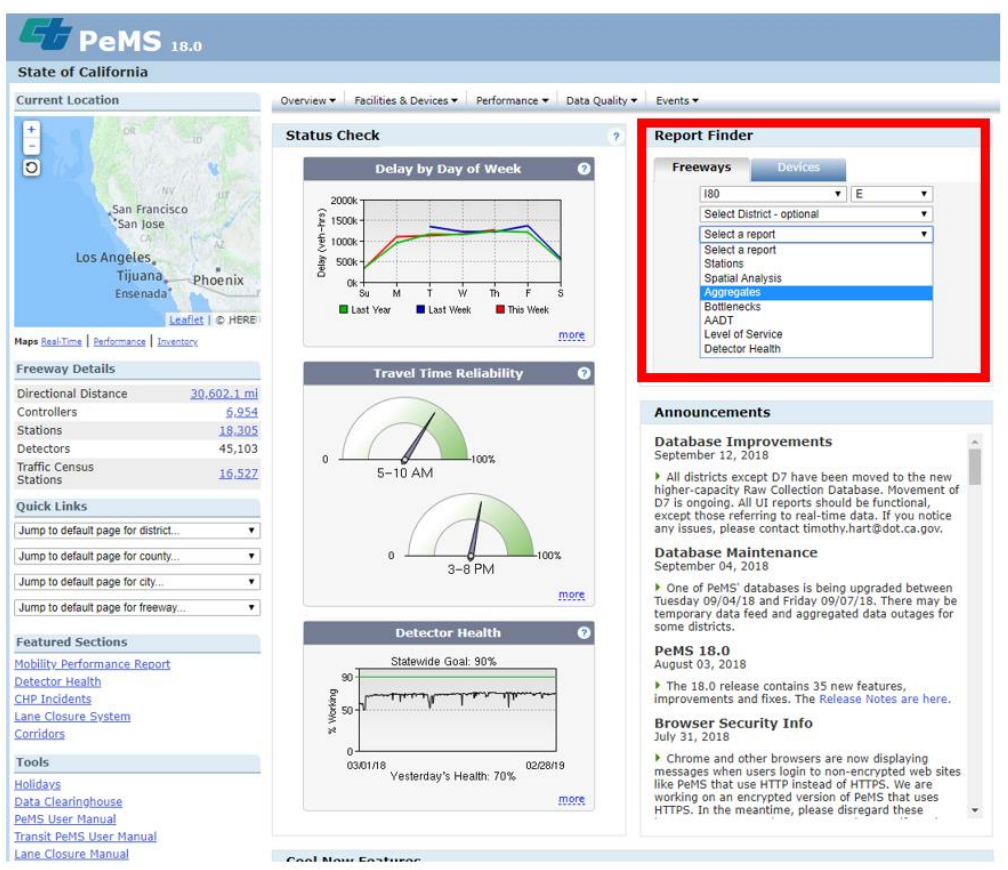

Figure 4. Report Finder of PeMS page

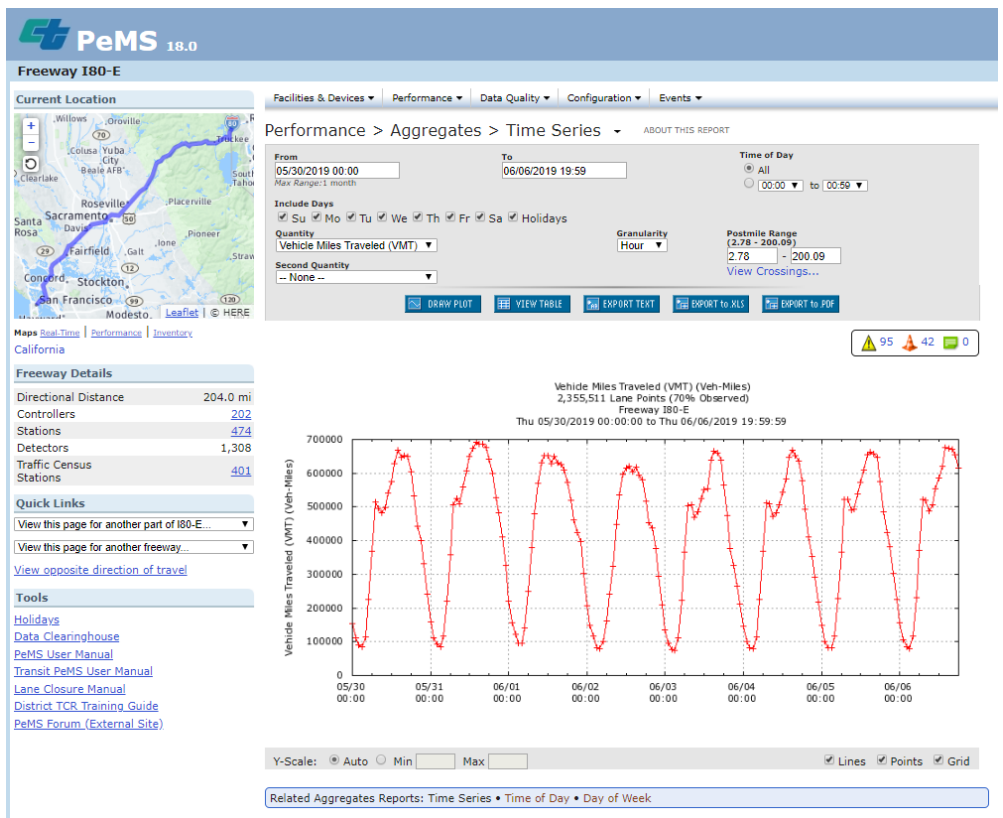

Figure 5. Aggregates Webpage for Time Series 


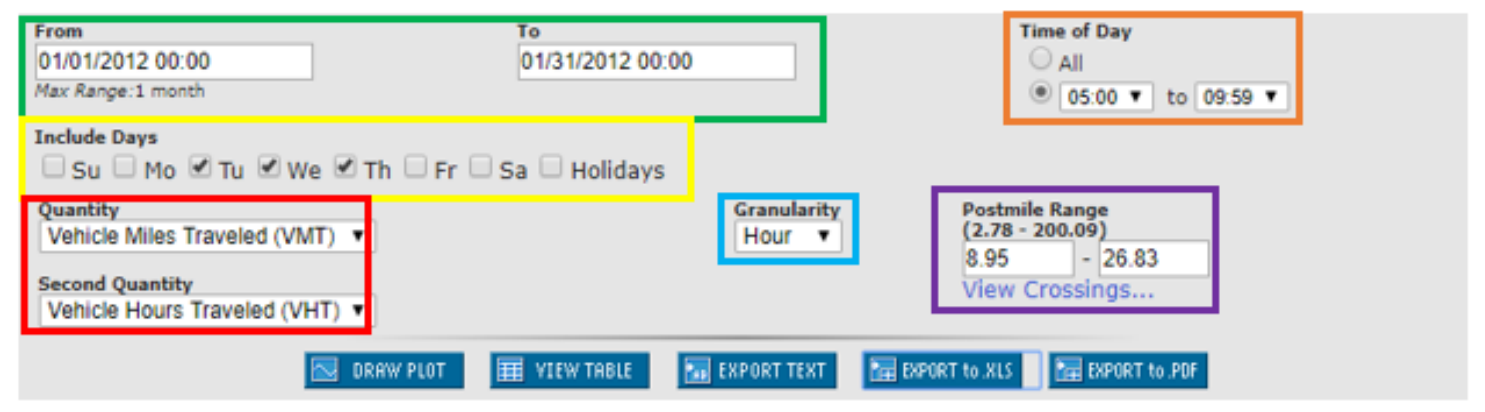

Figure 6. Parameter Inputs for VMT and VHT Data

The adjustable time range enables users to draw data anytime from 1993 up to the present day. For this analysis, the data was separated by month, e.g. "From 01/01/2012 to 01/31/2012", "From 06/01/2015 to 06/30/2015", and so forth.

The days of week were restricted to Tuesdays, Wednesdays, and Thursdays. Mondays and Fridays were both excluded because work schedules can vary substantially when full-time workers take days off from work. Weekends were excluded as neither Saturday nor Sunday are likely to show high volumes of traffic compared to weekday traffic. Holidays were not considered as they can show traffic conditions on either side of the spectrum - users may choose to spend said holidays indoors, which can result in low levels of traffic, or choose to travel, which can spike traffic levels beyond typical conditions.

The VMT and VHT data were processed during both AM and PM peak hours and segregated based on the hours of the peak period. In other words, the total VMT and VHT for a given hour (e.g., $5 \mathrm{AM}$ ) is aggregated for all the Tuesdays, Wednesdays, and Thursdays of each given month (e.g., January) and then divided to determine the average efficiency for the freeway during that hour. For this reason, the granularity is set for hourly data. In addition, since the total number of Tuesdays, Wednesdays, and Thursdays can vary depending on the month, the aggregated VMT and VHT values are normalized by dividing by that number. For example, the 
month of January in 2012 has 12 days that fall on a Tuesday, Wednesday, or Thursday, while March 2012 has 13 of these. The resulting VMT, VHT, and Q values are divided by 12 and 13 respectively in order to attain normalized values.

The peak hour periods for AM and PM times have been defined as 6 am to 9 am and $4 \mathrm{pm}$ to $7 \mathrm{pm}$, respectively. However, the congestion levels of this particular corridor are estimated to be abnormally high due to the enormous number of commuters using it to travel across the Bay into and out of the city of San Francisco. It is possible that daily traffic congestion occurs earlier and ends later than normal along this particular corridor. The analysts behind this study were interested to see how the efficiency of the freeway changes in the hour before the peak hour period begins and may show a trend worth exploring or discussing later on. Thus, the study lengthened the peak hour range from 5 am to 10 am and $3 \mathrm{pm}$ to $8 \mathrm{pm}$.

The PeMS database uses two types of postmiles to identify locations on the freeway: jurisdictional (Caltrans) and absolute postmiles. The Caltrans postmiles were assigned to geometric features on the freeway when it was originally built and are reset to zero at every county boundary line. However, Caltrans postmiles do not change after they are assigned, even when geometric changes are made to the freeway. Therefore, this study used the absolute postmiles, which represent the actual distance along the freeway from its origin to terminus and also update when changes are made due to construction.

This study also focused on a spatial analysis to determine the length of the I- 80 freeway where the ARM is deemed effective. Ramp metering, as noted in the literature review, has been found to be beneficial to drivers utilizing the freeway for long trips. However, as those trips decrease in length, users are less likely to benefit from the implementation of ramp metering and may choose to plan their trip via local streets instead to avoid unnecessary delay. As a result, several segments of the freeway, all originating from the same entrance ramp, were formed in hopes of providing a trend as the segments get longer (Table 2). 
Table 2. Absolute PM Ranges and Descriptions of I-80 Segments

\begin{tabular}{|c|c|c|}
\hline Segment Description & Absolute PM Range & PM Range Description \\
\hline Entire Segment & 8.95 to 26.83 & $\begin{array}{l}\text { EB Off to Powell to } \\
\text { EB Off to Pomona }\end{array}$ \\
\hline Segment 1 (Longest) & 13.45 to 22.06 & $\begin{array}{l}\text { EB Off to Central Avenue to } \\
\text { EB off to Pinole Valley Road }\end{array}$ \\
\hline Segment 2 & 13.45 to 20.74 & $\begin{array}{l}\text { EB Off to Central Avenue to } \\
\text { EB Off to Appian Way }\end{array}$ \\
\hline Segment 3 & 13.45 to 19.92 & $\begin{array}{c}\text { EB Off to Central Avenue to } \\
\text { EB Off to Richmond Parkway/Fitzgerald }\end{array}$ \\
\hline Segment 4 & 13.45 to 19.11 & $\begin{array}{c}\text { EB Off to Central Avenue to } \\
\text { EB Off to Hilltop Drive }\end{array}$ \\
\hline Segment 5 & 13.45 to 18.49 & $\begin{array}{l}\text { EB Off to Central Avenue to } \\
\text { El Portal Drive }\end{array}$ \\
\hline Segment 6 & 13.45 to 17.53 & $\begin{array}{c}\text { EB Off to Central Avenue to } \\
\text { EB Off to San Pablo Dam Road }\end{array}$ \\
\hline Segment 7 & 13.45 to 17.27 & $\begin{array}{l}\text { EB Off to Central Avenue to } \\
\text { WB Off to McBryde Avenue }\end{array}$ \\
\hline Segment 8 & 13.45 to 15.90 & $\begin{array}{l}\text { EB Off to Central Avenue to } \\
\text { EB Off to WB Macdonald Avenue }\end{array}$ \\
\hline Segment 9 & 13.45 to 14.87 & $\begin{array}{l}\text { EB Off to Central Avenue to } \\
\text { EB Off to Potrero Avenue }\end{array}$ \\
\hline Segment 10 (Shortest) & 13.45 to 14.14 & $\begin{array}{l}\text { EB off to Central Avenue to } \\
\text { EB Off to Carlson Boulevard }\end{array}$ \\
\hline
\end{tabular}


Once the appropriate parameters were input, the data was exported into an Excel spreadsheet. Each entry showed the totaled VMT and VHT for each given peak hour and for each specified day (Tuesday, Wednesday, or Thursday). The VMT and VHT values were aggregated based on peak hour and normalized to calculate the average Q value for each peak hour, the given month, and the particular segment.

This process was repeated for all months from January 2012 to June 2018. Since ramp metering was implemented in April 2017, data was compiled using that date as the "start" of the year. For example, the label for year "2016" implies the period from April 2016 through March 2017. This schema is detailed in Table 3. The "before" period is represented by the time period from April 2012 to March 2017, while the "after" period is represented by the time period from April 2017 to March 2018.

Table 3. Label of Year and Corresponding Duration of Analysis

\begin{tabular}{|c|c|}
\hline Label of Year & Corresponding Duration \\
\hline 2012 & April 2012 to March 2013 \\
\hline 2013 & April 2013 to March 2014 \\
\hline 2014 & April 2014 to March 2015 \\
\hline 2015 & April 2015 to March 2016 \\
\hline 2016 & April 2016 to March 2017 \\
\hline 2017 & April 2017 to March 2018 \\
\hline
\end{tabular}

Travel behavior can change drastically depending on the time of the year. For example, while holidays like Thanksgiving and Christmas are excluded from the data collection, trends may still exist in the days surrounding said holidays and are still included in the analysis. Due to this, the months of January, April, July, and October were chosen to represent the seasonal 
variation in travel behavior. These four months are evenly spaced out through the year, typical of the four seasons, and do not possess any large holidays that may distort commute patterns.

\subsubsection{Control Segment}

In order to better evaluate the performance of the I- 80 with ARM implementation and highlight any potential benefits, similar freeway segments without ARM implementation in the Bay Area were analyzed to serve as a comparison. This "control” segment was chosen from within the Bay Area freeway network to account for secular increase in congestion, changes in weather patterns over time, etc. Several segments similar to the original I-80 segment were analyzed from the I-580, I-880, US-101, I-680, and I-280 freeways. Initial analysis was conducted utilizing a freeway segment along the I-680; however, this analysis was discarded after discovering evidence of renovation on the existing high-occupancy vehicle (HOV) lanes between Rudgear Road and Alcosta Boulevard in the southbound direction and between Alcosta Boulevard and Livorna Road in the northbound direction (Berger, 2015). A segment along the I280 freeway was found to experience similar traffic patterns during the peak period and similar land use in surrounding neighborhoods. The extents of the control segment are shown in Figure 7 (Rahman, 2019) while the PM range for the segment is shown in Table 4. This control segment will be used for analysis when comparing the eastbound and westbound directions of the I-80 freeway. 


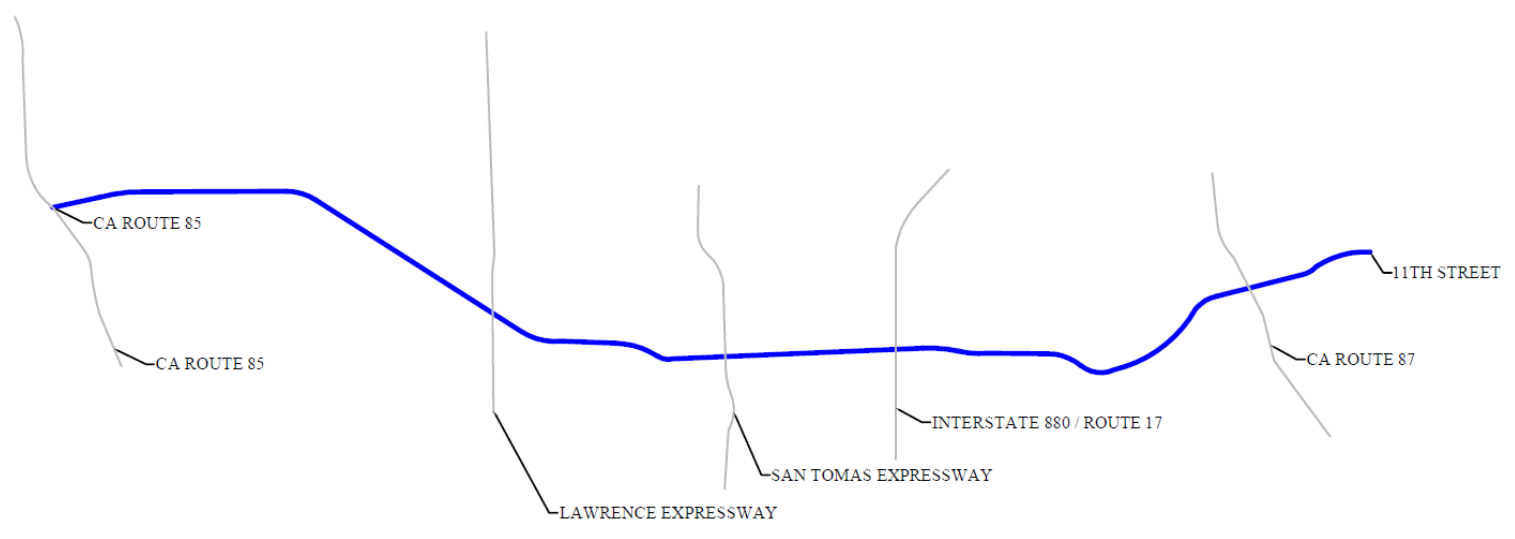

Figure 7. I-280 Control Segment

Table 4. Absolute PM Range and Description of I-280 Control Segment

\begin{tabular}{|c|c|c|}
\hline Segment Description & Absolute PM Range & PM Range Description \\
\hline Entire Segment & 1.54 to 11.76 & SB Off to $10^{\text {th }}$ Street to \\
& & SB On from Route 85 \\
\hline
\end{tabular}

\subsection{Safety Analysis}

\subsubsection{Data Source - Transportation Injury Mapping System (TIMS)}

Collision data was necessary for the naïve before-after study to establish a historical record of the collision history on the I-80 corridor. The Transportation Injury Mapping System (TIMS) has been developed over the past several years by Safe Transportation Research and Education Center (SafeTREC). It was founded in 2000 by the University of California, Berkeley, and is affiliated with the School of Public Health, the Institute of Transportation Studies, and the Department of City and Regional Planning, Public Policy, and Transportation Engineering. The database emphasizes three areas of focus: data analysis and data tools, technology for road safety, and policy analysis and community outreach. It is capable of providing quick and easy access to California crash data that has been geo-coded for easy mapping of said data. 
The TIMS database possesses a variety of useful tools that may be used to process and display collision data differently. For example, the California Statewide Integrated Traffic Records System (SWITRS) Query \& Map tool enables quick data access and can display the results as either a graphic (e.g., plot, chart, graph) or as a detailed spreadsheet for further analysis. Another tool, known as the SWITRS GIS Map, offers an interactive map that can depict collisions depending on the location and date of the incident. Several other factors pertaining to the collision itself, such as parties and victims involved, may also be applied to filter through the collision data more thoroughly (Figure 8).

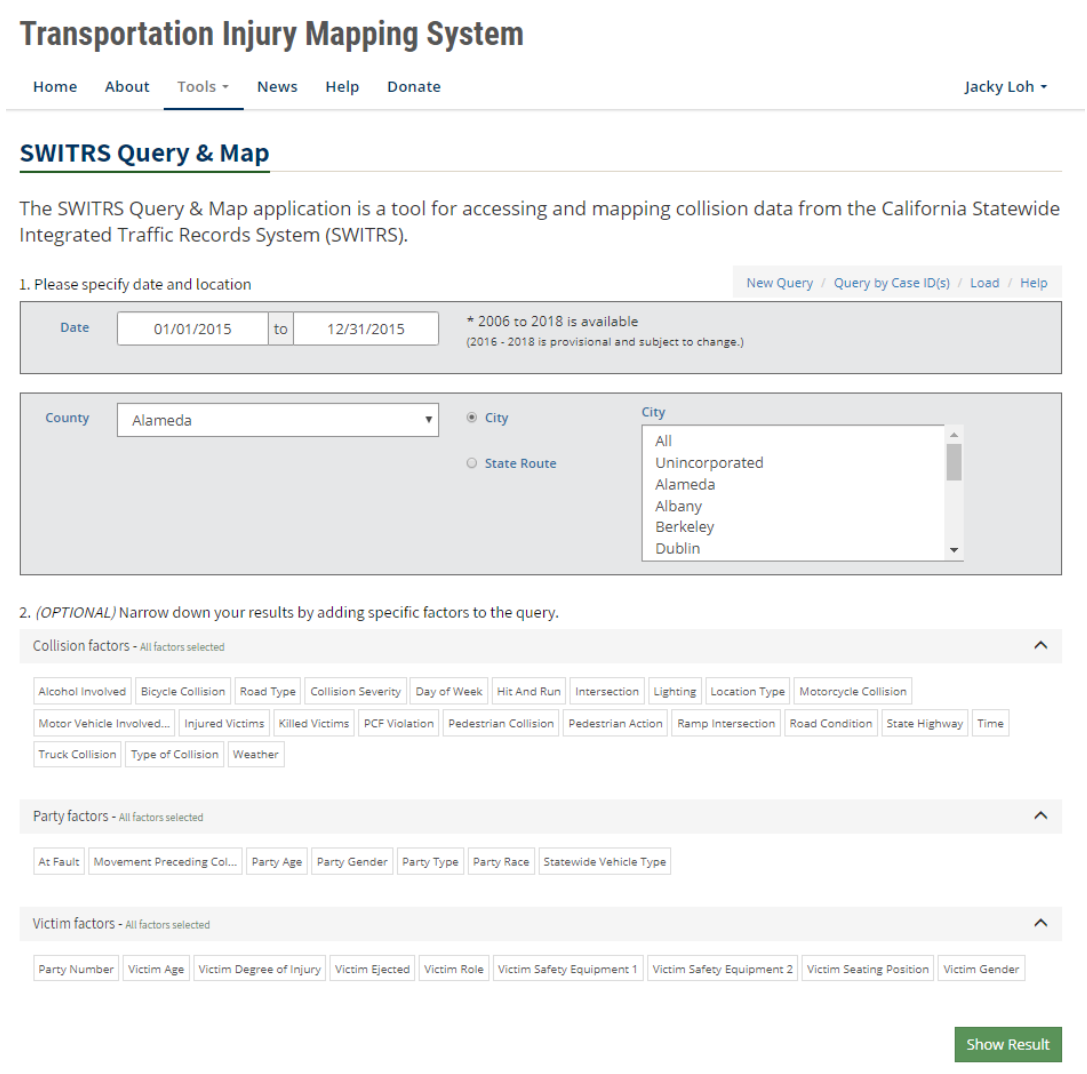

Figure 8. SWITRS Query \& Map User Interface 


\subsubsection{Methodology}

This thesis replicated the Empirical Bayes analysis on a segment along the I-80 corridor to establish a framework for a safety evaluation on the effects of the implementation of ARM. The Empirical Bayes analysis reduces the likelihood of regression to the mean being labelled as a decline in collisions due to the implementation of ramp metering but requires a large amount of data pertaining to the site. A site is defined by a speed-change lane or a homogenous freeway segment and can be further characterized by its cross section. The Empirical Bayes analysis is considered an effective analysis method when the follow three conditions are met: the roadway cross section that is modified within the project retains the same basic number of through lanes; minor changes in alignment may be made, but the majority of the alignment is to remain the same; a weaving section is introduced to the freeway, or any combination of said conditions.

This approach leads to what is considered a more reliable estimate of a site's expected crash frequency and improves the reliability of that estimate by combining the estimate with a predictive model using the test site's observed collision data. The model estimate describes the safety of a typical site with attributes matching those of the test site. In order to utilize this analysis method, a baseline estimate of crashes for the site is required, which was found in TIMS.

Official documentation of the site characteristics would have allowed for more efficient time spent gathering geometric data of the site. However, given the preliminary aspect of this study, basic measurements performed in Google Earth were considered adequate to establish a basic framework. Annual average daily traffic (AADT) volumes were obtained using Caltrans' Ramp Volumes reports, while collision data was collected from TIMS. If further research were to be conducted, data may be obtained from Caltrans for exact curve and lane data for the entire segment or freeway network.

The above data was input into the Enhanced Interchange Safety Analysis Tool (ISATe), which is an interactive spreadsheet that can provide information about the relationship between geometric design features and safety when given adequate information (Bonneson, Pratt, \& 
Geedipally, n.d.). The segment chosen for the safety evaluation runs from Cutting Boulevard to Macdonald Avenue. This segment is approximately 0.5 miles in length and possesses few geometric changes between the entrance ramp for westbound Cutting Boulevard and the exit ramp to Macdonald Avenue. It is typically ideal to choose a segment that historically has not undergone significant geometric changes. If a segment has, then it can become difficult to attribute any improvements or detriments in safety to the treatment and may instead be an effect of the geometric change. The figure below displays the segment divided into four subsections, separated by the inclusion of a lane add or drop. The split between these segments is the point along the site at which the freeway differentiates into a "new" segment with different site characteristics from the previous subsection.

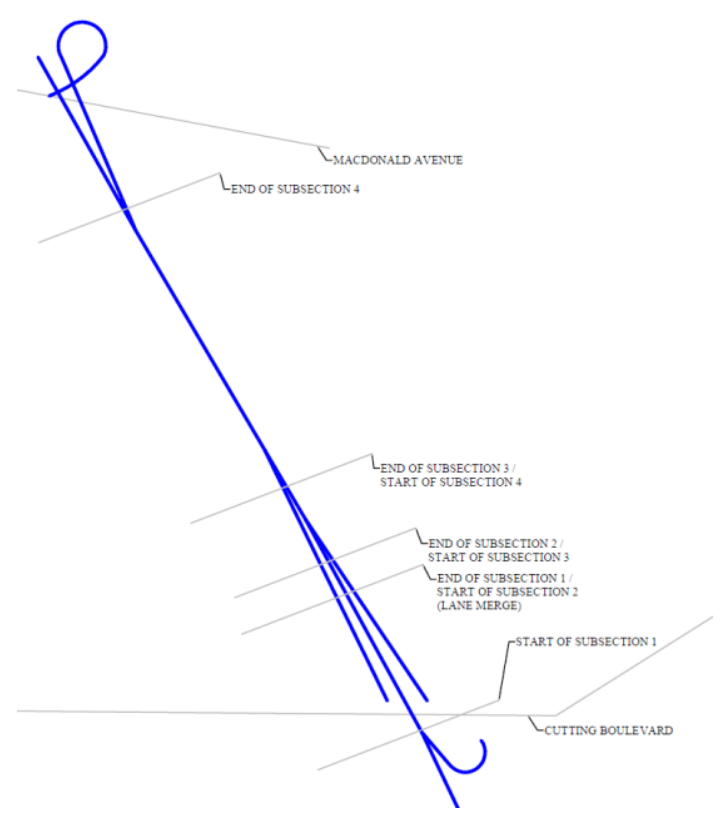

Figure 9. I-80 Segment from Cutting to Macdonald Split into Four Subsections

For each evaluation, both a "study period" and "crash period" are recommended for reliable results. There must be a defined "study period" that represents the consecutive number of years for which an estimate of the crash frequency is to be calculated. The "study period" is 
bound by the first and last year of analysis. The "crash period" is utilized in this case since adequate crash data is available and is defined by the first and last years of available crash data.

When developing the SPF, the following variables were measured via Google Maps and Google Earth:

- Number of through lanes

- Segment lengths

- Horizontal curve lengths and radii

- Lane, shoulder, and median Widths

- Lengths of entrance and exit ramps

- Clarification on presence of road barriers, weave segments, entrance and exit ramps

Due to the nature of the test segment, there were no ramp segments or ramp terminals present nor any curves along the direction of travel. This restricted the inputs needed for this segment to only the "Main" and "Input Freeway Segments" tab. Basic roadway data included the number of through lanes and segment lengths of each subsection (Figure 10). The freeway segment description was simply the analyst's designated name for each subsection. Additional data inputs, such as cross section, roadside, and ramp access characteristics, may be found in Appendix C. 


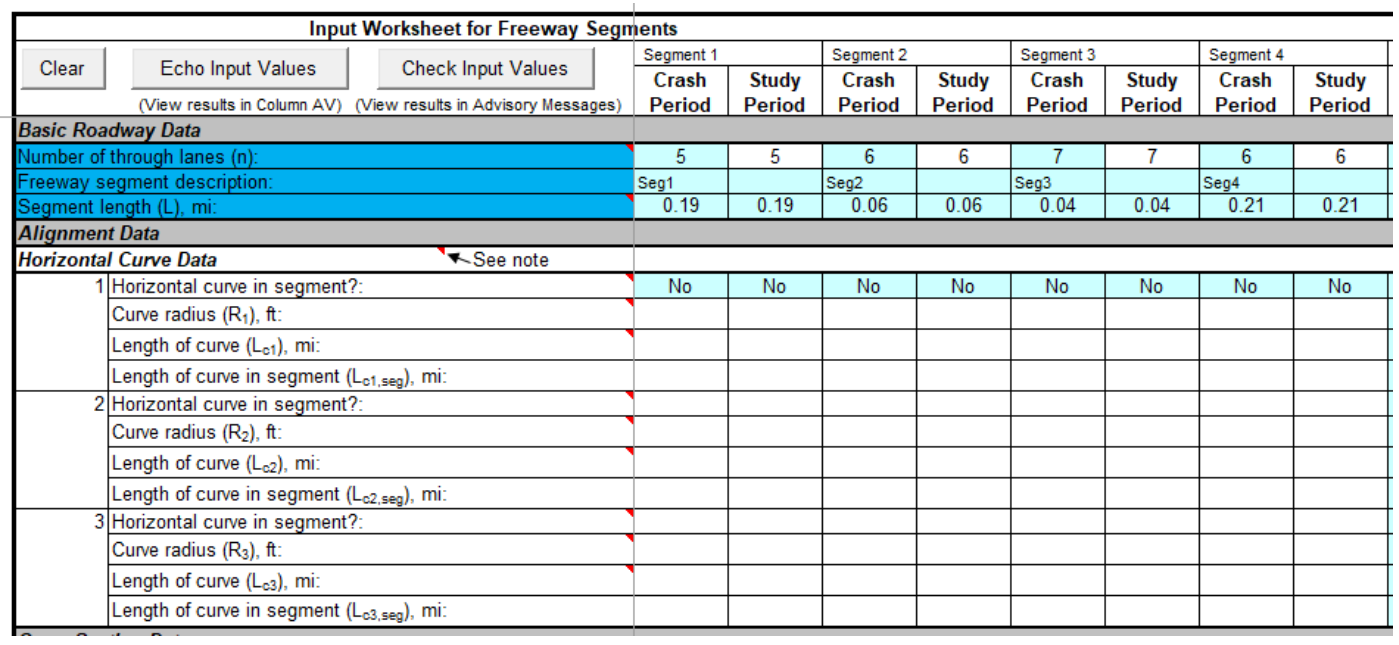

Figure 10. Basic Roadway and Alignment Data Inputs

The traffic inputs included the proportion of AADT during peak hour periods, or K-

value, and the AADT values for each segment. Given that the study site is only 0.5 miles long, the subsections are subsequently short. Considering Caltrans freeway volumes do not measure AADT to that level of precision along the freeway, the same AADT and K-values were assumed across all subsections. Since there were no entrance or exit ramps present within the segment, no AADT inputs were necessary (Figure 11).

Since the crash period of this study takes place in the future, there is no known AADT value available to input into the spreadsheet yet. The ISATe user manual recommends that for future crash periods, the AADT value is held constant for each subsequent year after the last known AADT value (Bonneson et al., n.d.). It is currently left blank in Figure 11 and will be further discussed in the safety analysis results section in Chapter 4. 


\begin{tabular}{|c|c|c|c|c|c|c|c|c|c|c|c|}
\hline \multicolumn{12}{|c|}{ Input Worksheet for Freeway Segments } \\
\hline \multirow{2}{*}{ Clear } & \multirow{2}{*}{ Echo Input Values } & \multirow{2}{*}{\multicolumn{2}{|c|}{ Check Input Values }} & \multicolumn{2}{|l|}{ Segment 1} & \multicolumn{2}{|l|}{ Segment 2} & \multicolumn{2}{|l|}{ Segmont 3} & \multicolumn{2}{|l|}{ Segment 4} \\
\hline & & & & $\begin{array}{l}\text { Crash } \\
\text { Period }\end{array}$ & $\begin{array}{l}\text { Study } \\
\text { Period }\end{array}$ & $\begin{array}{l}\text { Crash } \\
\text { Period }\end{array}$ & $\begin{array}{c}\text { Study } \\
\text { Period }\end{array}$ & \begin{tabular}{|l} 
Crash \\
Period
\end{tabular} & $\begin{array}{l}\text { Study } \\
\text { Period }\end{array}$ & $\begin{array}{l}\text { Crash } \\
\text { Period }\end{array}$ & $\begin{array}{l}\text { Study } \\
\text { Period }\end{array}$ \\
\hline Traffic D. & & & Year & & & & & & & & \\
\hline Proportion & AADT during high-volun & is $\left(P_{\text {av }}\right)$ & & 0 & & 0 & 07 & & 07 & 0 . & 07 \\
\hline Freeway & ment Data & & 2012 & & 000 & 198 & 1000 & & 3000 & & 3000 \\
\hline Average $\mathrm{C}$ & traffic $\left(\mathrm{AADT}_{\mathrm{t}}\right)$ by yea & & 2013 & & 000 & 198 & 1000 & & 3000 & & 3000 \\
\hline (enter da & only for those years for & & 2014 & 203 & 000 & 203 & 1000 & & 3000 & & 3000 \\
\hline it is ava & e, leave other years bla & & 2015 & & & & & & & & \\
\hline & & & 2016 & & & & & & & & \\
\hline & & & 2017 & & & & & & & & \\
\hline & & & 2018 & & & & & & & & \\
\hline & & & 2019 & & & & & & & & \\
\hline & & & 2020 & & & & & & & & \\
\hline Entrance & ne Data for Travel in lnc & g Milepost Dir. & Year & & & & & & & & \\
\hline Average C & 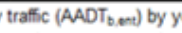 & & 2012 & & 0 & & 0 & & 0 & & 0 \\
\hline (enter dz & only for those years for & & 2013 & & & & 0 & & 0 & & 0 \\
\hline it is ava & le, leave other years bla & & 2014 & & j & & 0 & & 0 & & $\overline{0}$ \\
\hline & & & 2015 & & & & & & & & \\
\hline & & & 2016 & & & & & & & & \\
\hline & & & 2017 & & & & & & & & \\
\hline & & & 2018 & & & & & & & & \\
\hline & & & 2019 & & & & & & & & \\
\hline & & & 2020 & & & & & & & & \\
\hline & & orksheet for $\mathrm{Fr}$ & ay Segr & ients & & & & & & & \\
\hline Clear & Echo Input Values & Check Input I & & Segment 1 & & Sogment 2 & & Sogment 3 & & Sogment 4 & \\
\hline & (Vew resuts in Colum $A$ & w resuts in Advas & $\begin{array}{l}5 \\
\text { asseges) }\end{array}$ & $\begin{array}{l}\text { Crash } \\
\text { Period }\end{array}$ & $\begin{array}{l}\text { Study } \\
\text { Period }\end{array}$ & $\begin{array}{l}\text { Crash } \\
\text { Period }\end{array}$ & $\begin{array}{l}\text { Study } \\
\text { Period }\end{array}$ & $\begin{array}{l}\text { Crash } \\
\text { Period }\end{array}$ & $\begin{array}{l}\text { Study } \\
\text { Period }\end{array}$ & $\begin{array}{l}\text { Crash } \\
\text { Period }\end{array}$ & $\begin{array}{l}\text { Study } \\
\text { Period }\end{array}$ \\
\hline Exit Rams & ta for Travel in increasi & post Direction & Year & & & & & & & & \\
\hline Average c $c$ & traffic (AADT, ent) by $\mathrm{y}$ & & 2012 & 1 & & $\mathrm{c}$ & & 1 & & 0 & \\
\hline (enter da & only for those years for & & 2013 & I & & ( & 0 & I & & 0 & 0 \\
\hline it is ava & e, leave other years bla & & 2014 & - & & 气 & 0 & 7 & & 0 & $\overline{0}$ \\
\hline & & & 2015 & & & & & & & & \\
\hline & & & 2016 & & & & & & & & \\
\hline & & & 2017 & & & & & & & & \\
\hline & & & 2018 & & & & & & & & \\
\hline & & & 2019 & & & & & & & & \\
\hline & & & 2020 & & & & & & & & \\
\hline Entrance & np Data for Travel in De & ng Milepost Dir. & Year & & & & & & & & \\
\hline Average $\mathrm{c}$ & traffic (AADT. .ent) by ye & & 2012 & ( & & $\mathrm{c}$ & 0 & 1 & & 0 & 0 \\
\hline (enter da & only for those years for & & 2013 & I & & 8 & 0 & 7 & & 0 & 0 \\
\hline it is ava & e, leave other years bla & & 2014 & I & & c & 0 & - & & 0 & 0 \\
\hline & & & 2015 & & & & & & & & \\
\hline & & & 2016 & & & & & & & & \\
\hline & & & 2017 & & & & & & & & \\
\hline & & & 2018 & & & & & & & & \\
\hline & & & 2019 & & & & & & & & \\
\hline & & & 2020 & & & & & & & & \\
\hline & & orksheet for $\mathrm{Fr}$ & ay Segr & ents & & & & & & & \\
\hline & & & & Sogment 1 & & Segment 2 & & \begin{tabular}{|l} 
Sogment 3 \\
\end{tabular} & & Segment 4 & \\
\hline Clear & Echo Input Values & Check Input & & Crash & Study & Crash & Study & Crash & Study & Crash & Study \\
\hline & (New resuts in Colvm $A$ ) & w resuls in Aovis & esseges) & Period & Period & Period & Period & Period & Period & Period & Period \\
\hline Exit Ramg & ta for Travel in Decreas & lepost Direction & Year & & & & & & & & \\
\hline Average $\mathrm{C}$ & traffic $\left(A A D T_{b, 0 a}\right)$ by ye & & 2012 & 1 & & 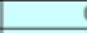 & 0 & & 0 & & 0 \\
\hline (enter da & Inly for those years for $y$ & & 2013 & I & 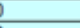 & 工 & 0 & & 0 & & 0 \\
\hline it is ava & e, leave other years bla & & 2014 & $I$ & & ( & 0 & & 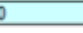 & & 0 \\
\hline & & & 2015 & & & & & & & & \\
\hline & & & 2016 & & & & & & & & \\
\hline & & & 2017 & & & & & & & & \\
\hline & & & 2018 & & & & & & & & \\
\hline & & & 2019 & & & & & & & & \\
\hline & & & 2020 & & & & & & & & \\
\hline
\end{tabular}

Figure 11. Traffic Data Inputs

The collision data from the TIMS database initially separated crashes according to severity into three classes: "fatal", "severe", and "complaint of pain". Every recorded collision from April 2012 to March 2015 was shown to include one of these categories and thus counted as a "Fatal-and-Injury (FI)" crash in the spreadsheet for conservative purposes (Figure 12). It is 
unlikely that many, if any, "Property-Damage-Only (PDO)" crashes exist within the TIMS database, as nearly all collisions typically result in some form of injury, however minor.

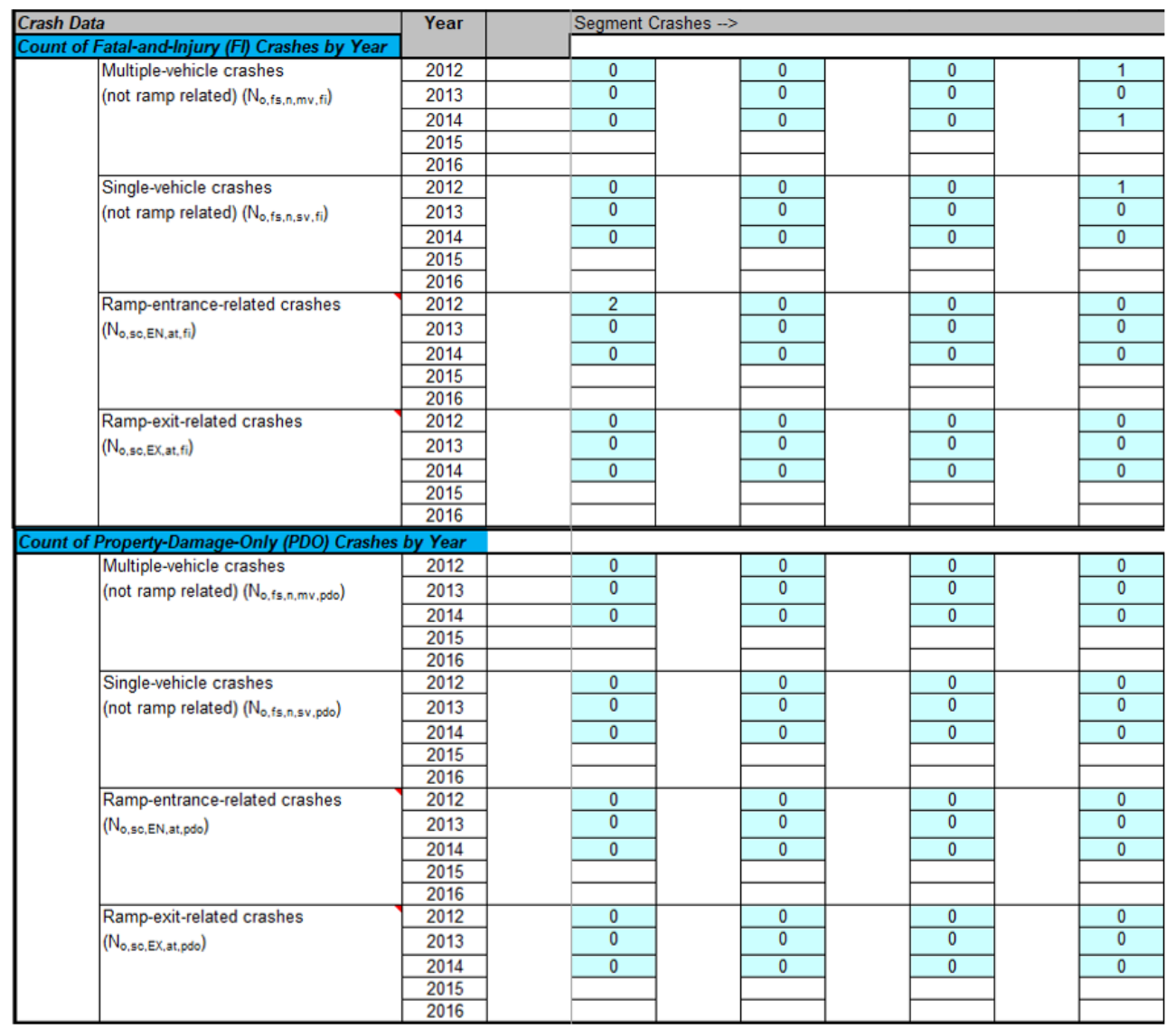

Figure 12. Crash Data Inputs

The final tabs within the spreadsheet relate to the outputs determined from the inputted data. This study sought to develop the counterfactual - in this case, the hypothesis that questions what would have happened had ARM not been implemented - of future performance to determine the overall effectiveness of ARM. Results of this methodology will be discussed in the next chapter in the section pertaining to the Empirical Bayes analysis. 


\section{CHAPTER 4 - ANALYSIS AND RESULTS}

The analysis herein involves the exploration of trends in efficiency and safety from April 2012 to March 2018. A control segment along the I-280 corridor was included within this study's efficiency analysis to provide a test site that experiences similar traffic congestion and lies within the region of the Bay Area but does not have ARM implemented. Since ARM on the I-80 officially began operation in April 2017, the study showcases the data in a yearly format where one could notice a trend starting at the beginning of the graph rather than towards the middle. Thus, all graphs showcase data points that take into account data gather from April of the year displayed through March of the following year. For example, the year 2017 represents the time duration from April 2017 through March 2018 (Table 3).

It is worthwhile to note that nearly all of these graphs within this section show some drop in efficiency when comparing the treated segment with the control I-280 segment. While this may lead one to initially conclude that ramp metering implementation did not actually lead to any benefits, the actual difference of the drop in efficiency can better explain the difference in results. In other words, the term "reduction" or "drop" in efficiency does not necessarily imply an automatic detriment to the freeway's performance. While the decrease in efficiency still occurred, in many cases, the ramp metering appears to have mitigated some of the decrease and thus shows from marginal increases in efficiency that may not be initially apparent.

\subsection{Efficiency Analysis Results}

\subsubsection{Traffic Demand}

The I-280 control segment was chosen due to its similarity with the I-80 in traffic patterns. As traffic volumes increase, congestion increases and eventually leads to a decrease in both efficiency and safety. This provides a potential outside factor that may affect the efficiencies of the I- 80 corridor besides the implementation of ARM. The critical segment on the I- 80 runs 
from the eastbound exit ramp to Central Avenue through the eastbound exit ramp to Pinole Valley Road and possesses the absolute postmile range of 13.45 to 22.06 . The length of said segment is approximately 8.3 miles long, while the control segment on the I- 280 runs from California Route 85 to 11th Street and is approximately 10.4 miles. While Powell Street actually holds a closer similarity in percent growth to California Route 85, the AADT of Powell is nearly twice as large and would not compare as easily as the traffic volumes running through Central Avenue would. This is caused by Powell Street lying relatively close to the I-80/I-580/I-880 interchange. The segment regularly receives vehicular flow from W Grand Avenue as well as from the westbound I-580 and eastbound I-80 directions, which leads to higher traffic counts, as shown in Table 5. Thus, the start of the critical segment was set to Central Avenue, which showcases a more relatable volume of daily traffic. 11th Street was chosen as the end of the segment as it possessed the closest AADT comparison on the I-280 while maintaining a similar segment length and percent growth from 2012 to 2017. Ultimately, the Central Avenue and Pinole Valley Road were chosen as the boundaries of the control segment due to possessing the most similar characteristics compared to the control segment on the I-280; this choice of segment was approved by Caltrans as well.

Table 5. I-80 AADT Volumes

\begin{tabular}{|c|c|c|c|c|}
\hline \multicolumn{7}{|c|}{ I-80 AADT Eastbound (Westbound) } \\
\hline Year & Powell (Abs PM 8.95) & Central (Abs PM 13.45) & Pinole Valley (Abs PM 22.06) & Crockett/Pomona (Abs PM 26.83) \\
\hline 2012 & $270,000(144,000)$ & $175,000(172,000)$ & $170,000(185,000)$ & $109,000(112,000)$ \\
\hline 2013 & $270,000(144,000)$ & $175,000(172,000)$ & $170,000(185,000)$ & $109,000(112,000)$ \\
\hline 2014 & $277,000(147,000)$ & $179,000(176,000)$ & $174,000(189,000)$ & $113,000(116,000)$ \\
\hline 2015 & $270,000(147,000)$ & $179,000(176,000)$ & $170,000(188,000)$ & $116,000(118,000)$ \\
\hline 2016 & $275,000(270,000)$ & $183,000(180,000)$ & $173,000(192,000)$ & $118,000(120,000)$ \\
\hline 2017 & $288,800(283,500)$ & $192,200(189,000)$ & $181,700(201,600)$ & $123,900(126,000)$ \\
\hline Percent Growth & $\mathbf{6 . 9 6 \%}$ & $\mathbf{9 . 8 3} \%$ & $\mathbf{6 . 8 8 \%}$ & $\mathbf{1 3 . 6 7 \%}$ \\
\hline
\end{tabular}


Table 6. I-280 AADT Volumes

\begin{tabular}{|c|c|c|}
\hline \multicolumn{3}{|c|}{ I-280 AADT Southbound } \\
\hline Year & CA 85 (Abs PM 11.76) & 11th St (10th St) (Abs PM 1.54) \\
\hline 2012 & 136,000 & 239,000 \\
\hline 2013 & 136,000 & 239,000 \\
\hline 2014 & 139,000 & 246,000 \\
\hline 2015 & 142,000 & 251,000 \\
\hline 2016 & 146,000 & 256,000 \\
\hline 2017 & 146,000 & 261,000 \\
\hline Percent Growth & $\mathbf{6 . 8 5} \%$ & $\mathbf{8 . 4 3 \%}$ \\
\hline
\end{tabular}

\subsubsection{Spatial Analysis}

Preliminary analysis revealed that the I-80 segments immediately upstream of the Pinole Valley Road bottleneck possessed exceptionally poor travel time reliability (Rahman, 2019). The subsequent analysis focused on these segments by anchoring Central Avenue as a start point and incrementally reducing the segment - starting from Pinole Valley Road - by one entrance ramp at a time. These segments are depicted in Figure 13.

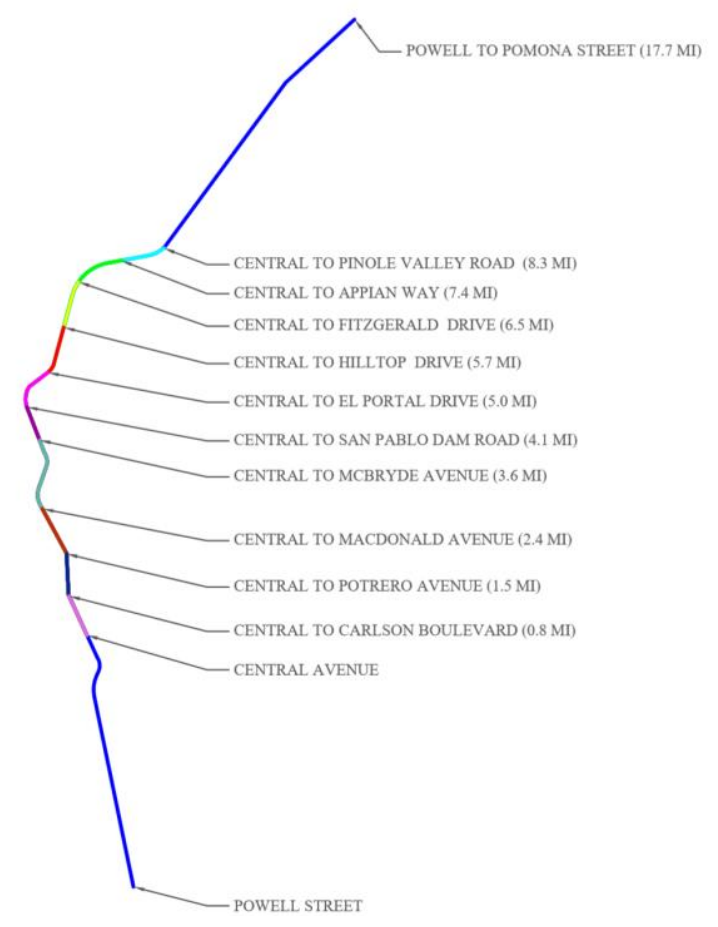

Figure 13. Incremental Study Segment Lengths along I-80 
Figures 14 and 15 below displays the average efficiency by segment for the full segment length of the I-80 and I-280 freeways as well as the partial segments, hereafter referred to as "critical" or "partial" segments, of the I-80 corridor. For the sake of clarity, Figure 14 and 15 only display the full-length and critical segments of the I-80 and the comparison segment of the I-280. More detailed plots exhibiting all segments can be found in Appendix A. In the "before" period, the westbound direction of the I-80 corridor shows relatively consistent efficiency during the AM peak hour, though this changes after 2014. At this point, the trend begins to slope downward at a steeper angle. The eastbound direction shows more variability over time - the efficiency actually increases from 2013 through 2014 and subsequently decreases quickly thereafter. The I-280 control segment shows a strange trend during this period with a rather steep decrease in efficiency. This may have been caused by some external factor outside of the study's control, such as a construction project, special event, or scheduled closure.

All I-80 eastbound segments, regardless of length, appear to lose efficiency as time progresses. This trend continues even after ARM has been activated along the corridor. However, it is prudent to note that the downward trend for most of the segments flatten out somewhat after 2016 while the I-280 control segment continues to decrease rapidly. This could relate to the ARM marginally improving conditions along the freeway, but due to the increasing demand in the region, the freeway's efficiency continues to decrease.

On the other hand, a few of the I-80 WB AM segments experienced marginal increases in efficiency after March 2016. In comparison, the I-280 control segment continued to lose efficiency after 2013 and shows a more obvious decrease during the 2017 period than any other I80 segment. These findings imply that the implementation of ARM has helped to improve the efficiency of the freeway somewhat, as segments 1,2, and 3 all show marginal increases in efficiency. 


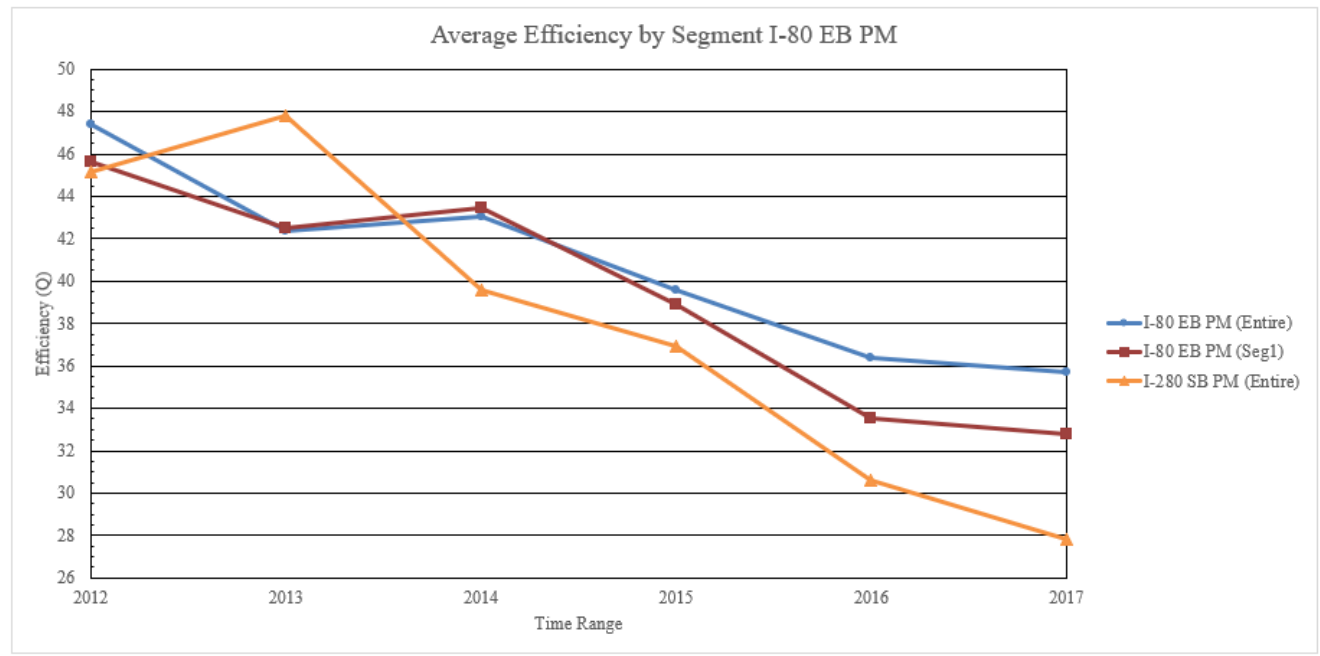

Figure 14. Average Efficiency Comparing I-80 EB PM and I-280 SB PM

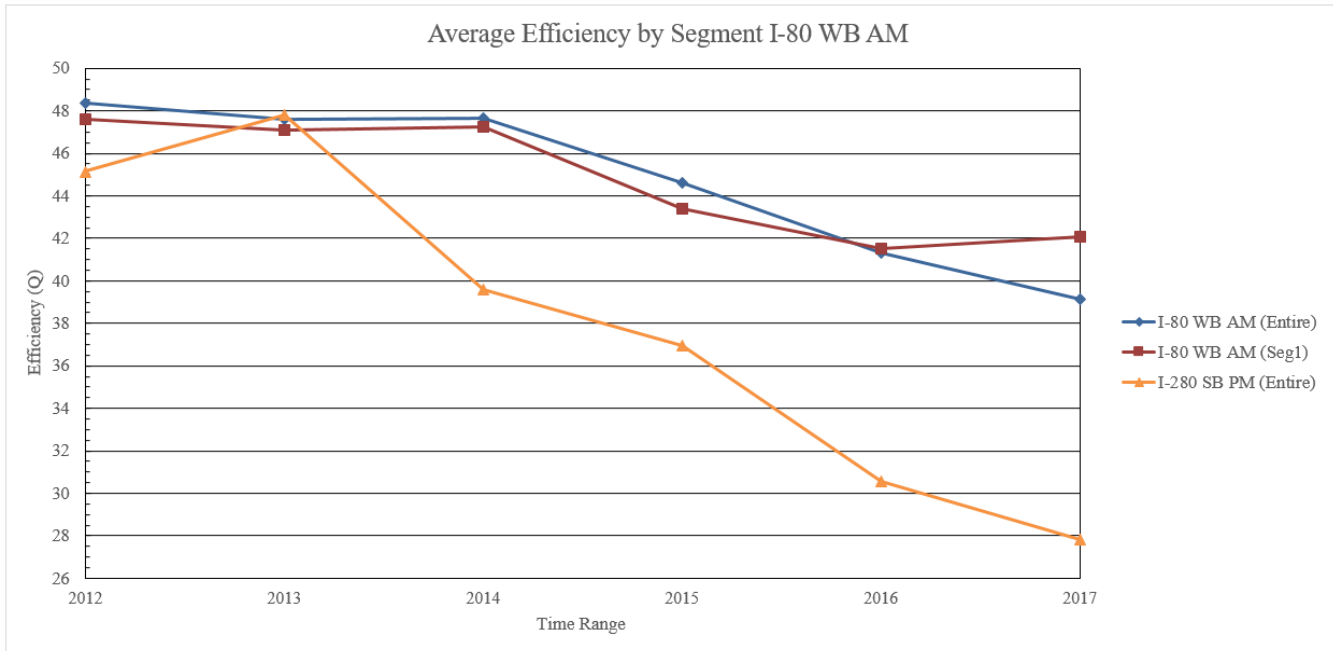

Figure 15. Average Efficiency Comparing I-80 WB AM and I-280 SB PM

Figures 16 and 17 depict the "before" and "after" efficiencies of the I-80 eastbound and westbound directions for each analyzed segment. Segment 1 is the longest segment and decreases in length until Segment 10, the shortest segment. The eastbound direction does not appear to have a strong correlation among the segment length, though there is a noticeable drop in efficiency from Segment 5 to Segment 6. This could imply that for trips longer than the length of Segment 6 
(4.1 miles), users may actually experience even higher drops in efficiency. However, the Entire Segment for the eastbound direction shows a substantially smaller drop in efficiency, which could mean that among the segments analyzed, the effective length lies between Segment 1 (8.3 miles) and the Entire Segment (17.7 miles). As for the westbound direction, as the length of the segment is increased, the drop in efficiency is originally much higher for Segments 9 (1.5 miles) and 10 (0.8 miles) but flattens out to an average of $7.5 \%$ for Segments 1 through 8 . This could imply that for users travelling along the I-80 for trips longer than Segment 8's length (2.4 miles), ARM is considered effective rather than detrimental.

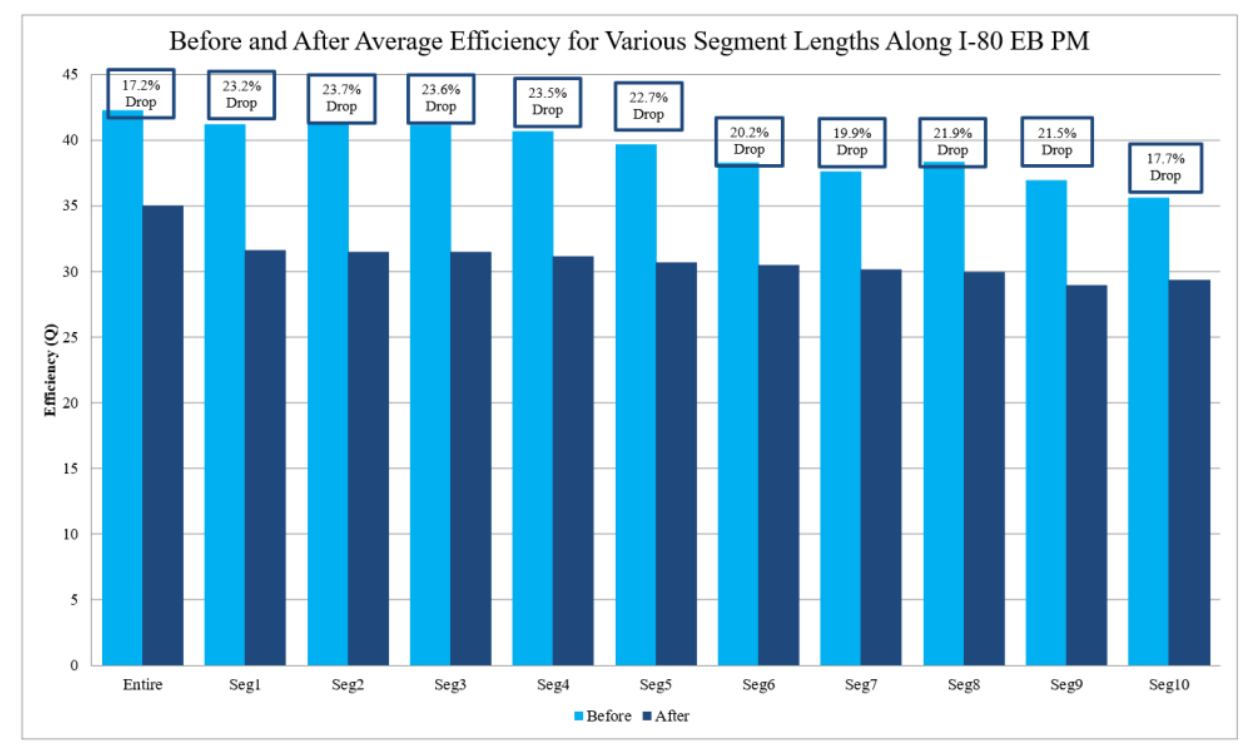

Figure 16. Average Efficiency for Various Segment Lengths along I-80 EB PM 


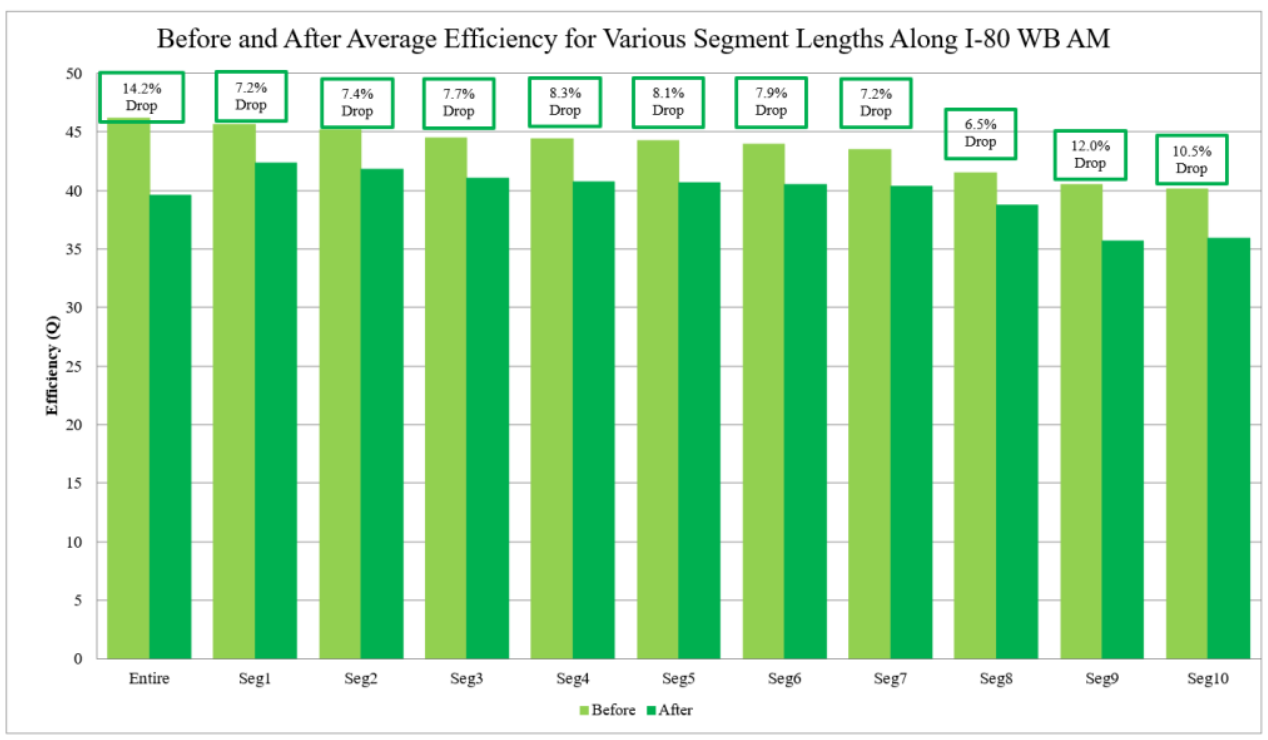

Figure 17. Average Efficiency for Various Segment Lengths along I-80 WB AM

\subsubsection{Seasonal Variation}

The seasonal variation bar charts shown in Figures 16 and 17 depict the January, April, July, and October average efficiencies in the "before" and "after" scenarios. For the month of January, the "before" scenario takes into account years 2012 through March 2017 while the “after" period represents May 2017 through June 2018. For the months of April, July, and October, the "before" scenario takes into account year 2012-2016 while the "after" period represents only the years 2017 and 2018. As ARM was officially implemented in April 2017, the efficiency data from that month was excluded from the analysis. This was done to account for users adjusting to any new changes in traffic patterns or atypical scenarios that arose due to the activation of the ramp metering.

When comparing the seasonal variation between the peak directions on the I-80 alone, the eastbound PM direction is consistently less efficient than the westbound AM direction (Figure 16). This showcases either an increase in vehicle-miles traveled or decrease in vehicle-hours traveled, both of which can imply increased congestion and/or delay for the eastbound direction. 
In the "after" period, the eastbound and westbound directions decrease in efficiency by an average of 14.6 and $13.4 \%$, respectively.

Figure 17 shows the seasonal variation in efficiency comparing the critical segment extending from Central Avenue to Pinole Valley Road on the I-80 and the I-280 control segment ranging from the California Route 85 to 11th Street. Between the "before" and "after" periods, the critical segment of the I- 80 shows an average drop in efficiency of $27 \%$ while the I-280 lost an average $31.8 \%$ in efficiency across the seasonal months. The implementation of ARM could have mitigated some of the loss of efficiency between the "before" and after" on the I-80 corridor, while the I-280 segment suffered more delay and congestion due to a lack of metering.

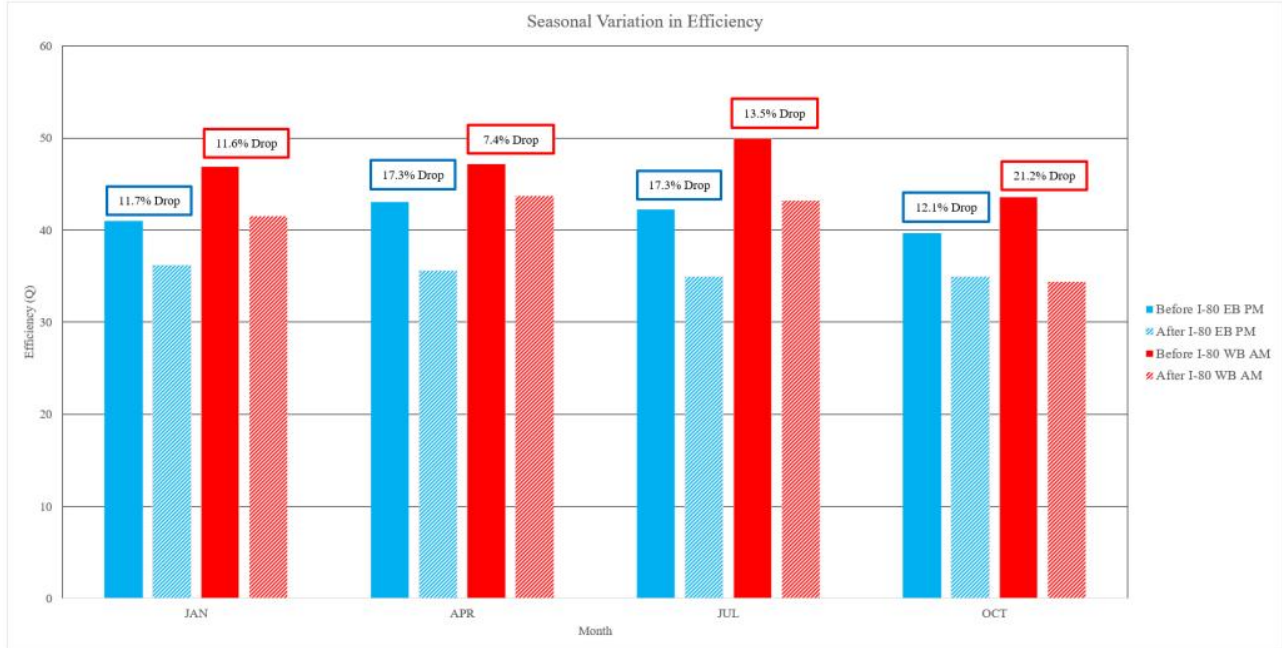

Figure 18. Seasonal Variation in Efficiency between I-80 EB PM and WB AM Directions 
Seasonal Variation in Efficiency

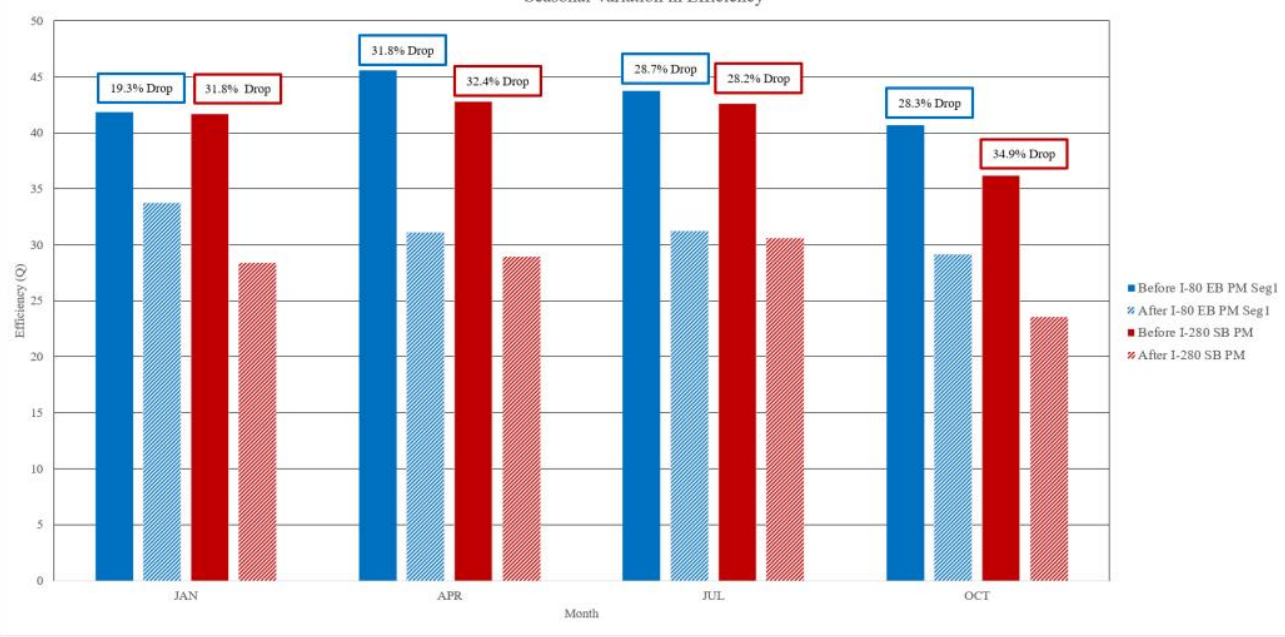

Figure 19. Seasonal Variation in Efficiency between I-80 Critical Segment and I-280 Control

\section{Segment}

\subsubsection{Monthly Variation}

Figures 18, 19, 20, and 21 show the variation of efficiencies for each month throughout the entire duration of this study. There is a slight downward trend implying that as time goes on, all efficiencies for all corridors have decreased incrementally. This is especially true of the eastbound direction of the I-80 - the downward trend for all months show a relatively consolidated and steady decrease from average efficiencies from mid-high 40's down to mid-30s for the entire and critical segments. As for the westbound direction of the I-80, the trend shows a remarkable consolidation in 2015 where the average efficiency throughout the entire year barely fluctuated. However, this was a short-lived duration, as segments split off once more as 2016 occurred. The monthly variation for the I-280 southbound direction also gradually decreases as time goes on and ranges from mid-40s in the "before" period and high 20's for the "after" period. Once again, this implies the idea that while all corridors have showcased decreasing efficiencies, the I-80 corridor that has been treated with ARM has shown less severe drops over time. 


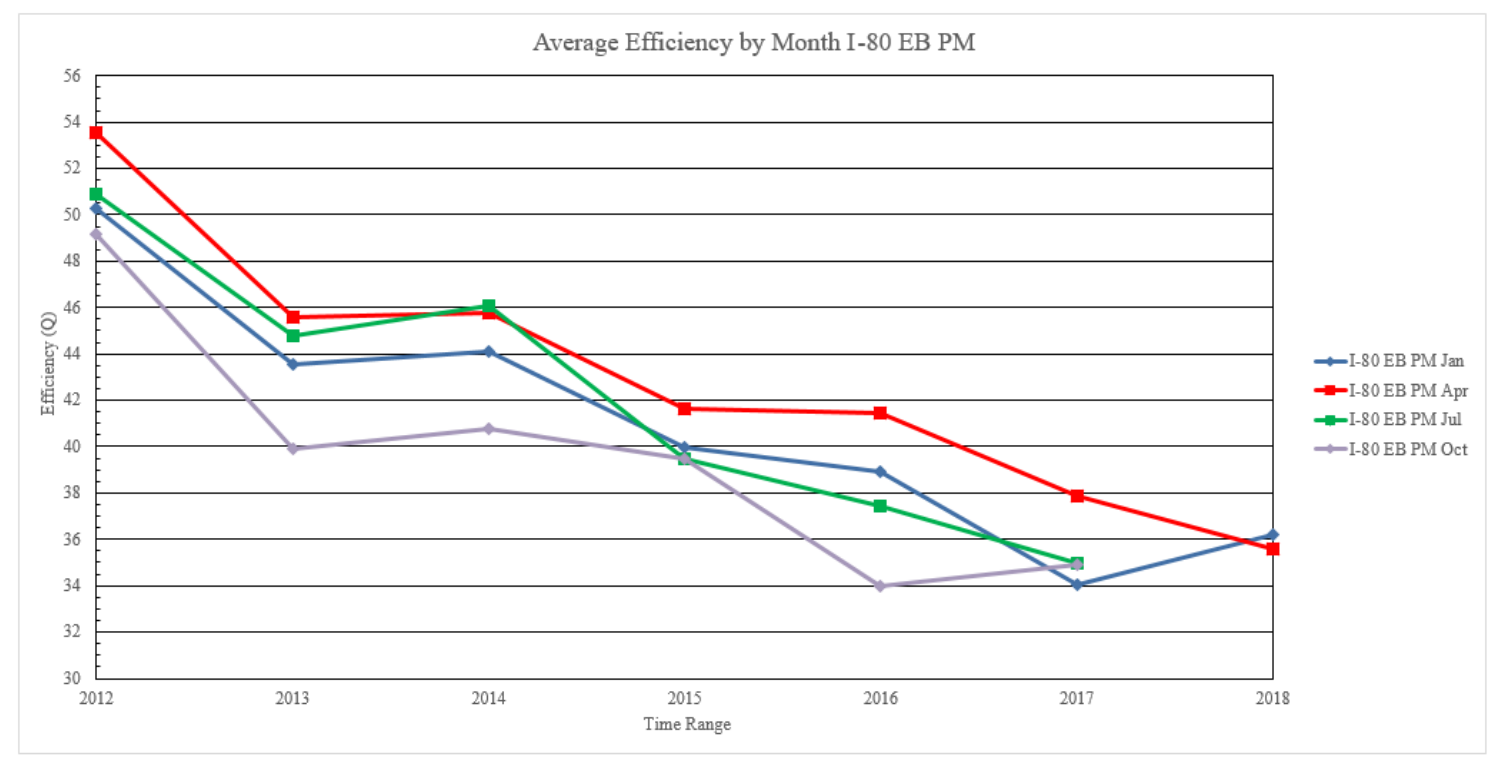

Figure 20. Monthly Variation of Efficiency along I-80 EB PM

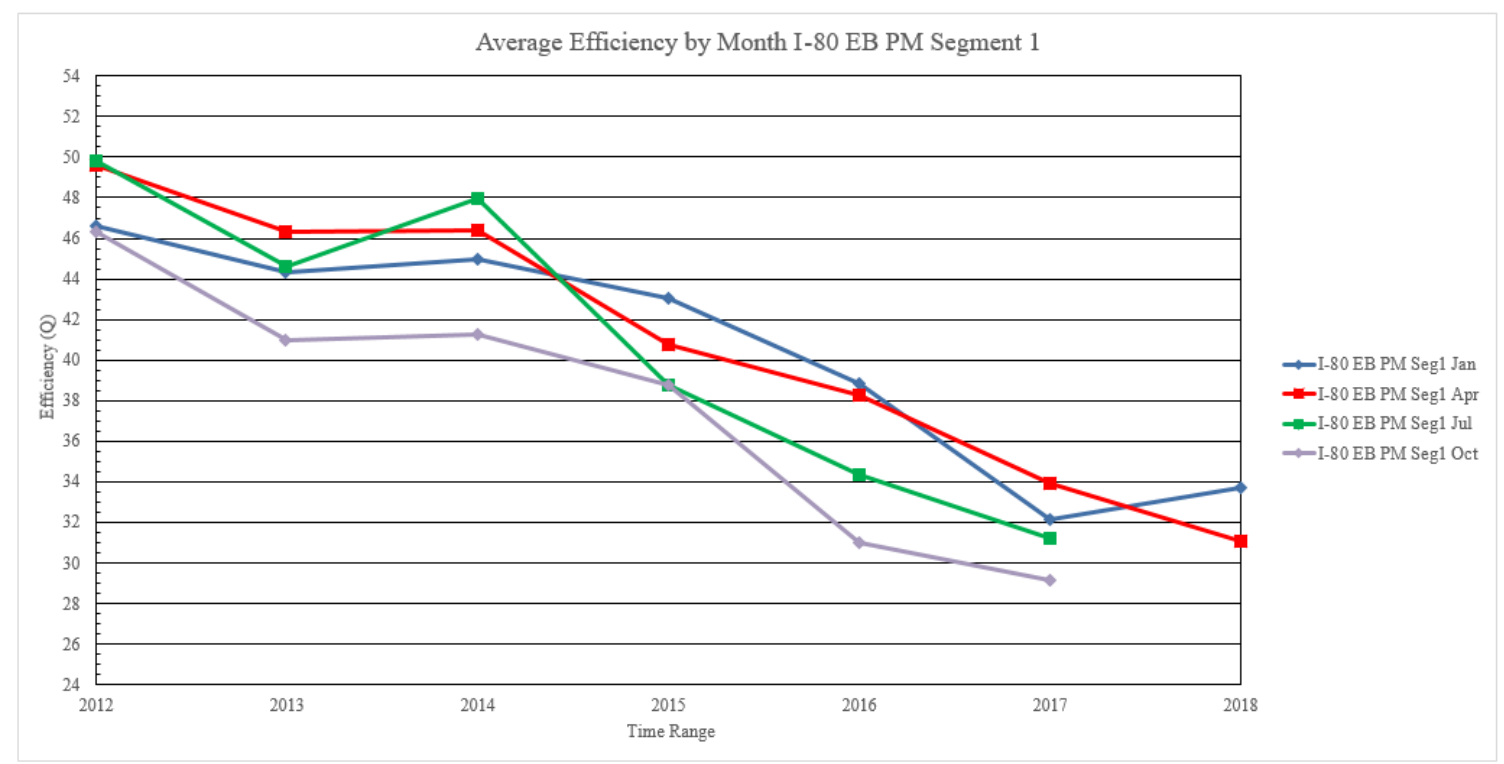

Figure 21. Monthly Variation of Efficiency along I-80 EB PM Segment 1 


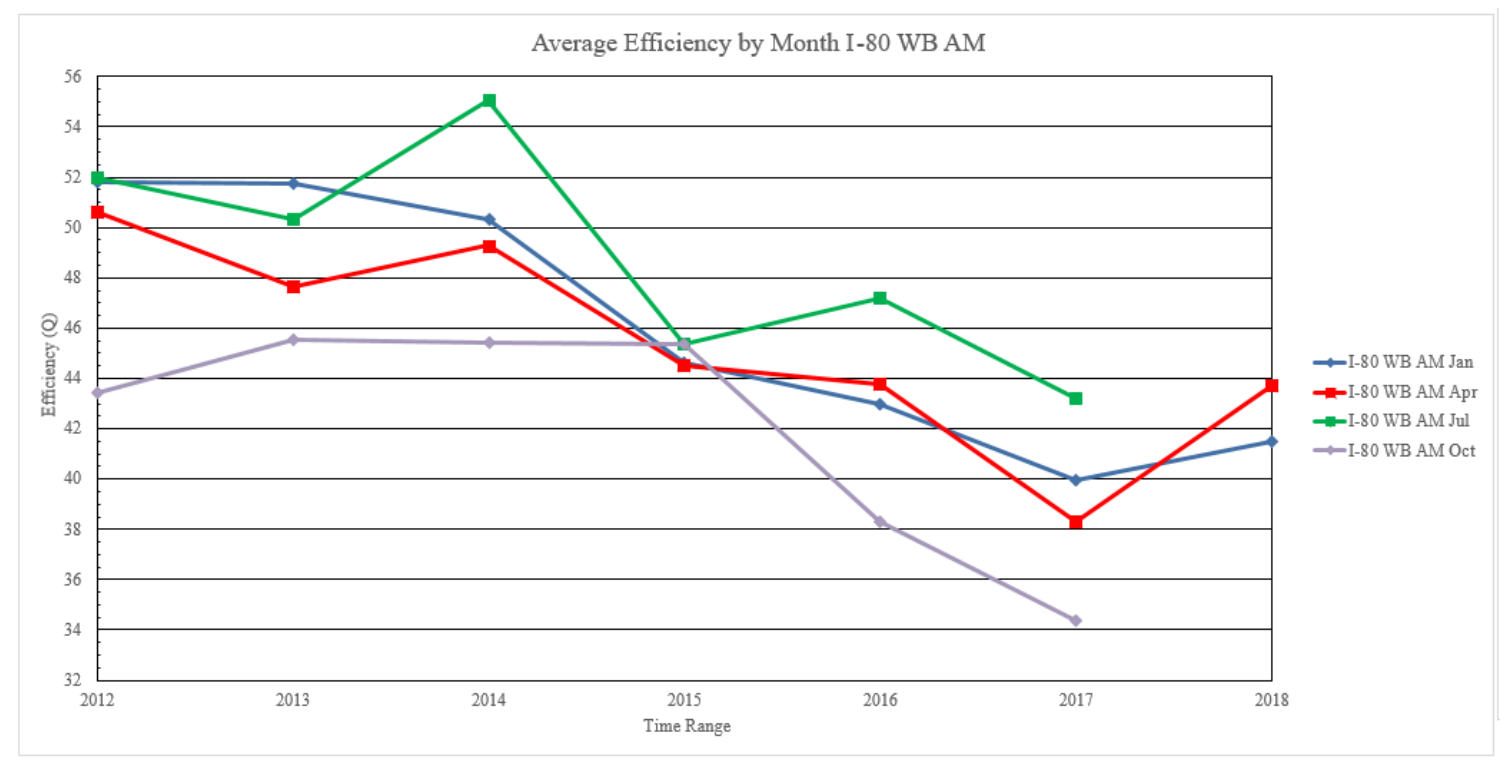

Figure 22. Monthly Variation of Efficiency along I-80 WB AM

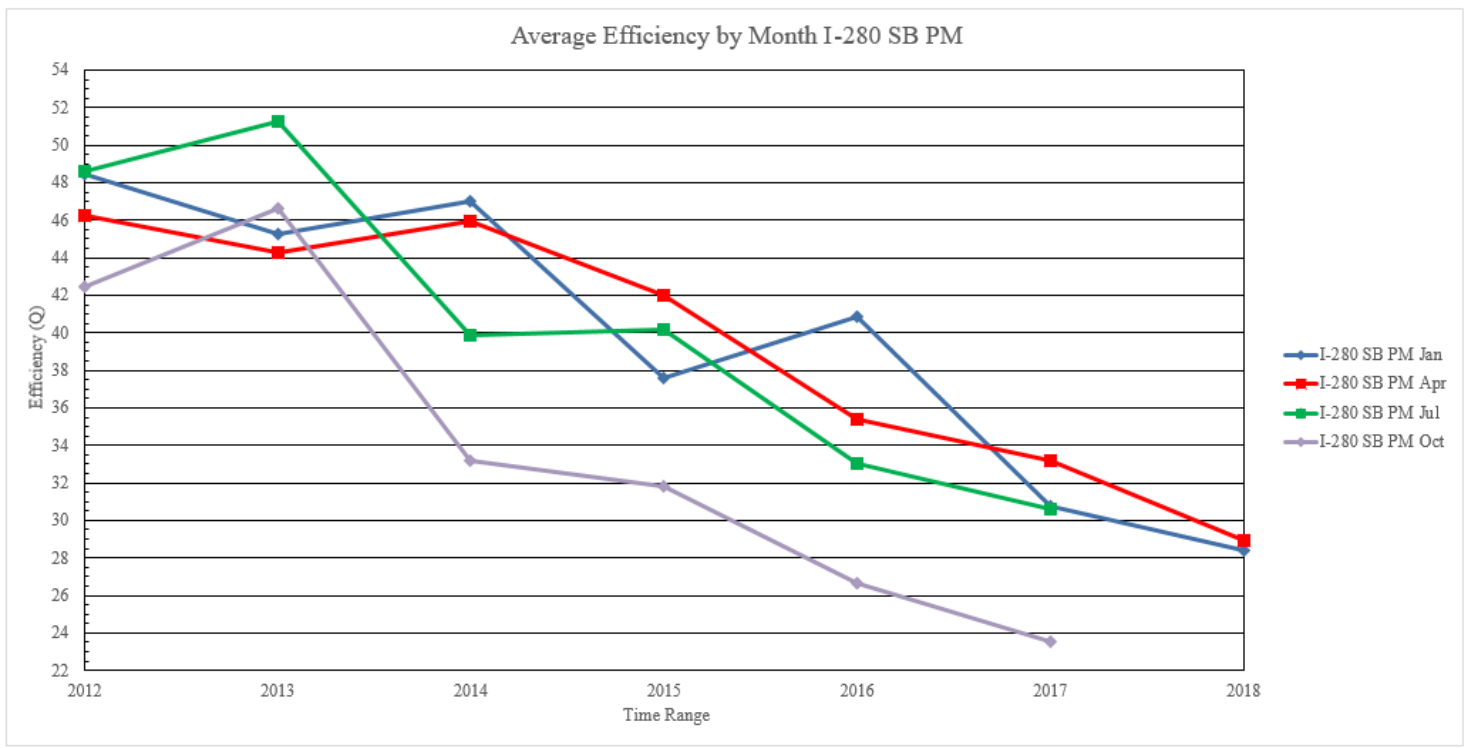

Figure 23. Monthly Variation of Efficiency along I-280 SB PM 


\subsubsection{Hourly Variation}

Figure 22 shows all major segments sorted by average efficiency according to peak hour. All segments show similar fluctuations throughout the PM peak period. This is to be expected as traffic flows during PM peak hours are similar in volume and traffic patterns. Given that the I-80 critical segment lies within the I-80 full-length segment and that traffic flow from I-280 likely travels through the I-80 as well and vice versa, it is fully expected that these three segments mirror one another. On the other hand, the westbound segment of the I-80 shows substantial deviation from the other three segments (Figure 23). This is most likely due to the different peak periods being analyzed.

In addition, the traffic congestion is heaviest around the 5 to $6 \mathrm{PM}$ range when the efficiency of the freeway is lowest. On either side of the figure, efficiency remains high due to the absence of traffic - the peak hour period is defined only as 6 to 9 am and 4 to $7 \mathrm{pm}$. This is especially noticeable on the I-80 westbound segment, where efficiency is relatively high from 5 to 6 am but drops substantially during the AM peak period. While this time period does no coincide with the active period of the ramp meters, it is optimistic to realize that the ramp metering is activated at the appropriate time periods and is appropriately inactive during those four hours (5-6 am, 9-10 am, 3-4 pm, and 7-8 pm).

In the "before" period, all three segments shown in Figure 22 show a concentrated trend throughout the peak hour period indicating similar performances. However, in the "after" period, the I-80 segments both show higher average efficiency across the entire peak hour range than the I-280. This may imply that as time increased, the I-280 continued to worsen at a steeper decline than the I-80. However, as this trend also extends to the four hours in which ARM is not active, other external factors may have played a role as well. 


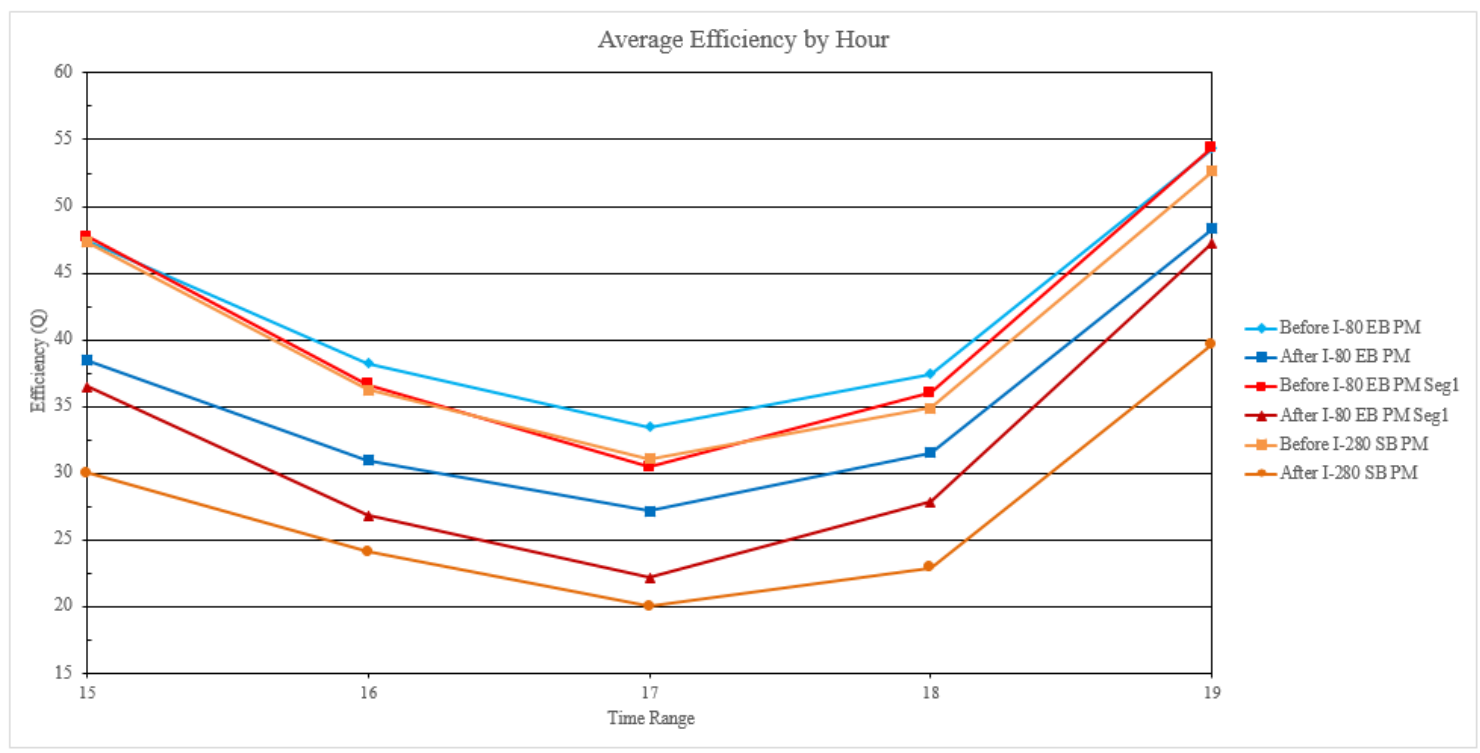

Figure 24. Average Efficiency by PM Peak Hour for Major Segments

Figures 23 through 26 display the average efficiencies based on individual hour within the peak hour range. Once again, the overall trend amongst all four figures show a slowly decreasing efficiency as times goes on. The middle hour within the peak period is shown as having the worst efficiency over time, with the two hours surrounding the middle hour showing identical trends. The same can be said for the first and last hours of the peak period.

The westbound direction, however, shows a slightly different trend - the second hour of the peak period, or the first hour in which ARM is activated, possesses the highest average efficiency throughout all years while the first hour of the peak period shows the second highest. In addition, instead of having the second and fourth hours of each peak period showing identical trends, the westbound direction shows the third and fourth hours behaving similarly. This may imply that for the westbound direction, the peak hour period is not strictly from 6 to 9 am and is subject to some fluctuation.

Once ARM had been implemented on the I-80, some of the efficiencies appeared to have recovered from the consistent decreasing trend. While some trends did continue a constant decrease, the westbound direction of the I-80 shows the 16:00, 17:00, and 18:00 hours all 
showing more efficient performances. Other increases, such as the 15:00 hour of the eastbound I80 and 9:00 hour of the westbound I-80, are disregarded as the ARM was not active during this time and the peak period is technically over - it should be expected that during these first and last hours of the study period, efficiencies should remain high or be recovering as traffic congestion is yet to occur or has already passed. Even so, many of the decreasing trends after 2017 do show some flattening, which could imply a marginal improvement by the ARM ITS tool. 


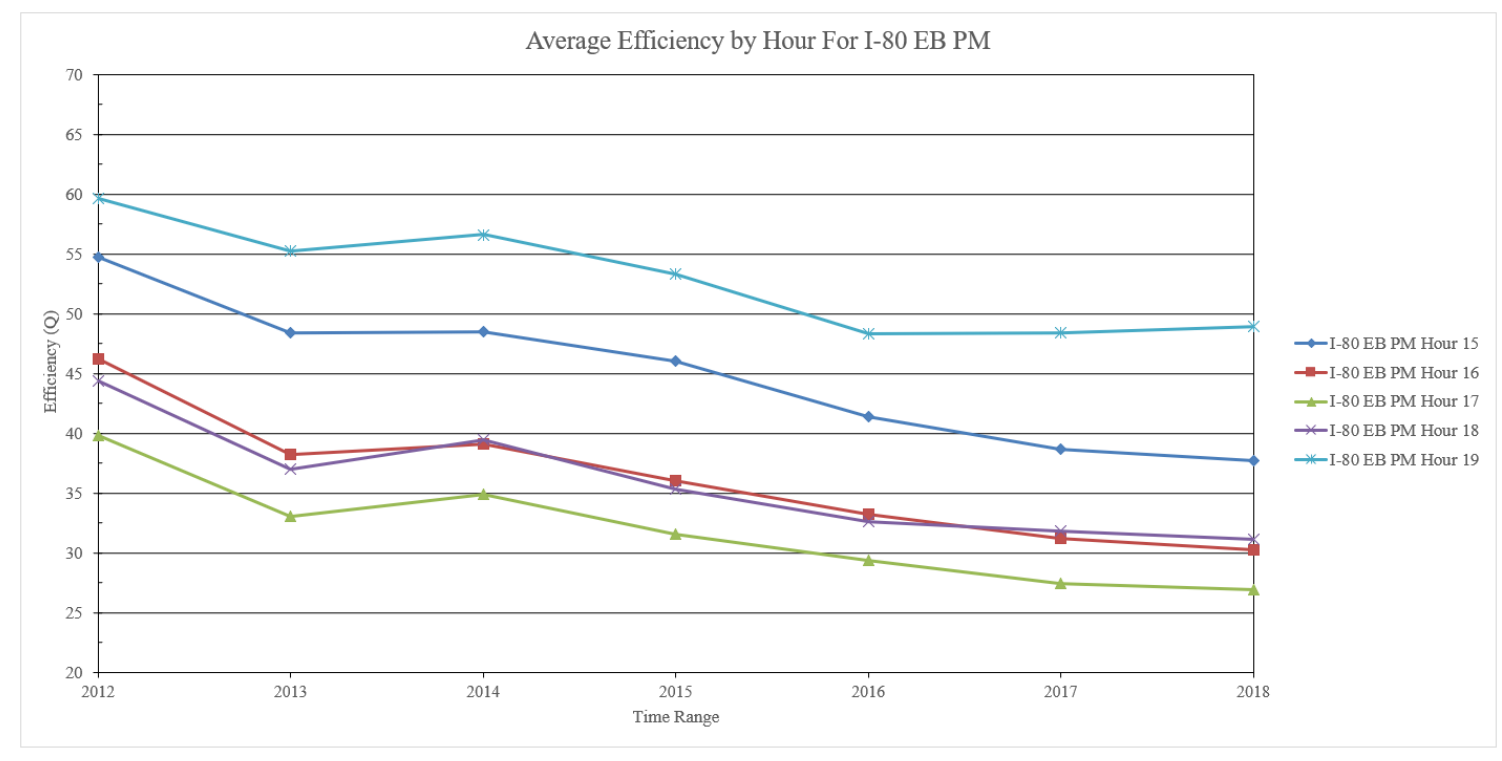

Figure 25. Average Efficiency by Hour for I-80 EB PM

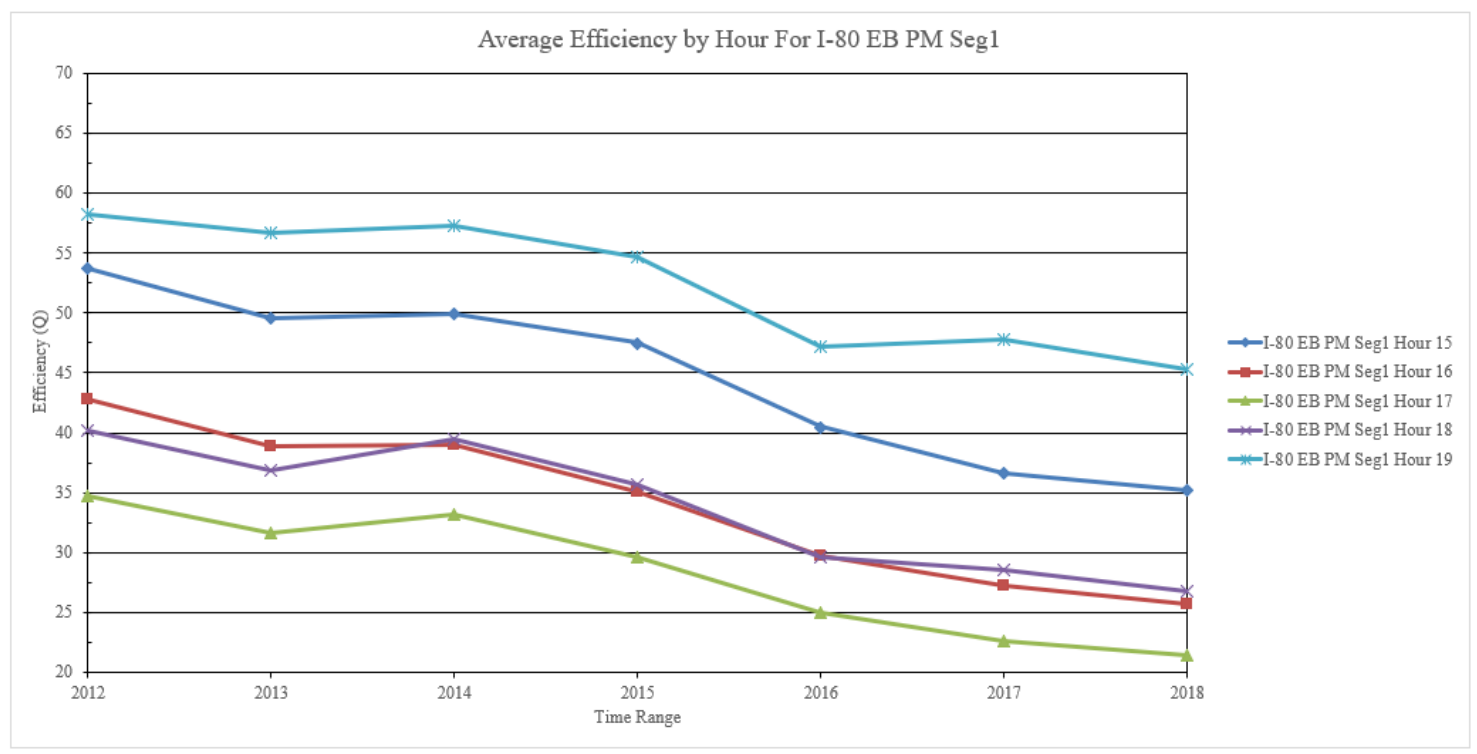

Figure 26. Average Efficiency by Hour for I-80 EB PM Seg1 


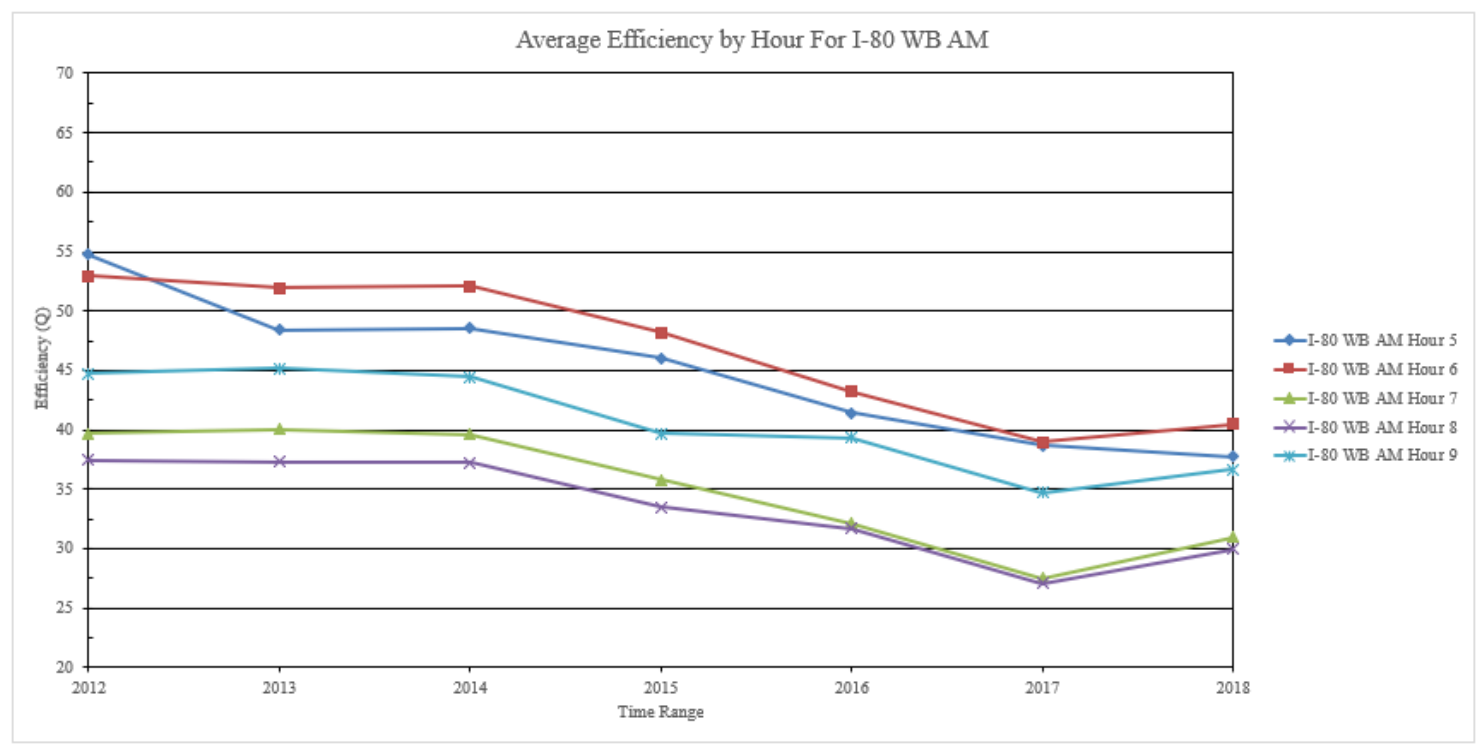

Figure 27. Average Efficiency by Hour for I-80 WB AM

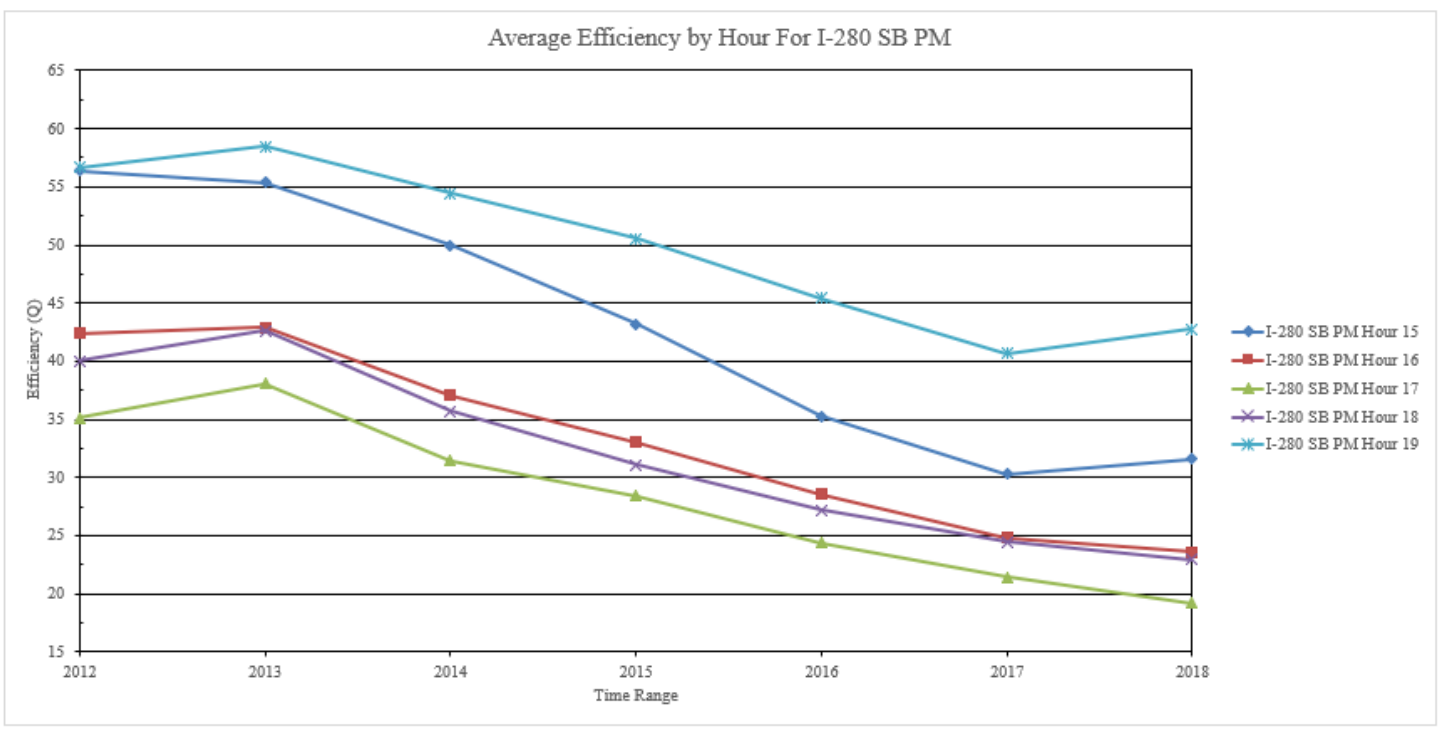

Figure 28. Average Efficiency by Hour for I-280 SB PM

\subsection{Safety Analysis Results}

The output worksheets are split into the following sections: Crash Modification Factors, Expected Average Crash Frequency, Intermediate Results, and Traffic Data. 
Figure 28 below provides a partial summary of the calculated CMF values. Each of the CMF values is associated with a geometric design feature that was accounted for during data input. Its values are equal to 1.0 when the feature's characteristics are the same as those used to define the base condition for the predictive model. The value is lower (or higher) than 1.0 if the characteristics of the feature are different from those of the base condition or if any comparative sites that have the same variation of the feature experience fewer (or more) crashes than other similar sites.

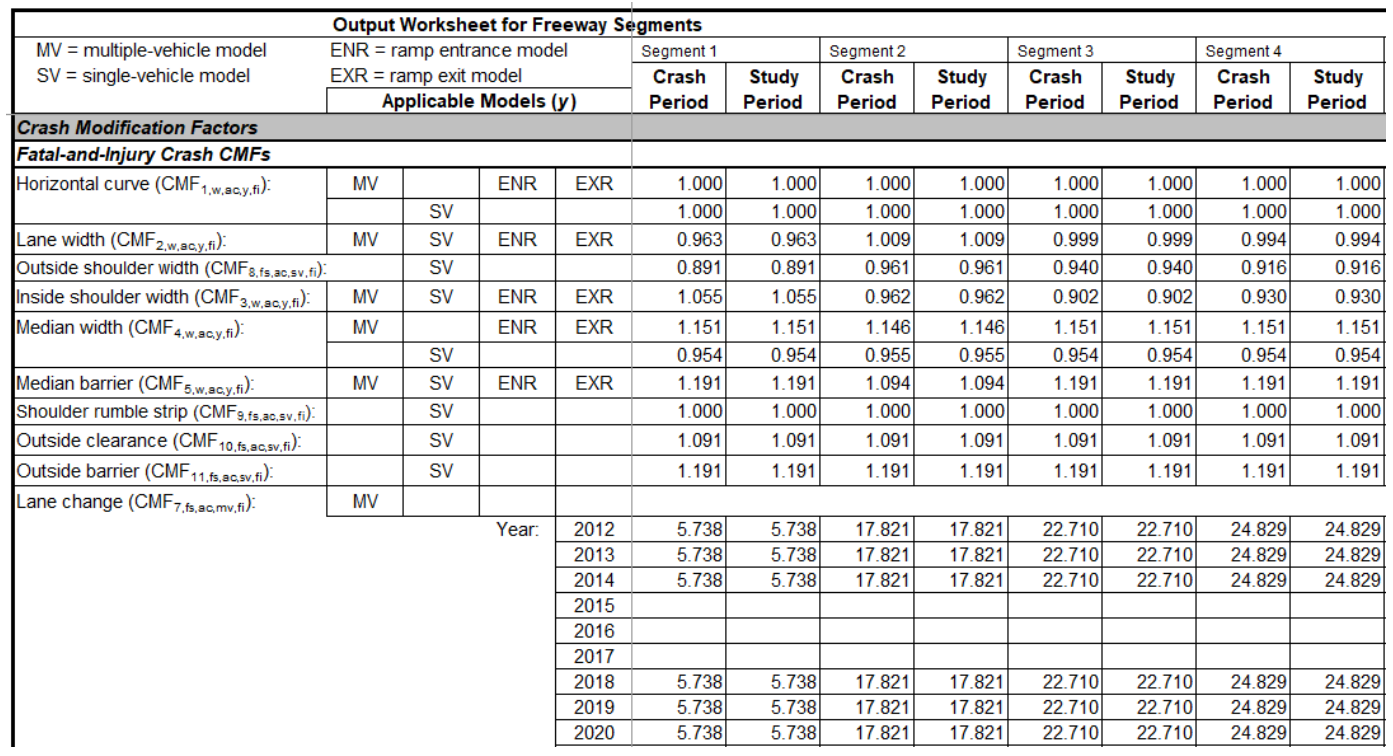

Figure 29. Summary of Calculated Crash Modification Factors (CMFs)

A portion of the Expected Average Crash Frequency section is shown in Figure 29 detailing the FI crash frequencies. This page is further divided into Fatal-and-Injury (FI) Crash Frequency, Property-Damage-Only (PDO) Crash Frequency, and Crash Severity Distribution categories. The row containing the Overdispersion parameter and all rows beneath it are estimated utilizing the Empirical Bayes method. If any cells are left blank, then the Empirical Bayes method was not applied in the calculation of that parameter. 


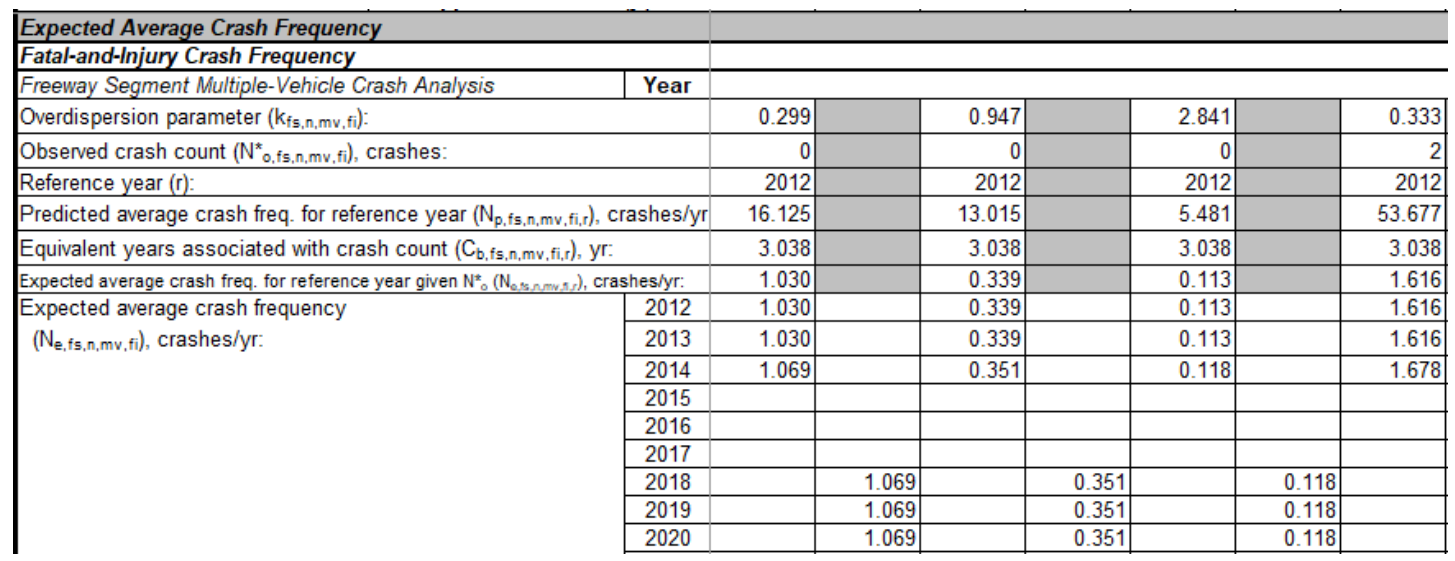

Figure 30. Expected Average Crash Frequency Data Output

At the end of the Expected Average Crash Frequency section, the distribution of predicted collisions and their severity is displayed (Figure 30). The estimates are calculated as the sum for all years within the study period and using severity distribution functions inherent within the predictive model. They help to predict this distribution based on the test site's geometric characteristics and traffic control features.

\begin{tabular}{|c|c|c|c|}
\hline \begin{tabular}{|l}
$\begin{array}{l}\text { Crash Severity Distribution } \\
\text { (during Study Period) }\end{array}$ \\
\end{tabular} & & & \\
\hline 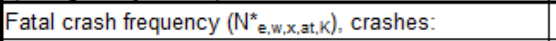 & 0.064 & 0.028 & 0.012 \\
\hline Incapacitating injury crash freq. $\left(\mathrm{N}^{*}{ }^{*}, w, x, a t, A\right)$, crashes: & 0.220 & 0.069 & 0.031 \\
\hline 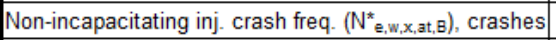 & 1.526 & 0.510 & 0.225 \\
\hline Possible injury crash freq. $\left(\mathrm{N}^{*}{ }_{\mathrm{e}, w, \mathrm{x}, \mathrm{at}, \mathrm{C}}\right)$, crashes: & 3.336 & 1.051 & 0.468 \\
\hline Total fatal-and-injury crash freq. $\left(\mathrm{N}_{\mathrm{e}, \mathrm{w}, \mathrm{x}, \mathrm{at}, \mathrm{f}, \mathrm{f}) \text {, crashes: }}\right.$ & 5.146 & 1.658 & 0.735 \\
\hline Property-damage-only crash freq. $\left(\mathrm{N}^{*}\right.$ ewx,sipdo $)$, crashes: & 6.589 & 2.042 & 1.539 \\
\hline Total crash frequency $\left(\mathrm{N}_{\mathrm{e}, \mathrm{w}, \mathrm{x}, \mathrm{at}, \mathrm{as}}\right)$, crashes: & 11.735 & 3.700 & 2.274 \\
\hline
\end{tabular}

Figure 31. Crash Severity Distribution Output Summary

Figure 31 shows part of the Traffic Data results pertaining to the AADT inputs. If an AADT value is input for every year during data collection, then the values will match what is shown in the input tab of the spreadsheet. As previously noted, the AADT was only input for some of the years. AADT volumes for the remaining years are automatically assumed, per 
recommendation from the user manual, to remain the same for subsequent years (Bonneson et al., n.d.).

\begin{tabular}{|c|c|c|c|c|c|}
\hline Traffic Data & Year & & & & \\
\hline Freeway Segment Data & 2012 & 198000 & 198000 & 198000 & 198000 \\
\hline \multirow{23}{*}{ Average daily traffic $\left(\mathrm{AADT}_{\mathrm{fs}}\right)$ by year, veh/d: } & 2013 & 198000 & 198000 & 198000 & 198000 \\
\hline & 2014 & 203000 & 203000 & 203000 & 203000 \\
\hline & 2015 & 203000 & 203000 & 203000 & 203000 \\
\hline & 2016 & 203000 & 203000 & 203000 & 203000 \\
\hline & 2017 & 203000 & 203000 & 203000 & 203000 \\
\hline & 2018 & 203000 & 203000 & 203000 & 203000 \\
\hline & 2019 & 203000 & 203000 & 203000 & 203000 \\
\hline & 2020 & 203000 & 203000 & 203000 & 203000 \\
\hline & 2021 & 203000 & 203000 & 203000 & 203000 \\
\hline & 2022 & 203000 & 203000 & 203000 & 203000 \\
\hline & 2023 & 203000 & 203000 & 203000 & 203000 \\
\hline & 2024 & 203000 & 203000 & 203000 & 203000 \\
\hline & 2025 & 203000 & 203000 & 203000 & 203000 \\
\hline & 2026 & 203000 & 203000 & 203000 & 203000 \\
\hline & 2027 & 203000 & 203000 & 203000 & 203000 \\
\hline & 2028 & 203000 & 203000 & 203000 & 203000 \\
\hline & 2029 & 203000 & 203000 & 203000 & 203000 \\
\hline & 2030 & 203000 & 203000 & 203000 & 203000 \\
\hline & 2031 & 203000 & 203000 & 203000 & 203000 \\
\hline & 2032 & 203000 & 203000 & 203000 & 203000 \\
\hline & 2033 & 203000 & 203000 & 203000 & 203000 \\
\hline & 2034 & 203000 & 203000 & 203000 & 203000 \\
\hline & 2035 & 203000 & 203000 & 203000 & 203000 \\
\hline
\end{tabular}

Figure 32. Traffic Data Output Summary

There is a plethora of remaining calculations and values associated with the safety analysis. However, these remaining parameters hold little significance to the safety results presented in the scope of this study, which is to provide a preliminary framework for a more detailed safety evaluation in future studies. The full output summary relating to freeway segment data may be found in Appendix C. Output summaries for ramp segments and ramp terminals are not included due to the simplicity of the analyzed segment - there is simply no input data for the two facilities, hence no results.

In the output summary shown in Figure 32, the counterfactual estimated predicts 32.8 crashes occurring in the years 2018 through 2020 based on collision data obtained for years 2012 through 2014. This translates to roughly 11 vehicle collisions per year, which approximately 20.6 crashes occurring as a result of multiple vehicles. The remaining 12.2 crashes result from single 
vehicles. Among the crash type category, the most commonly predicted is a collision due to rearend crashes or a fixed object for multiple and single vehicles, respectively.



Figure 33. Output Summary for Entire Safety Analysis

Due to the estimates being predicted for the years of 2018 through 2020, it is not possibly yet to make a concrete comparison between collision data as the time has not yet passed.

However, future studies may verify these preliminary findings and hopefully expand upon them to include ramp segment and ramp terminal input data for a more complex study site. 


\section{CHAPTER 5 - CONCLUSIONS}

This research explored the effects of the implementation of ARM on efficiency and safety by comparing the VMT/VHT, or Q, values from before and after the ITS tool was activated in April 2017. Results were compared with a similarly congested segment on the I-280 to act as a control segment with no ARM implementation.

\subsection{Efficiency}

Implementation of ARM did not appear to have any substantial effect on efficiency. Some segments did show marginal improvements of the Q value in the "after" period but did not show consistently across enough segments to show a clear benefit as opposed to a neutral effect. The comparison between the critical segment on the I- 80 corridor and the control segment on the I-280 corridor shows little differences between efficiencies when measured based on season, month or hour. It is interesting to note that the I-280 corridor appears to have suffered a slightly higher drop in efficiency after April 2017 than the I-80 corridor. However, once again, the difference is minimal enough where it may not be considered substantial.

\subsection{Safety}

Within the safety analysis, a predicted 32.8 collisions is expected to occur with a threeyear timeframe based off historical collision data and geometric characteristics of the freeway. It is not yet appropriate to make a conclusive statement as the expected number of collisions is appropriate for the years 2018 through 2020, which have not passed as of the conclusion of this thesis; hence, the "preliminary framework" aspect of this thesis.

However, an estimated 11 collisions per year or so appears to show a large increase in collisions compared to the input data. This implies that ARM can have substantial safety benefits 
when implemented properly and reduce the likelihood of collisions. More research is necessary to explore the entire freeway network that is affected by the implementation of ARM.

\subsection{Recommendations and Future Research}

Based off personal experience with the data collection, processing and analysis for efficiency and safety performance measures, a list of recommendations is shown below for future analysts or parties interested in continuing this research.

- During data collection of VMT and VHT data, data was separated into countless data spreadsheets where each held one month (of 78 analyzed) of data for one (of two) peak directions for 12 unique segments, not including segment analysis of the I-680 for a control segment. I would heavily recommend that this data collection be streamlined through the use of a Python script that may gather PeMS data for the analyst rather than attempting to manually compile the data. Alternatively, mass data that covers all 78 months may be collected at once from the database and a VBA script may be developed to separate and process the data appropriately.

- Use of the PeMS database has historically included delay as a performance measure for study. It may prove useful for future research to explore this parameter in addition to efficiency Q. The definition of D is explained in the "Measures of Efficiency" section of Chapter 3.

- During the safety analysis, I gathered preliminary measurements via the use of Google Earth and Maps. However, these measurements are not entirely accurate due to satellite imagery quality and human error. I would recommend that for extensive measurements of these segments, including curve data, future researchers may find more detailed inputs via a Caltrans database and a VBA script. This will allow the data to be drawn from the 
database and placed it within the spreadsheet without any manual input, thus streamlining the data input process.

- Caltrans has recommended the use of Traffic Accident Surveillance and Analysis System (TASAS) for safety evaluations.

The I-80 SMART Corridor Project was a collaboration of countless agencies and stakeholders working to install multiple types of technologies and improvements to the freeway in an effort to improve the freeway's performance in terms of travel time reliability, efficiency, safety, and overall user satisfaction. However, each ITS tool implemented is meant to help with a specific part of the freeway's performance, e.g. ramp metering helping with travel time and efficiency, the incident management with safety and recovery from collisions and congestion, etc., but can easily result in having indirect effects on other performance parameters as well. The scope of this thesis relates to the study on an empirical basis, where observations of the study will generate the findings rather than an isolated experiment where everything is controlled except one independent variable. However, this introduces some unreliability into the findings due to the implementation of several ITS technologies on the same corridor at very nearly the same time. It becomes difficult to completely isolate the ramp metering application and focus on the effects of that sole treatment. The findings found in this thesis may have been indirectly impacted via any of the other ITS technologies or a combination of them without ARM being the sole cause. It is recommended that in future research, the scope may be expanded to empirically analyze the I80's performance in a certain aspect, such as safety, as a result of the entire SMART Corridor project rather than just one ITS tool.

Alternatively, it has been generally noted and accepted among transportation professional that any ITS implementation takes extended periods of time to produce the full effects of said implementation. It may prove useful to allow more time for travel time, efficiency, and safety data to accumulate in the "after" period before attempting to re-evaluate the I- 80 corridor. Once an appropriate period of time, perhaps four to five years, has passed, then an isolated experiment 
may be performed, similar to the Twin Cities shutdown case study, during which the ramp metering system may be shut down for a short period of time to gather data specifically for a system that is missing only the implementation of ARM. In other words, the ARM system would be essentially shut down, but all other congestion management system implemented in the I- 80 SMART Corridor project remain fully operational to effectively explore the isolated effects of a freeway network with and without ramp metering. Careful considerations, however, should be made to address any safety risks that may entail this experiment.

Ultimately, this analysis may be best suited to serve as a template for future research due to some limitations with timing of the study and external factors outside of the analyst's and study's control. The idea is that once more travel time, efficiency, and collision data has been collected, a more comprehensive and conclusive analysis may be conducted to ascertain the effects of adaptive ramp metering on the I- 80 . 


\section{REFERENCES}

Aghdashi, S., Khazraeian, S., Trask, J. L., Hadi, M., \& Rouphail, N. (2016). Incorporating Adaptive (Traffic Responsive) Ramp Metering in the Highway Capacity Manual Context. Insitute of Transportation Research \& Education (ITRE), NC State University, Department of Civil and Environmental Engineering, Florida International University, 17.

Ahn, S., Bertini, R. L., Auffray, B., \& Ross, J. H. (2007). Evaluating the Benefits of a SystemWide Adaptive Ramp-Metering Strategy in Portland, Oregon. 14.

Berger, N. (2015). Express Lane Construction Under Way Along I-680 in Contra Costa County. Metropolitan Transportation Commission, 17.

Bogenberger, K., Vukanovic, S., \& Keller, H. (2002). ACCEZZ—Adaptive Fuzzy Algorithms for Traffic Responsive and Coordinated Ramp Metering. Applications of Advanced Technologies in Transportation (2002), 744-753. https://doi.org/10.1061/40632(245)94

Bonneson, J. A., Pratt, M. P., \& Geedipally, S. (n.d.). Enhanced Interchange Safety Analysis Tool: User Manual. Texas A\&M University, 142.

Caltrans. (n.d.). I-80 Smart Corridor Spring 2016 Presentation. Caltrans.

Cambridge Systematics, Inc., SRF Consulting Group, Inc., \& N.K. Friedrichs Consulting, Inc. (2001, February 1). Twin Cities Ramp Meter Evaluation. Minnesota Department of Transportation.

Carter, M. (1997, July). Effectiveness of Ramp Metering- Field Data and Simulation Results. National Library of Canada.

Chambers, A. L. (2016). Benefits of Advanced Traffic Management Solutions: Before and After Crash Analysis for Deployment of a Variable Advisory Speed Limit System (California Polytechnic State University). https://doi.org/10.15368/theses.2016.112 
Chen, C. (2003). Freeway Performance Measurement System (PeMS). University of California, Berkeley, Institute of Transportation Studies, 216.

Chu, L., Liu, H. X., Recker, W., \& Zhang, H. M. (2004). Performance Evaluation of Adaptive Ramp-Metering Algorithms Using Microscopic Traffic Simulation Model. Journal of Transportation Engineering, 130(3), 330-338. https://doi.org/10.1061/(ASCE)0733947X(2004)130:3(330)

Hagen, L. (2014). Empirical Bayes Analysis For Safety. Florida Department of Transportation, 56.

Haj-Salem, H., \& Papageorgiou, M. (1995). Ramp Metering Impact on Urban Corridor Traffic: Field Results. Transportation Research Part A: Policy and Practice, 29(4), 303-319. https://doi.org/10.1016/0965-8564(94)00034-8

Han, Y., Meng, Y., Zheng, J., \& Liu, H. (2019). An Urban Freeway Ramp Metering Control System Based on Trajectory Data. 14.

Hourdakis, J., \& Michalopoulos, P. G. (2002). Evaluation of Ramp Control Effectiveness in Two Twin Cities Freeways. Transportation Research Record: Journal of the Transportation Research Board, 1811(1), 21-29. https://doi.org/10.3141/1811-03

Kan, D. (2017, January 8). Increasing Freeway Capacity by Efficiently Timing Its Nearby Signals. Transportation Research Board.

Kan, X. (David), Lu, X.-Y., \& Skabardonis, A. (2019). Impact of Ramp Metering Queue Override on the Capacity of an Isolated Freeway Merge. 11.

Kan, X. (David), Lu, X.-Y., \& Skabardonis, A. (n.d.). Increasing Freeway Capacity by Efficiently Timing Its Nearby Arterial Traffic Signals. Transportation Research Board.

Kang, S., \& Gillen, D. (1999, July). Assessing the Benefits and Costs of Intelligent Transportation Systems - Ramp Meters. University of California, Berkeley, Institute of Transportation Studies. 
Lee, C., Hellinga, B., \& Ozbay, K. (2006). Quantifying Effects of Ramp Metering on Freeway Safety. Accident Analysis \& Prevention, 38(2), 279-288. https://doi.org/10.1016/j.aap.2005.09.011

Levinson, D., Zhang, L., Das, S., \& Sheikh, A. (2001). Ramp Meters on Trial - Evidence from the Twin Cities Ramp Meters Shut-Off. 35.

Liu, C., \& Wang, Z. (2013). Ramp Metering Influence on Freeway Operational Safety near OnRamp Exits. International Journal of Transportation Science and Technology, 2(2), 8794. https://doi.org/10.1260/2046-0430.2.2.87

Low, T. C. (2017). Early Empirical Evidence for the Effects of Adaptive Metering of Measures of Travel Time Reliability. California Polytechnic State University, San Luis Obispo, 80.

Mizuta, A., Roberts, K., Jacobsen, L., \& Thompson, N. (2014, October). Ramp Metering: A Proven Cost-Effective Operational Strategy.

Rahman, F. (2019). Before and After Analysis on Effects of Adaptive Ramp Metering on Measures of Travel Time Reliability. 83.

Shladover, S., \& Lu, X.-Y. (2017, March 15). Field Test of Coordinated Ramp Metering (CRM). University of California, Berkeley, Institute of Transportation Studies.

Yuan, K., Knoop, V. L., \& Hoogendoorn, S. P. (2015). Capacity Drop - Relationship Between Speed in Congestion and the Queue Discharge Rate. Transportation Research Record: Journal of the Transportation Research Board, 2491(1), 72-80. https://doi.org/10.3141/2491-08

Yuan, Y., Daamen, W., Hoogendoorn, S., \& Vrancken, J. (2009). Coordination Concepts for Ramp Metering Control in a Freeway Network. IFAC Proceedings Volumes, 42(15), 612-618. https://doi.org/10.3182/20090902-3-US-2007.0039 
Appendix A. Detailed Graphs Showing Spatial Analysis and Monthly Variations

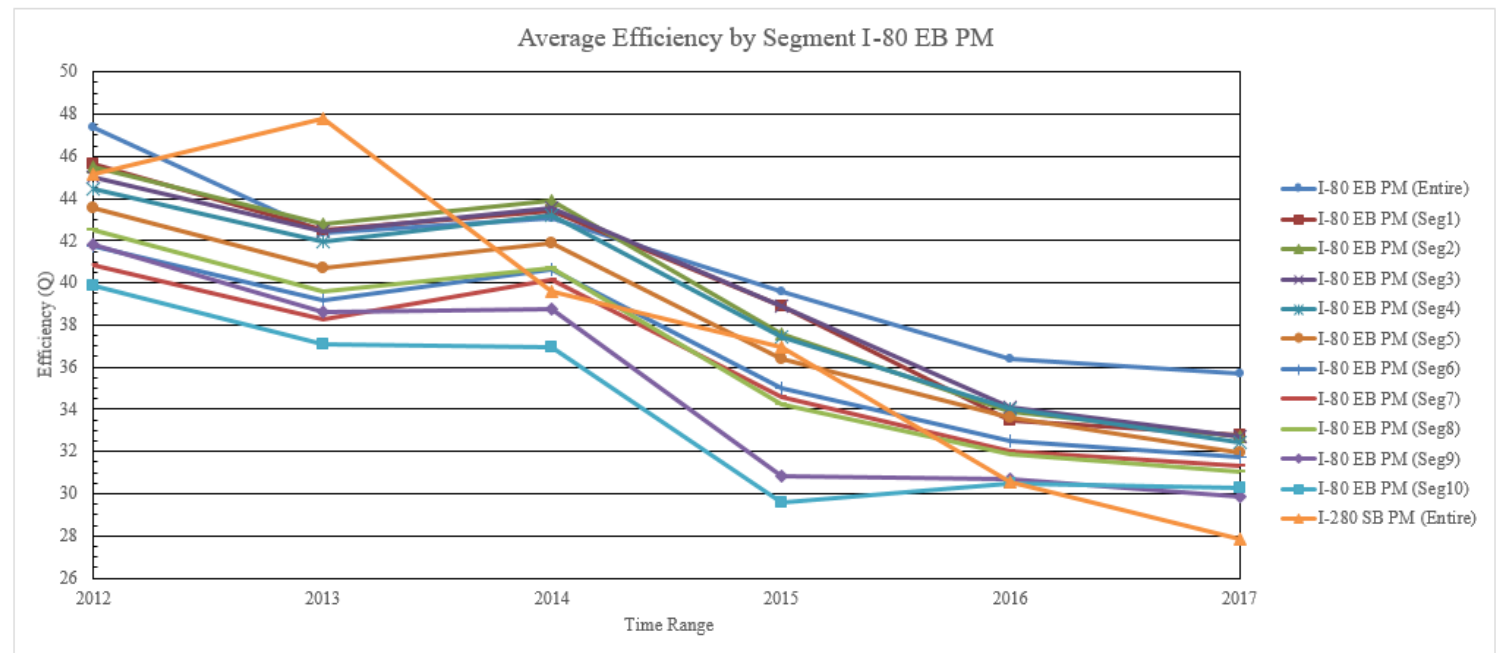

Average Efficiency Showing All Segments along I-80 EB PM and I-280 SB PM

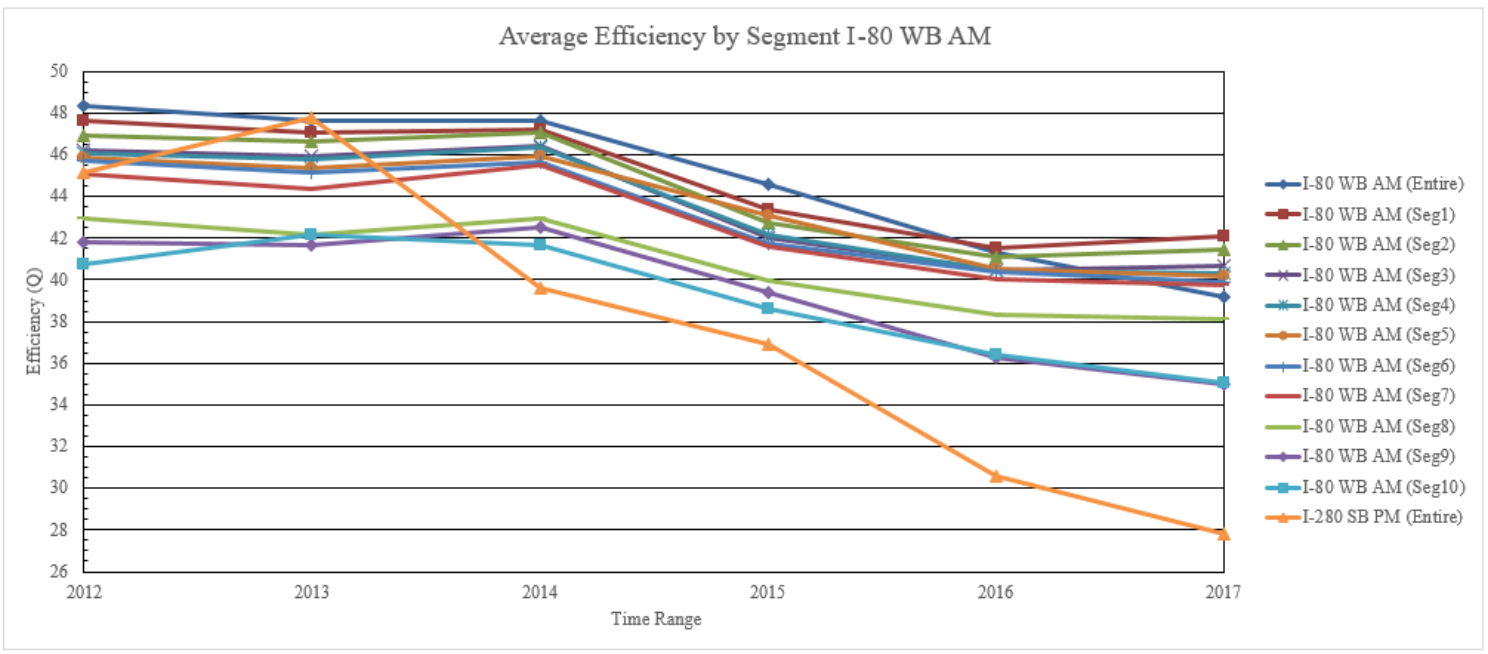

Average Efficiency Showing All Segments along I-80 WB AM and I-280 SB PM 


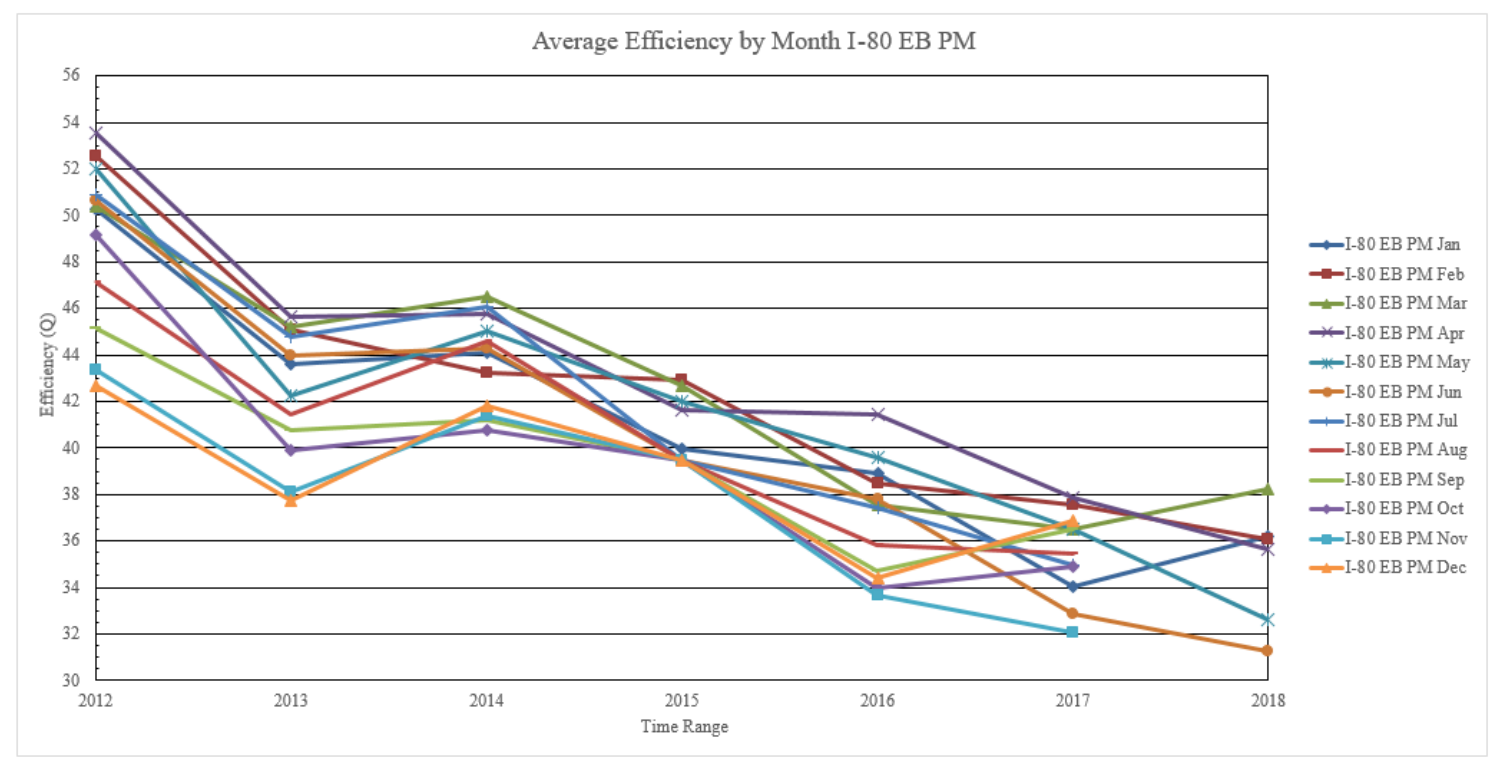

Monthly Variation of Efficiency along I-80 EB PM across All Months

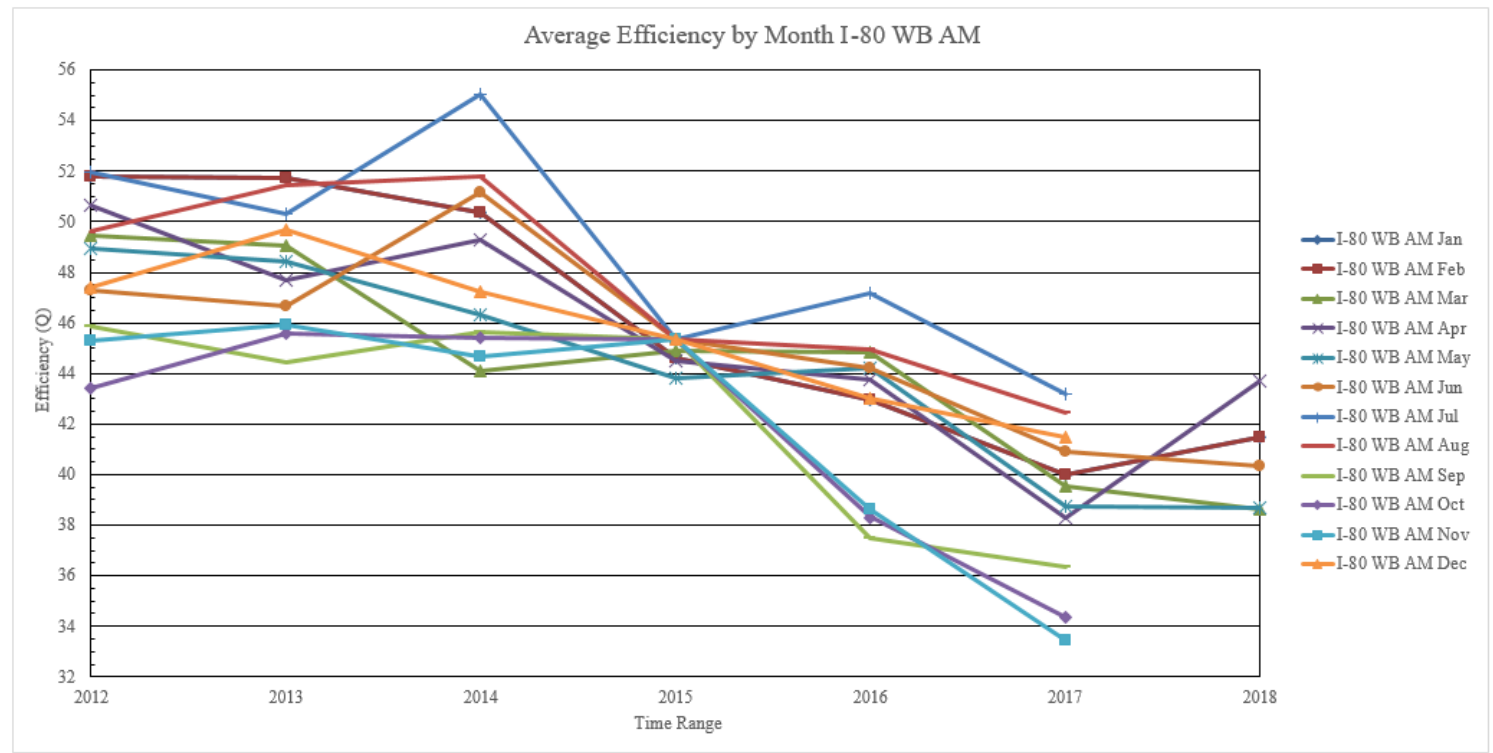

Monthly Variation of Efficiency along I-80 WB AM Across All Months 


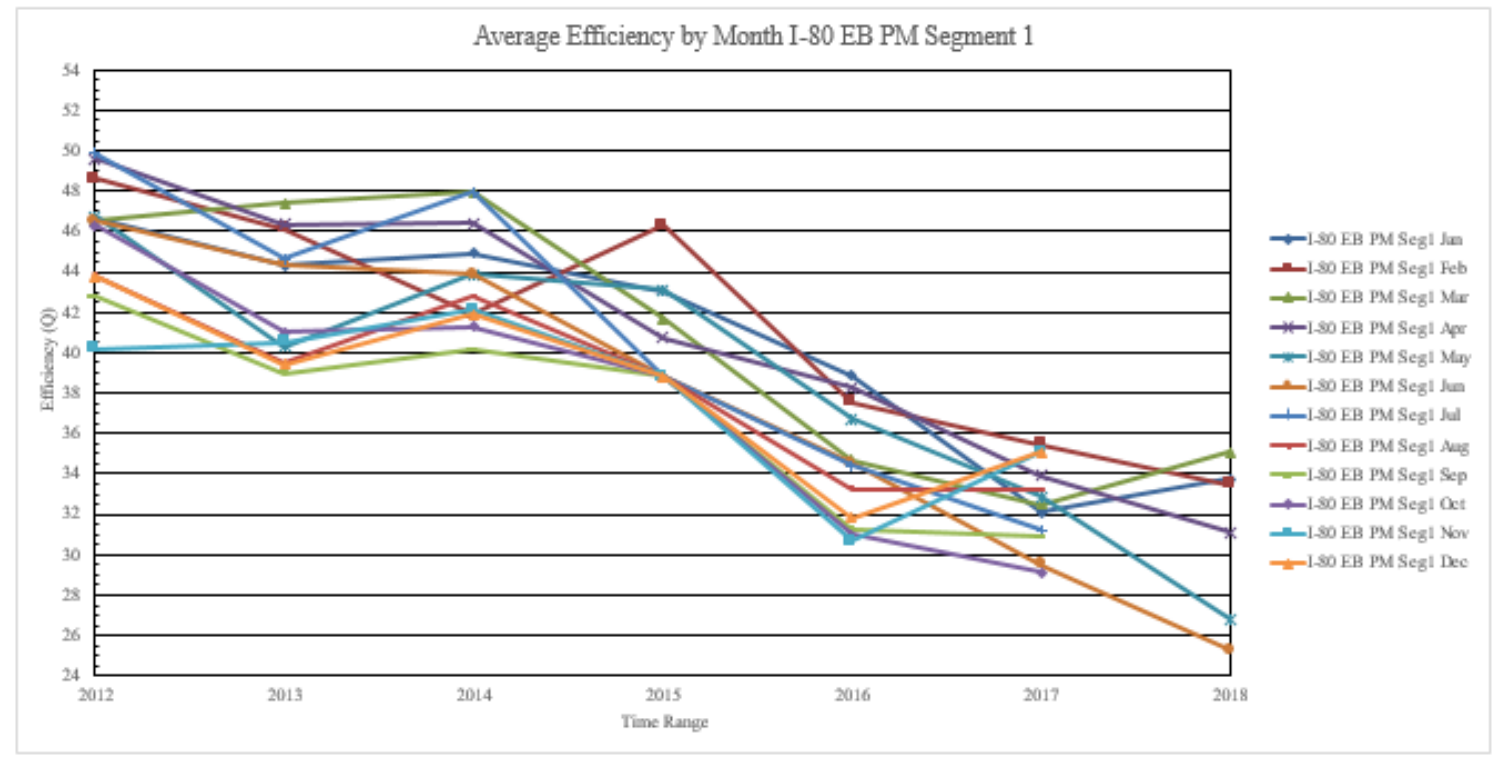

Monthly Variation of Efficiency along I-80 Seg1 EB PM across All Months

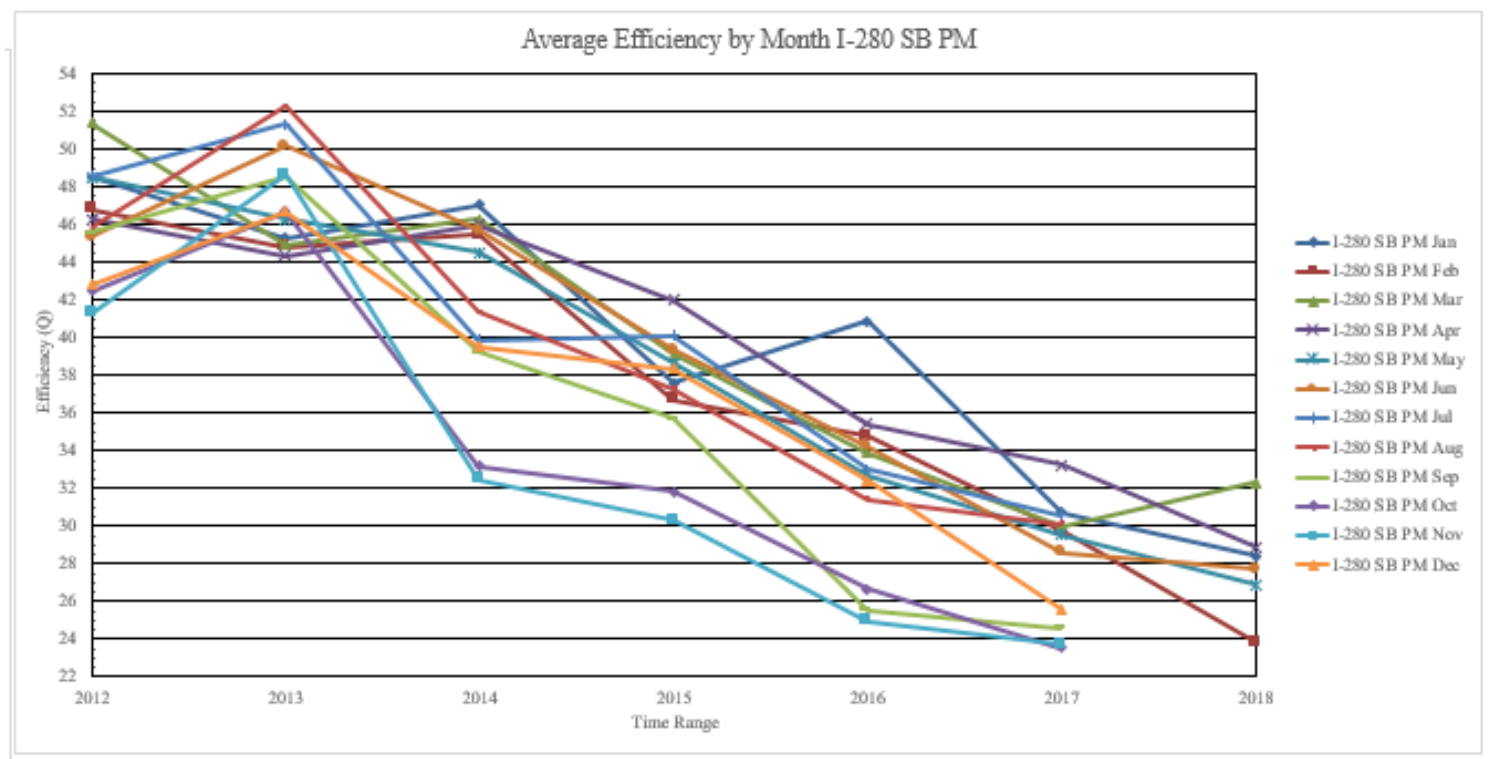

Monthly Variation of Efficiency along I-280 SB PM across All Months 
Appendix B. Step-by-Step Guide Acquiring Data from PeMS Database

Data acquisition for VMT and VHT was a relatively straightforward process as the database's interface allowed for simple inputs via drop-down menus (Figures 4 and 5).

For this study, both the eastbound and westbound directions were chosen to comprehensively analyze the freeway performance. The peak period for each direction differs as commuters make their way to and from the workplace. As a result, the I-80 analysis utilized eastbound PM data, which is collected while workers travel back home in the evening, and westbound AM data, which is collected while workers make their commute to work in the morning.

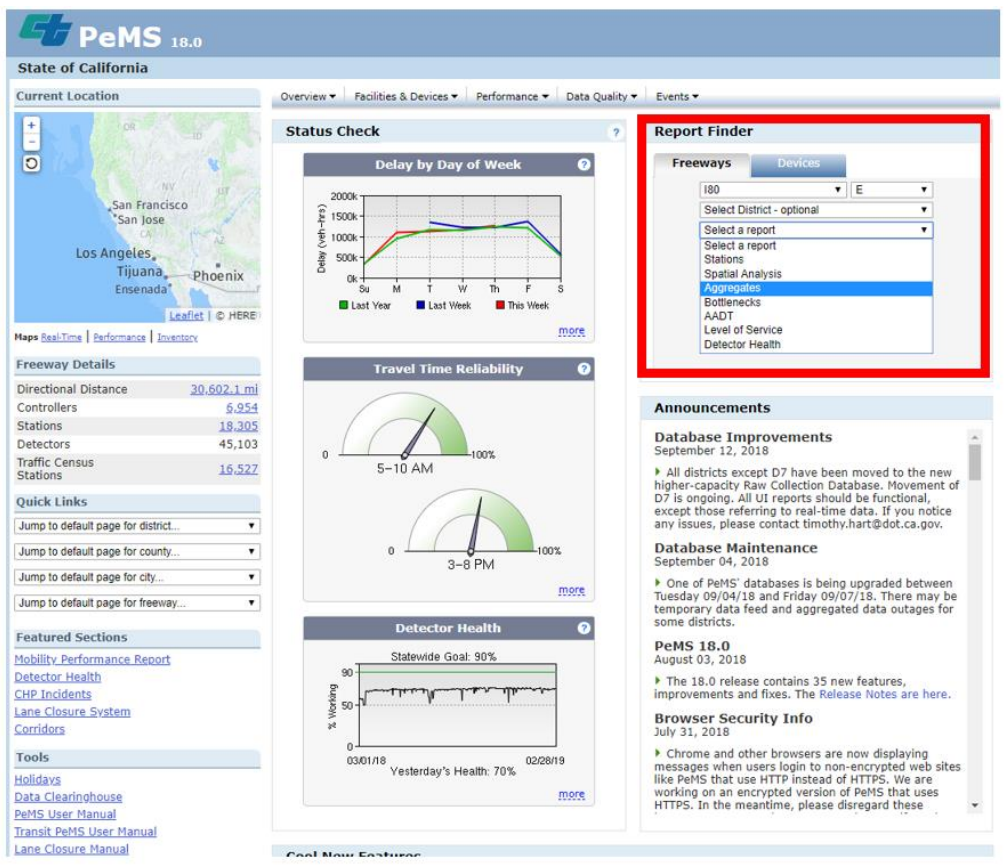

Figure 4: Report Finder of PeMS page 


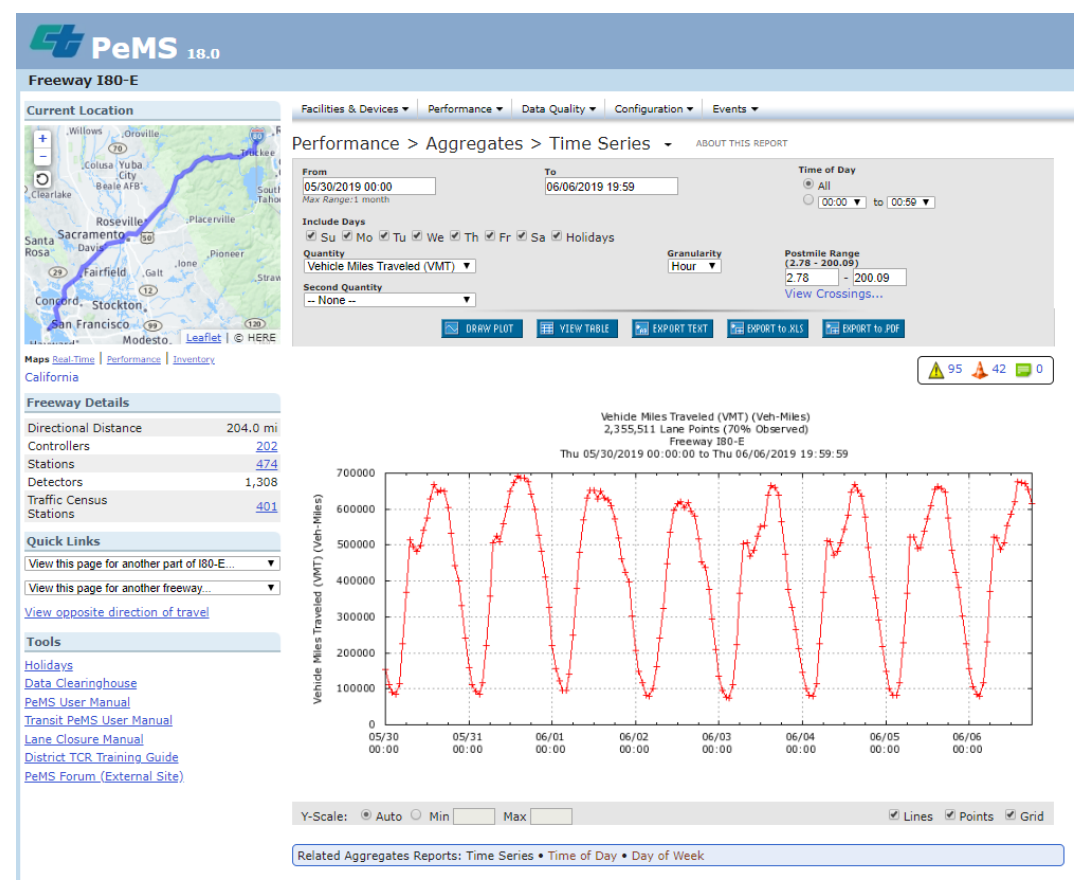

Figure 5: Aggregates Webpage for Time Series

In the Performance > Aggregates > Time Series tab (Figure 6), the interface displays several additional parameters used to define the study. These include:

- $\quad$ Time Range of Study (Green)

- Days of week included in collected data (Yellow)

- Quantity, or Variable (Red)

- Granularity (Blue)

- Time of Day (Orange)

- $\quad$ Postmile (PM) Range (Purple)

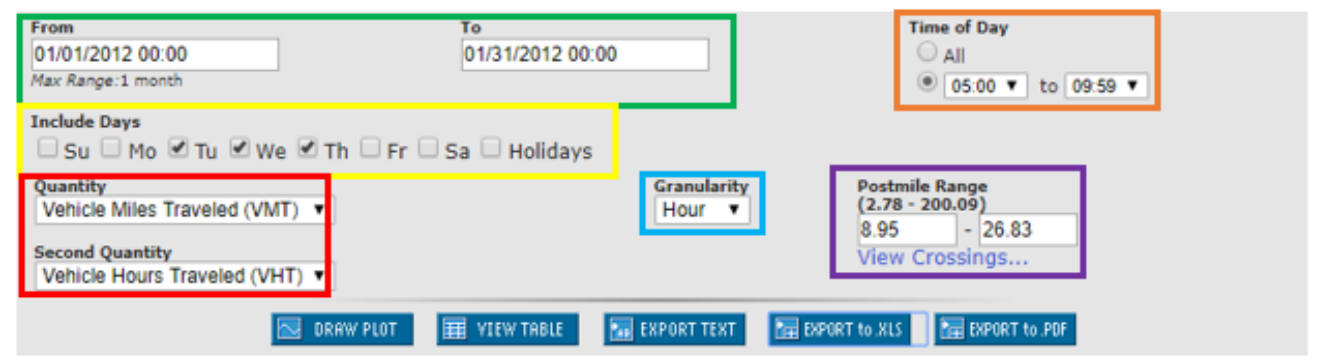


Figure 6: Parameter Inputs for VMT and VHT Data

Appendix C. ISATe Spreadsheet Data Inputs

\begin{tabular}{|c|c|c|c|c|c|c|c|c|c|c|}
\hline \multicolumn{11}{|c|}{ Input Worksheet for Freeway Segments } \\
\hline \multirow{2}{*}{ Clear } & Echo Input Values & \multirow{2}{*}{$\begin{array}{l}\text { Check Input Values } \\
\text { iew results in Advisory Messages) }\end{array}$} & \multicolumn{2}{|l|}{ Segment 1} & \multicolumn{2}{|l|}{ Segment 2} & \multicolumn{2}{|l|}{ Segment 3} & \multicolumn{2}{|l|}{ Segment 4} \\
\hline & (View results in Column AV) (View results in Advisory Messages) & & $\begin{array}{l}\text { Crash } \\
\text { Period }\end{array}$ & $\begin{array}{l}\text { Study } \\
\text { Period }\end{array}$ & $\begin{array}{l}\text { Crash } \\
\text { Period }\end{array}$ & $\begin{array}{l}\text { Study } \\
\text { Period }\end{array}$ & $\begin{array}{l}\text { Crash } \\
\text { Period }\end{array}$ & $\begin{array}{l}\text { Study } \\
\text { Period }\end{array}$ & $\begin{array}{l}\text { Crash } \\
\text { Period }\end{array}$ & $\begin{array}{l}\text { Study } \\
\text { Period }\end{array}$ \\
\hline \multicolumn{11}{|c|}{ Cross Section Data } \\
\hline \multicolumn{3}{|c|}{ Lane width $\left(\mathrm{W}_{\mathrm{i}}\right)$, ft: } & 13.04 & 13.04 & 11.76 & 11.76 & 12.02 & 12.02 & 12.16 & 12.16 \\
\hline \multicolumn{3}{|c|}{ Outside shoulder width $\left(\mathrm{W}_{\mathrm{s}}\right)$, $\mathrm{ft}$ : } & 11.78 & 11.78 & 10.62 & 10.62 & 10.96 & 10.96 & 11.35 & 11.35 \\
\hline \multicolumn{3}{|c|}{ Inside shoulder width $\left(\mathrm{W}_{\mathrm{is}}\right)$, ft: } & 2.91 & 2.91 & 8.27 & 8.27 & 12 & 12 & 10.19 & 10.19 \\
\hline \multicolumn{3}{|c|}{ Median width $\left(\mathrm{W}_{\mathrm{m}}\right)$, $\mathrm{ft}$ : } & 63.74 & 63.74 & 52.84 & 52.84 & 38.82 & 38.82 & 22.62 & 22.62 \\
\hline \multicolumn{3}{|c|}{ Rumble strips on outside shoulders?: } & No & No & No & No & No & No & No & No \\
\hline & \multicolumn{10}{|c|}{ Length of rumble strips for travel in increasing milepost direction, mi: } \\
\hline & \multicolumn{10}{|c|}{ Length of rumble strips for travel in decreasing milepost direction, mi: } \\
\hline \multicolumn{3}{|c|}{ Rumble strips on inside shoulders? } & No & No & No & No & No & No & No & No \\
\hline & \multicolumn{10}{|c|}{ Length of rumble strips for travel in increasing milepost direction, mi: } \\
\hline & \multicolumn{10}{|c|}{ Length of rumble strips for travel in decreasing milepost direction, mi: } \\
\hline Presenc & \multicolumn{2}{|l|}{ of barrier in median: } & Offset & Offset & Offset & Offset & Offset & Offset & Offset & Offset \\
\hline \multicolumn{11}{|c|}{1 Length of barrier $\left(L_{i b, 1}\right)$, mi: } \\
\hline \multicolumn{11}{|c|}{ Distance from edge of traveled way to barrier face $\left(W_{\text {ofini } 1}\right)$, ft: } \\
\hline \multicolumn{11}{|c|}{2 Length of barrier $\left(L_{i b, 2}\right)$, mi: } \\
\hline \multicolumn{11}{|c|}{ Distance from edge of traveled way to barrier face $\left(\mathrm{W}_{\mathrm{olli}} 2\right)$, $\mathrm{ft}$ : } \\
\hline \multicolumn{11}{|c|}{\begin{tabular}{l|l|} 
Length of barrier $\left(\mathrm{L}_{\mathrm{ib}, 3}\right), \mathrm{mi}:$ \\
\end{tabular}} \\
\hline \multicolumn{11}{|c|}{ Distance from edge of traveled way to barrier face $\left(\mathrm{W}_{\mathrm{allin}, 3}\right)$, ft: } \\
\hline \multicolumn{11}{|c|}{4 Length of barrier $\left(L_{i b, 4}\right)$, mi: } \\
\hline \multicolumn{11}{|c|}{ Distance from edge of traveled way to barrier face $\left(\mathrm{W}_{\mathrm{ollin}}, 4\right)$, $\mathrm{ft}$ : } \\
\hline \multicolumn{11}{|c|}{5 Length of barrier $\left(\mathrm{L}_{\mathrm{ib}, 5}\right)$, mi: } \\
\hline & Distance from edge of trav & ay to barrier face $\left(W_{\text {ollin. }}\right)$, ft: & & & & & & & & \\
\hline Median $\mathrm{t}$ & arrier width $\left(\mathrm{W}_{\mathrm{bb}}\right), \mathrm{ft}$ : & & 57.7 & 57.7 & 3 & 3 & 3 & 3 & 3 & 3 \\
\hline Nearest & istance from edge of travel & $y$ to barrier face $\left(W_{\text {near }}\right)$, ft: & 2.91 & 2.91 & 8.27 & 8.27 & 12 & 12 & 10.19 & 10.19 \\
\hline
\end{tabular}

\section{Cross Section Data Inputs}

\begin{tabular}{|c|c|c|c|c|c|c|c|c|c|c|}
\hline \multicolumn{11}{|c|}{ Input Worksheet for Freeway Segments } \\
\hline \multirow{2}{*}{ Clear } & \multirow{2}{*}{ Echo Input Values } & \multirow{2}{*}{$\begin{array}{c}\text { Check Input Values } \\
\text { iew results in Advisory Messages) }\end{array}$} & \multicolumn{2}{|l|}{ Segment 1} & \multicolumn{2}{|l|}{ Segment 2} & \multicolumn{2}{|l|}{ Segment 3} & \multicolumn{2}{|l|}{ Segment 4} \\
\hline & & & $\begin{array}{l}\text { Crash } \\
\text { Period }\end{array}$ & $\begin{array}{c}\text { Study } \\
\text { Period }\end{array}$ & $\begin{array}{l}\text { Crash } \\
\text { Period }\end{array}$ & $\begin{array}{l}\text { Study } \\
\text { Period }\end{array}$ & $\begin{array}{c}\text { Crash } \\
\text { Period }\end{array}$ & $\begin{array}{l}\text { Study } \\
\text { Period }\end{array}$ & $\begin{array}{l}\text { Crash } \\
\text { Period }\end{array}$ & $\begin{array}{l}\text { Study } \\
\text { Period }\end{array}$ \\
\hline \multicolumn{11}{|c|}{ Roadside Data } \\
\hline \multicolumn{3}{|c|}{ Clear zone width $\left(\mathrm{W}_{\mathrm{ho}}\right)$, $\mathrm{ft}$ : } & 30 & 30 & 30 & 30 & 30 & 30 & 30 & 30 \\
\hline \multicolumn{3}{|c|}{ Presence of barrier on roadside: } & Full & Full & Full & Full & Full & Full & Full & Full \\
\hline \multicolumn{11}{|c|}{1 Length of barrier $\left(\mathrm{L}_{o b, 1}\right), \mathrm{mi}:$} \\
\hline & \multicolumn{10}{|c|}{ Distance from edge of traveled way to barrier face $\left(\mathrm{W}_{\mathrm{off}, 0,1}\right), \mathrm{ft}$} \\
\hline \multicolumn{11}{|c|}{2 Length of barrier $\left(L_{o b, 2}\right), \mathrm{mi}:$} \\
\hline & \multicolumn{10}{|c|}{ Distance from edge of traveled way to barrier face $\left(\mathrm{W}_{\mathrm{off}, 0,2}\right), \mathrm{ft}$. } \\
\hline \multicolumn{11}{|c|}{3 Length of barrier $\left(\mathrm{L}_{\mathrm{ob}, 3}\right)$, mi: } \\
\hline \multicolumn{11}{|c|}{ Distance from edge of traveled way to barrier face $\left(\mathrm{W}_{\mathrm{off}, 0,3}\right), \mathrm{ft}$ : } \\
\hline \multicolumn{11}{|c|}{4 Length of barrier $\left(\mathrm{L}_{\mathrm{ob}, 4}\right)$, mi: } \\
\hline \multicolumn{11}{|c|}{ Distance from edge of traveled way to barrier face $\left(\mathrm{W}_{\mathrm{off}, 0.4}\right), \mathrm{ft}$. } \\
\hline \multicolumn{11}{|c|}{5 Length of barrier $\left(\mathrm{L}_{\mathrm{ob}, 5}\right)$, mi: } \\
\hline \multicolumn{11}{|c|}{ Distance from edge of traveled way to barrier face $\left(\mathrm{W}_{\mathrm{off}, 0,5}\right), \mathrm{ft}$} \\
\hline \multirow{2}{*}{\multicolumn{3}{|c|}{ 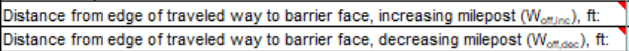 }} & 11.78 & 11.78 & 10.62 & 10.62 & 10.96 & 10.96 & 11.35 & 11.35 \\
\hline & & & 11.78 & 11.78 & 10.62 & 10.62 & 10.96 & 10.96 & 11.35 & 11.35 \\
\hline
\end{tabular}

\section{Roadside Data Inputs}




\begin{tabular}{|c|c|c|c|c|c|c|c|c|c|c|}
\hline \multicolumn{11}{|c|}{ Input Worksheet for Freeway Segments } \\
\hline \multirow{2}{*}{ Clear } & \multirow{2}{*}{ Echo Input Values } & \multirow[b]{2}{*}{$\begin{array}{l}\text { Check Input Values } \\
\text { w results in Advisory Messages) }\end{array}$} & \multicolumn{2}{|l|}{ Segment 1} & \multicolumn{2}{|l|}{ Segment 2} & \multicolumn{2}{|l|}{ Segment 3} & \multicolumn{2}{|l|}{ Segment 4} \\
\hline & & & $\begin{array}{l}\text { Crash } \\
\text { Period }\end{array}$ & \begin{tabular}{|c|} 
Study \\
Period
\end{tabular} & $\begin{array}{l}\text { Crash } \\
\text { Period }\end{array}$ & $\begin{array}{l}\text { Study } \\
\text { Period }\end{array}$ & $\begin{array}{l}\text { Crash } \\
\text { Period }\end{array}$ & $\begin{array}{l}\text { Study } \\
\text { Period }\end{array}$ & $\begin{array}{l}\text { Crash } \\
\text { Period }\end{array}$ & \begin{tabular}{|l|} 
Study \\
Period
\end{tabular} \\
\hline \multicolumn{11}{|c|}{ Ramp Access Data } \\
\hline \multicolumn{11}{|c|}{ Travel in Increasing Milepost Direction } \\
\hline \multirow{5}{*}{$\begin{array}{l}\text { Entrance } \\
\text { Ramp }\end{array}$} & \multicolumn{2}{|c|}{ Ramp entrance in segment? (If yes, indicate type.): } & Lane Add & Lane Add & Lane Add & Lane Add & S-C Lane & S-C Lane & S-C Lane & S-C Lane \\
\hline & \multicolumn{2}{|c|}{ Distance from begin milepost to upstream entrance ramp gore $\left(X_{\mathrm{sen}}\right)$, mi: } & & & & & & & & \\
\hline & \multicolumn{2}{|c|}{ Length of ramp entrance $\left(L_{e n, i n c}\right)$, mi: } & & & & & 0.119038 & 0.119038 & 0.119038 & 0.119038 \\
\hline & \multicolumn{2}{|c|}{ Length of ramp entrance in segment $\left(\mathrm{L}_{\mathrm{en}, \mathrm{seg}, \mathrm{ino}}\right)$, mi: } & & & & & 0.04 & 0.04 & 0.079038 & 0.079038 \\
\hline & \multicolumn{2}{|l|}{ Entrance side?: } & & & & & Left & Left & Left & Left \\
\hline \multirow{5}{*}{$\begin{array}{l}\text { Exit } \\
\text { Ramp }\end{array}$} & \multicolumn{2}{|c|}{ Ramp exit in segment? (If yes, indicate type.): } & No & No & No & No & No & No & Lane Drop & Lane Drop \\
\hline & \multicolumn{2}{|c|}{ Distance from end milepost to downstream exit ramp gore $\left(X_{\text {cox }}\right)$, mi: } & 0.323063 & 0.323063 & 0.263163 & 0.263163 & 0.224386 & 0.224386 & & \\
\hline & \multicolumn{2}{|c|}{ Length of ramp exit $\left(L_{\text {ex,inc }}\right)$, mi: } & & & & & & & & \\
\hline & \multicolumn{2}{|c|}{ Length of ramp exit in segment ( Lex,seg,inco $)$ mi: } & & & & & & & & \\
\hline & \multicolumn{2}{|c|}{\begin{tabular}{|l|l} 
Exit side?: \\
\end{tabular}} & & & & & & & & \\
\hline \multirow{3}{*}{ Weave } & \multicolumn{2}{|l|}{ Type B weave in segment?: } & Yes & Yes & Yes & Yes & Yes & Yes & Yes & Yes \\
\hline & \multicolumn{2}{|c|}{ Length of weaving section $\left(\mathrm{L}_{\text {mev }}, \mathrm{nn}\right), \mathrm{mi}$ : } & 0.32954 & 0.32954 & 0.32954 & 0.32954 & 0.32954 & 0.32954 & 0.32954 & 0.32954 \\
\hline & \multicolumn{2}{|c|}{ Length of weaving section in segment $\left(\mathrm{L}_{\text {wev,seg,ino }}\right)$, mi: } & 0.19 & 0.19 & 0.06 & 0.06 & 0.04 & 0.04 & 0.21 & 0.21 \\
\hline \multicolumn{11}{|c|}{ Travel in Decreasing Milepost Direction } \\
\hline Entrance & Ramp entrance in segme & yes, indicate type.): & No & No & No & No & No & No & No & No \\
\hline Ramp & Distance from end milepost to & Im entrance ramp gore $\left(X_{0}\right.$ cort $)$, mi: & 0.327581 & 0.327581 & 0.36668 & 0.36668 & 0.427184 & 0.427184 & 0.621407 & \begin{tabular}{|l|}
0.621407 \\
\end{tabular} \\
\hline & Length of ramp entrance & a), mi: & & & & & & & & \\
\hline & Length of ramp entrance & 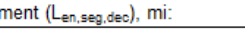 & & & & & & & & \\
\hline & Entrance side?: & & & & & & & & & \\
\hline Exit & Ramp exit in segment? (If & indicate type.): & No & No & Lane Drop & Lane Drop & Lane Drop & Lane Drop & No & No \\
\hline Ramp & Distance from begin milepost to & stream exit ramp gore $\left(X_{6}\right.$ eat $)$, mi: & 0.981549 & 0.981549 & & & & & 0.293926 & 0.293926 \\
\hline & Length of ramp exit ( $L_{\text {ex }}$ de & & & & & & & & & \\
\hline & Length of ramp exit in seg & $\left(L_{e x, s e g, d e c}\right), \mathrm{mi}:$ & & & & & & & & \\
\hline & Exit side?: & & & & & & & & & \\
\hline Weave & Type B weave in segment & & No & No & Yes & Yes & Yes & Yes & Yes & Yes \\
\hline & Length of weaving section & dec), mi: & & & 0.413006 & 0.413006 & 0.413006 & 0.413006 & 0.413006 & 0.413006 \\
\hline & Length of weaving section & gment $\left(\mathrm{L}_{\text {wev, seg,dec }}\right)$, mi: & & & 0.040716 & 0.040716 & 0.04 & 0.04 & 0.21 & 0.21 \\
\hline
\end{tabular}

Ramp Access Data Inputs 


\section{Appendix D. ISATe Spreadsheet Outputs}

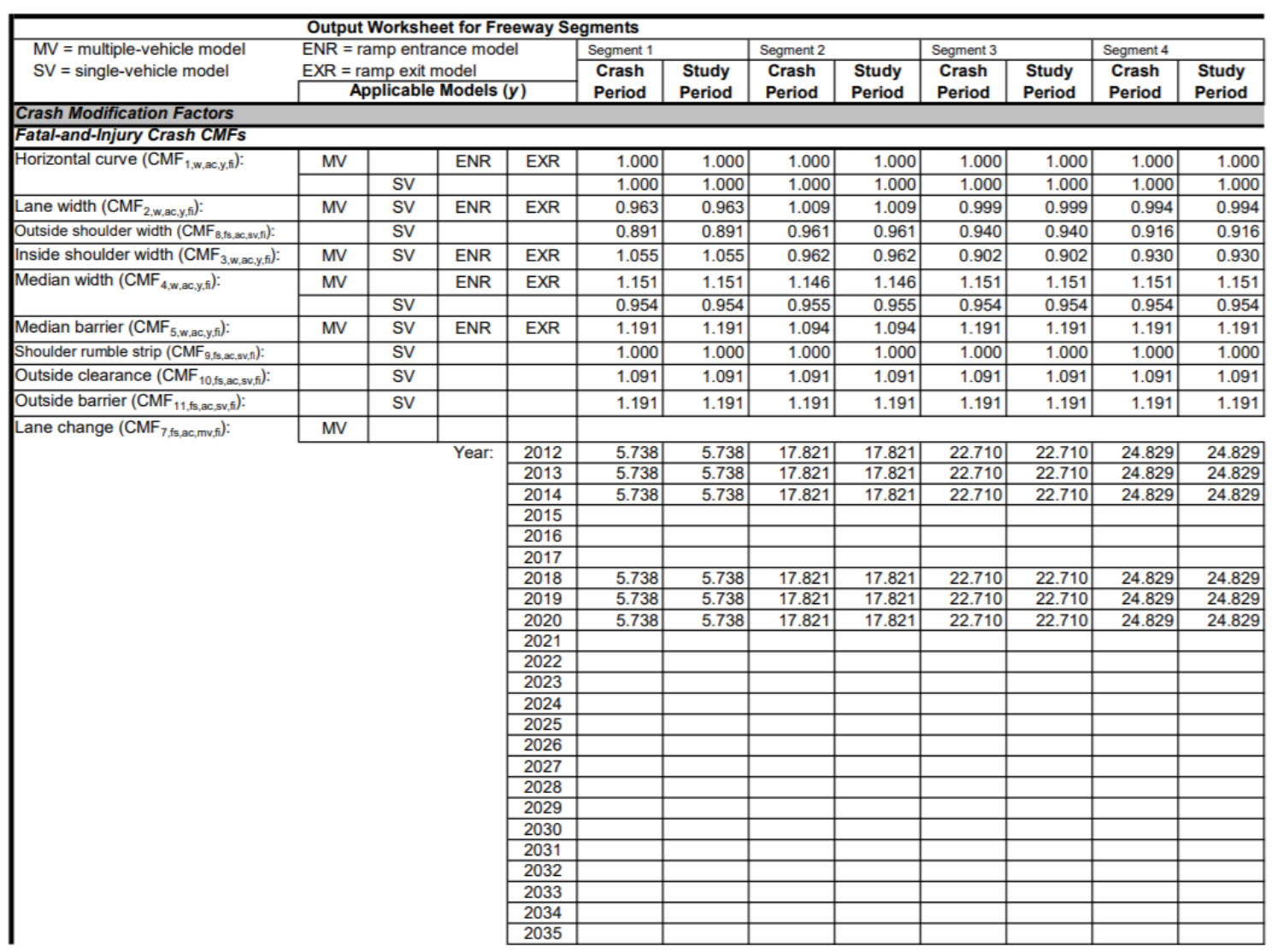

\begin{tabular}{|c|c|c|c|c|c|c|c|c|c|c|c|c|}
\hline \multirow[t]{25}{*}{ 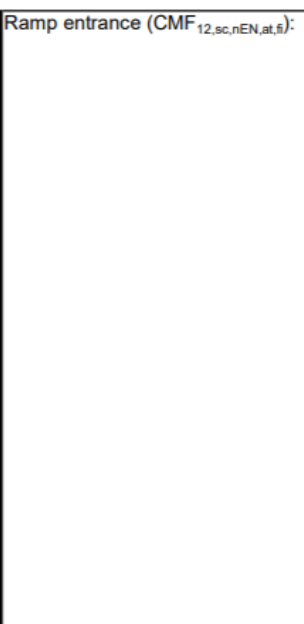 } & & & \multirow{2}{*}{$\begin{array}{l}\text { ENR } \\
\text { Year: }\end{array}$} & \multirow[b]{2}{*}{2012} & \multirow[b]{2}{*}{1.000} & \multirow[b]{2}{*}{1.000} & \multirow[b]{2}{*}{1.000} & \multirow[b]{2}{*}{1.000} & \multirow[b]{2}{*}{0.382} & \multirow[b]{2}{*}{0.382} & \multirow[b]{2}{*}{0.382} & \multirow[b]{2}{*}{0.382} \\
\hline & & & & & & & & & & & & \\
\hline & & & & 2013 & 1.000 & 1.000 & 1.000 & 1.000 & 0.382 & 0.382 & 0.382 & 0.382 \\
\hline & & & & 2014 & 1.000 & 1.000 & 1.000 & 1.000 & 0.382 & 0.382 & 0.382 & 0.382 \\
\hline & & & & 2015 & & & & & & & & \\
\hline & & & & 2016 & & & & & & & & \\
\hline & & & & 2017 & & & & & & & & \\
\hline & & & & 2018 & 1.000 & 1.000 & 1.000 & 1.000 & 0.382 & 0.382 & 0.382 & 0.382 \\
\hline & & & & 2019 & 1.000 & 1.000 & 1.000 & 1.000 & 0.382 & 0.382 & 0.382 & 0.382 \\
\hline & & & & 2020 & 1.000 & 1.000 & 1.000 & 1.000 & 0.382 & 0.382 & 0.382 & 0.382 \\
\hline & & & & 2021 & & & & & & & & \\
\hline & & & & 2022 & & & & & & & & \\
\hline & & & & 2023 & & & & & & & & \\
\hline & & & & 2024 & & & & & & & & \\
\hline & & & & 2025 & & & & & & & & \\
\hline & & & & 2026 & & & & & & & & \\
\hline & & & & 2027 & & & & & & & & \\
\hline & & & & 2028 & & & & & & & & \\
\hline & & & & 2029 & & & & & & & & \\
\hline & & & & 2030 & & & & & & & & \\
\hline & & & & 2031 & & & & & & & & \\
\hline & & & & 2032 & & & & & & & & \\
\hline & & & & 2033 & & & & & & & & \\
\hline & & & & 2034 & & & & & & & & \\
\hline & & & & 2035 & & & & & & & & \\
\hline Ramp exit $\left(\mathrm{CMF}_{13, \mathrm{sc}, \mathrm{nEX}, \mathrm{at}, \mathrm{f}) \text { : }}\right.$ & & & & EXR & 1.000 & 1.000 & 1.000 & 1.000 & 1.000 & 1.000 & 1.000 & 1.000 \\
\hline High volume $\left(\mathrm{CMF}_{6, w, a c, y . f)}\right)$ : & MV & & ENR & EXR & 1.000 & 1.000 & 1.000 & 1.000 & 1.000 & 1.000 & 1.000 & 1.000 \\
\hline & & SV & & & 1.000 & 1.000 & 1.000 & 1.000 & 1.000 & 1.000 & 1.000 & 1.000 \\
\hline
\end{tabular}




\begin{tabular}{|c|c|c|c|c|c|c|c|c|c|c|c|c|}
\hline \multicolumn{13}{|l|}{ Property-Damage-Only Crash CMFs } \\
\hline \multirow[t]{2}{*}{ Horizontal curve $\left(\mathrm{CMF}_{1, \mathrm{w}, \text { ac,y.pdo }}\right)$ : } & MV & & ENR & EXR & 1.000 & 1.000 & 1.000 & 1.000 & 1.000 & 1.000 & 1.000 & 1.000 \\
\hline & & SV & & & 1.000 & 1.000 & 1.000 & 1.000 & 1.000 & 1.000 & 1.000 & 1.000 \\
\hline Lane width $\left(\mathrm{CMF}_{2, w, a c, y, p d o}\right):$ & MV & SV & ENR & EXR & 1.000 & 1.000 & 1.000 & 1.000 & 1.000 & 1.000 & 1.000 & 1.000 \\
\hline \multicolumn{2}{|l|}{ Outside shoulder width $\left(\mathrm{CMF}_{8, \mathrm{ss}, \mathrm{sc}, \mathrm{sx}, \mathrm{pso}}\right)$ : } & SV & & & 1.000 & 1.000 & 1.000 & 1.000 & 1.000 & 1.000 & 1.000 & 1.000 \\
\hline \multirow{3}{*}{$\begin{array}{l}\text { Inside shoulder width }\left(\mathrm{CMF}_{3, \mathrm{w}, \mathrm{ac}, \mathrm{y} \text {.poo }}\right) \text { : } \\
\text { Median width }\left(\mathrm{CMF}_{4, w, a c, y, p d o}\right):\end{array}$} & MV & SV & ENR & EXR & 1.048 & 1.048 & 0.966 & 0.966 & 0.912 & 0.912 & 0.938 & 0.938 \\
\hline & MV & & ENR & EXR & 1.145 & 1.145 & 1.140 & 1.140 & 1.145 & 1.145 & \begin{tabular}{l|l}
1.145 \\
\end{tabular} & 1.145 \\
\hline & & SV & & & 1.144 & 1.144 & 1.139 & 1.139 & 1.144 & 1.144 & 1.144 & 1.144 \\
\hline Median barrier $\left(\mathrm{CMF}_{5, w, a c, y, p d o}\right)$ : & MV & SV & ENR & EXR & 1.253 & 1.253 & 1.123 & 1.123 & 1.253 & 1.253 & 1.253 & 1.253 \\
\hline Shoulder rumble strip ( CMF $\left._{9, \mathrm{~s}, a c, s v p d o}\right)$ : & & SV & & & 1.000 & 1.000 & 1.000 & 1.000 & 1.000 & 1.000 & 1.000 & 1.000 \\
\hline Outside clearance $\left(\mathrm{CMF}_{10, \mathrm{fs}, \mathrm{ac}, \mathrm{sv}, \mathrm{pdo})}\right)$ & & SV & & & 1.000 & 1.000 & 1.000 & 1.000 & 1.000 & 1.000 & 1.000 & 1.000 \\
\hline Outside barrier $\left(\mathrm{CMF}_{11, \mathrm{fs}, \mathrm{ac}, \mathrm{sv}, \mathrm{pdo})}\right)$ : & & SV & & & 1.253 & 1.253 & 1.253 & 1.253 & 1.253 & 1.253 & 1.253 & 1.253 \\
\hline Lane change $\left(\mathrm{CMF}_{7, \mathrm{fs}, \mathrm{ac}, \mathrm{mvpdo})}\right)$ & MV & & & & & & & & & & & \\
\hline & & & Year: & 2012 & 5.076 & 5.076 & 16.277 & 16.277 & 20.587 & 20.587 & 22.785 & 22.785 \\
\hline & & & & 2013 & 5.076 & 5.076 & 16.277 & 16.277 & 20.587 & 20.587 & 22.785 & 22.785 \\
\hline & & & & 2014 & 5.076 & 5.076 & 16.277 & 16.277 & 20.587 & 20.587 & 22.785 & 22.785 \\
\hline & & & & 2015 & & & & & & & & \\
\hline & & & & 2016 & & & & & & & & \\
\hline & & & & 2017 & & & & & & & & \\
\hline & & & & 2018 & 5.076 & 5.076 & 16.277 & 16.277 & 20.587 & 20.587 & 22.785 & 22.785 \\
\hline & & & & 2019 & 5.076 & 5.076 & 16.277 & 16.277 & 20.587 & 20.587 & 22.785 & 22.785 \\
\hline & & & & 2020 & 5.076 & 5.076 & 16.277 & 16.277 & 20.587 & 20.587 & 22.785 & 22.785 \\
\hline & & & & 2021 & & & & & & & & \\
\hline & & & & 2022 & & & & & & & & \\
\hline & & & & 2023 & & & & & & & & \\
\hline & & & & 2024 & & & & & & & & \\
\hline & & & & 2025 & & & & & & & & \\
\hline & & & & 2026 & & & & & & & & \\
\hline & & & & 2027 & & & & & & & & \\
\hline & & & & 2028 & & & & & & & & \\
\hline & & & & 2029 & & & & & & & & \\
\hline & & & & 2030 & & & & & & & & \\
\hline & & & & 2031 & & & & & & & & \\
\hline & & & & 2032 & & & & & & & & \\
\hline & & & & 2033 & & & & & & & & \\
\hline & & & & 2034 & & & & & & & & \\
\hline & & & & 2035 & & & & & & & & \\
\hline Ramp entrance $\left(\mathrm{CMF}_{12, \mathrm{sc}, \mathrm{n} \in \mathrm{N} \text {,at,pdo }}\right)$ : & & & ENR & & 1.000 & 1.000 & 1.000 & 1.000 & 2.817 & 2.817 & 2.817 & 2.817 \\
\hline Ramp exit ( $\mathrm{CMF}_{13, \text { sc,nEX,at,pdo): }}$ & & & & EXR & 1.000 & 1.000 & 1.000 & 1.000 & 1.000 & 1.000 & 1.000 & 1.000 \\
\hline High volume $\left(\mathrm{CMF}_{6, w, a c, y . \text { pdo }}\right)$ : & MV & & ENR & EXR & 1.000 & 1.000 & 1.000 & 1.000 & 1.000 & 1.000 & 1.000 & 1.000 \\
\hline & & SV & & & 1.000 & 1.000 & 1.000 & 1.000 & 1.000 & 1.000 & 1.000 & 1.000 \\
\hline Expected Average Crash Frequenc & & & & & & & & & & & & \\
\hline Fatal-and-Injury Crash Frequency & & & & & & & & & & & & \\
\hline Freeway Segment Multiple-Vehicle Cr & $\operatorname{sh} A n$ & & & Year & & & & & & & & \\
\hline Overdispersion parameter $\left(\mathrm{k}_{\mathrm{fs}, n, \mathrm{mv}, \mathrm{f}}\right)$ : & & & & & 0.299 & & 0.947 & & 2.841 & & 0.333 & \\
\hline Observed crash count $\left(\mathrm{N}^{*}{ }_{0, \mathrm{f}, \mathrm{n}, \mathrm{m}, \mathrm{mv}, \mathrm{ff}}\right), \mathrm{cra}$ & hes: & & & & 0 & & 0 & & 0 & & 2 & \\
\hline Reference year (r): & & & & & 2012 & & 2012 & & 2012 & & 2012 & \\
\hline Predicted average crash freq. for refer & nce ye & $N_{p, f s, r}$ & fir.t, cras & es/yr: & 16.125 & & 13.015 & & 5.481 & & 53.677 & \\
\hline Equivalent years associated with cras & count & $\mathrm{is,n,mv}$ & & & 3.038 & & 3.038 & & 3.038 & & 3.038 & \\
\hline Expected average crash freq. for reference year & $\operatorname{iven}^{*}$ & $\tan m x, t$ & rashes/yr: & & 1.030 & & 0.339 & & 0.113 & & \begin{tabular}{l|l}
1.616 \\
\end{tabular} & \\
\hline Expected average crash frequency & & & & 2012 & 1.030 & & 0.339 & & 0.113 & & \begin{tabular}{l|l}
1.616 \\
\end{tabular} & \\
\hline 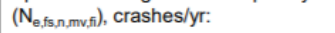 & & & & 2013 & 1.030 & & 0.339 & & 0.113 & & \begin{tabular}{l|l}
1.616 \\
\end{tabular} & \\
\hline & & & & 2014 & 1.069 & & 0.351 & & 0.118 & & 1.678 & \\
\hline & & & & 2015 & & & & & & & & \\
\hline & & & & 2016 & & & & & & & & \\
\hline & & & & 2017 & & & & & & & & \\
\hline & & & & 2018 & & 1.069 & & 0.351 & & 0.118 & & 1.678 \\
\hline & & & & 2019 & & 1.069 & & 0.351 & & 0.118 & & 1.678 \\
\hline & & & & 2020 & & 1.069 & & 0.351 & & 0.118 & & 1.678 \\
\hline & & & & 2021 & & & & & & & & \\
\hline & & & & 2022 & & & & & & & & \\
\hline & & & & 2023 & & & & & & & & \\
\hline & & & & 2024 & & & & & & & & \\
\hline & & & & 2025 & & & & & & & & \\
\hline & & & & 2026 & & & & & & & & \\
\hline & & & & 2027 & & & & & & & & \\
\hline & & & & 2028 & & & & & & & & \\
\hline & & & & 2029 & & & & & & & & \\
\hline & & & & 2030 & & & & & & & & \\
\hline & & & & 2031 & & & & & & & & \\
\hline & & & & 2032 & & & & & & & & \\
\hline & & & & 2033 & & & & & & & & \\
\hline & & & & 2034 & & & & & & & & \\
\hline & & & & 2035 & & & & & & & & \\
\hline Freeway Segment Single-Vehicle Cra & Ana & & & Year & & & & & & & & \\
\hline
\end{tabular}




\begin{tabular}{|c|c|c|c|c|c|c|c|c|c|}
\hline \multicolumn{2}{|l|}{ Overdispersion parameter $\left(\mathrm{k}_{\mathrm{fs}, \mathrm{n}, \mathrm{sv}, \mathrm{ff}}\right)$ : } & 0.175 & & 0.554 & & 1.661 & & 0.195 & \\
\hline \multicolumn{2}{|c|}{ 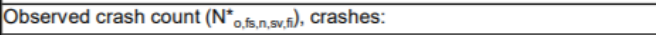 } & 0 & & 0 & & 0 & & 1 & \\
\hline \multicolumn{2}{|l|}{ Reference year $(\mathrm{r})$ : } & 2012 & & 2012 & & 2012 & & 2012 & \\
\hline \multicolumn{2}{|c|}{ Predicted average crash freq. for reference year $\left(\mathrm{N}_{\mathrm{p}, \mathrm{fs}, \mathrm{n}, \mathrm{sv}, \mathrm{fi}, \mathrm{r}}\right)$, crashes/yr: } & 0.956 & & 0.296 & & 0.101 & & 0.831 & \\
\hline \multicolumn{2}{|c|}{ Equivalent years associated with crash count $\left(\mathrm{C}_{\mathrm{b}, \mathrm{fs}, \mathrm{n}, \mathrm{sv}, \mathrm{fif}, \mathrm{r}}\right), \mathrm{yr}:$} & 3.016 & & 3.016 & & 3.016 & & 3.016 & \\
\hline \multicolumn{2}{|c|}{ Expected average crash freq. for reference year given $\mathrm{N}^{*}$ 。 $\left(\mathrm{N}_{\text {atsansvats }}\right)$, crashes/yr. } & 0.635 & & 0.198 & & 0.067 & & 0.667 & \\
\hline \multirow{24}{*}{$\begin{array}{l}\text { Expected average crash frequency } \\
\left(\mathrm{N}_{\mathrm{e}, \mathrm{fs}, \mathrm{n}, \mathrm{sv}, \mathrm{f})}\right) \text {, crashes/yr: }\end{array}$} & 2012 & 0.635 & & 0.198 & & 0.067 & & 0.667 & \\
\hline & 2013 & 0.635 & & 0.198 & & 0.067 & & 0.667 & \\
\hline & 2014 & 0.646 & & 0.201 & & 0.068 & & 0.678 & \\
\hline & 2015 & & & & & & & & \\
\hline & 2016 & & & & & & & & \\
\hline & 2017 & & & & & & & & \\
\hline & 2018 & & 0.646 & & 0.201 & & 0.068 & & 0.678 \\
\hline & 2019 & & 0.646 & & 0.201 & & 0.068 & & 0.678 \\
\hline & 2020 & & 0.646 & & 0.201 & & 0.068 & & 0.678 \\
\hline & 2021 & & & & & & & & \\
\hline & 2022 & & & & & & & & \\
\hline & 2023 & & & & & & & & \\
\hline & 2024 & & & & & & & & \\
\hline & 2025 & & & & & & & & \\
\hline & 2026 & & & & & & & & \\
\hline & 2027 & & & & & & & & \\
\hline & 2028 & & & & & & & & \\
\hline & 2029 & & & & & & & & \\
\hline & 2030 & & & & & & & & \\
\hline & 2031 & & & & & & & & \\
\hline & 2032 & & & & & & & & \\
\hline & 2033 & & & & & & & & \\
\hline & 2034 & & & & & & & & \\
\hline & 2035 & & & & & & & & \\
\hline Ramp Entrance Crash Analysis & Year & & & & & & & & \\
\hline Overdispersion parameter $\left(\mathrm{k}_{\mathrm{sc}, \mathrm{EN}, \mathrm{at}, \mathrm{f}}\right)$ & & 0.000 & & 0.000 & & 0.958 & & 0.485 & \\
\hline 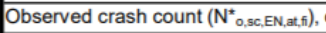 & & 2 & & 0 & & 0 & & 0 & \\
\hline Reference year $(\mathrm{r})$ : & & 2012 & & 2012 & & 2012 & & 2012 & \\
\hline Predicted average crash freq. for ref & hes/yr: & 0.000 & & 0.000 & & 0.069 & & 0.158 & \\
\hline Equivalent years associated with cra & & 3.000 & & 3.000 & & 3.030 & & 3.030 & \\
\hline Expected average crash freq. for reference ye & & 0.000 & & 0.000 & & 0.057 & & 0.128 & \\
\hline Expected average crash frequency & 2012 & 0.000 & & 0.000 & & 0.057 & & 0.128 & \\
\hline$\left(\mathrm{N}_{\mathrm{e}, \mathrm{sc}, \mathrm{EN}, \mathrm{at}, \mathrm{f})}\right)$, crashes/yr: & 2013 & 0.000 & & 0.000 & & 0.057 & & 0.128 & \\
\hline & 2014 & 0.000 & & 0.000 & & 0.059 & & 0.132 & \\
\hline & 2015 & & & & & & & & \\
\hline & 2016 & & & & & & & & \\
\hline & 2017 & & & & & & & & \\
\hline & 2018 & & 0.000 & & 0.000 & & 0.059 & & 0.132 \\
\hline & 2019 & & 0.000 & & 0.000 & & 0.059 & & 0.132 \\
\hline & 2020 & & 0.000 & & 0.000 & & 0.059 & & 0.132 \\
\hline & 2021 & & & & & & & & \\
\hline & 2022 & & & & & & & & \\
\hline & 2023 & & & & & & & & \\
\hline & 2024 & & & & & & & & \\
\hline & 2025 & & & & & & & & \\
\hline & 2026 & & & & & & & & \\
\hline & 2027 & & & & & & & & \\
\hline & 2028 & & & & & & & & \\
\hline & 2029 & & & & & & & & \\
\hline & 2030 & & & & & & & & \\
\hline & 2031 & & & & & & & & \\
\hline & 2032 & & & & & & & & \\
\hline & 2033 & & & & & & & & \\
\hline & 2034 & & & & & & & & \\
\hline & 2035 & & & & & & & & \\
\hline Ramp Exit Crash Analysis & Year & & & & & & & & \\
\hline Overdispersion parameter $\left(k_{\mathrm{sc}, \mathrm{EX}, \mathrm{at}, \mathrm{f} \mathrm{f})}\right.$ & & 0.000 & & 0.000 & & 0.000 & & 0.000 & \\
\hline 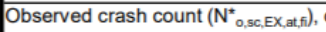 & & 0 & & 0 & & 0 & & 0 & \\
\hline Reference year $(\mathrm{r})$ : & & 2012 & & 2012 & & 2012 & & 2012 & \\
\hline Predicted average crash freq. for ref & hes/yr: & 0.000 & & 0.000 & & 0.000 & & 0.000 & \\
\hline Equivalent years associated with cra & & 3.000 & & 3.000 & & 3.000 & & 3.000 & \\
\hline Expected average crash freq. for reference ye & & 0.000 & & 0.000 & & 0.000 & & 0.000 & \\
\hline Expected average crash frequency & 2012 & 0.000 & & 0.000 & & 0.000 & & 0.000 & \\
\hline$\left(\mathrm{N}_{\mathrm{e}, \mathrm{sc}, \mathrm{EX}, \mathrm{at}, \mathrm{f})}\right)$, crashes/yr: & 2013 & 0.000 & & 0.000 & & 0.000 & & 0.000 & \\
\hline & 2014 & 0.000 & & 0.000 & & 0.000 & & 0.000 & \\
\hline & 2015 & & & & & & & & \\
\hline & 2016 & & & & & & & & \\
\hline & 2017 & & & & & & & & \\
\hline & 2018 & & 0.000 & & 0.000 & & 0.000 & & 0.000 \\
\hline
\end{tabular}




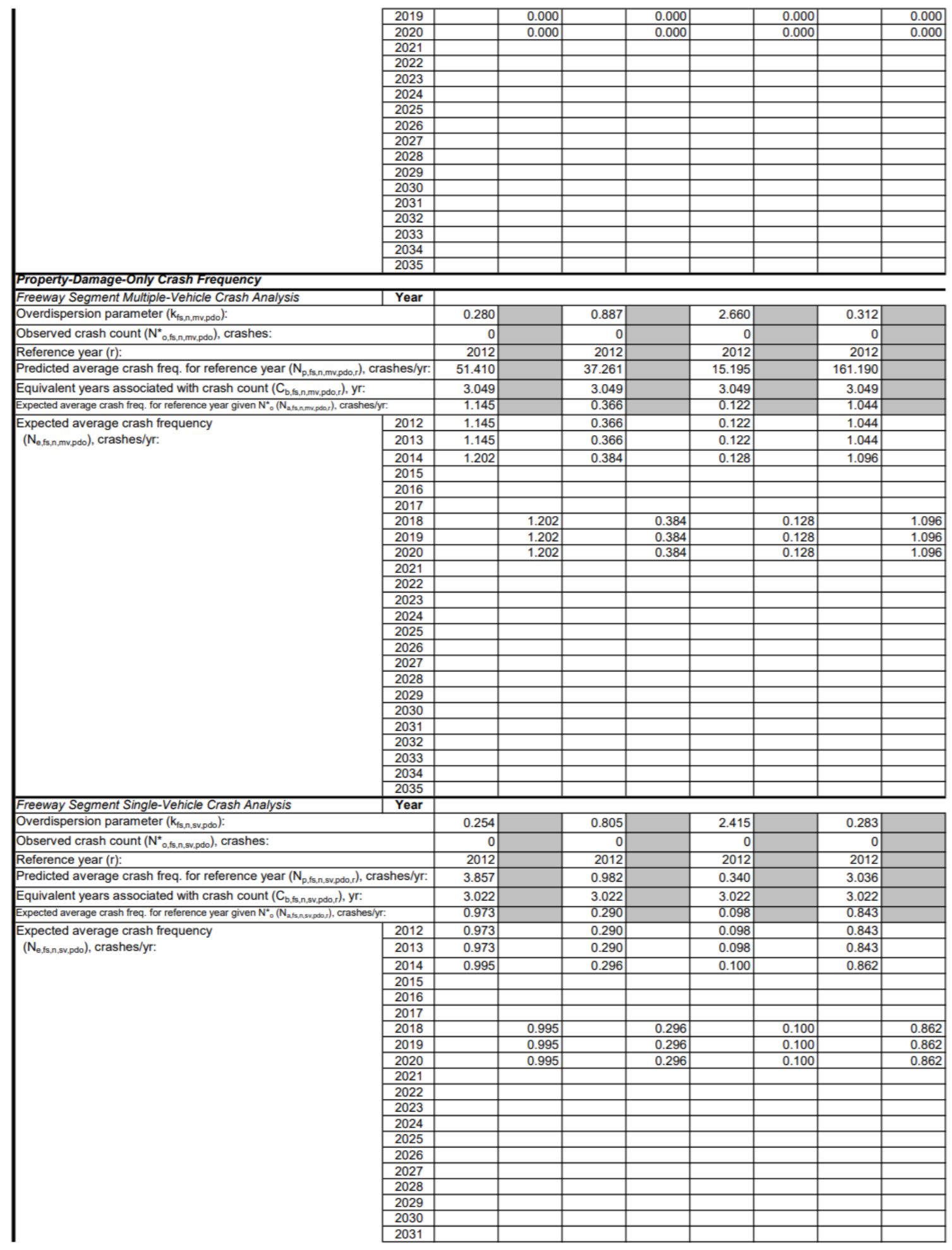




\begin{tabular}{|c|c|c|c|c|c|c|c|c|c|}
\hline & & & & & & & & & \\
\hline & 2032 & & & & & & & & \\
\hline & 2033 & & & & & & & & \\
\hline & 2034 & & & & & & & & \\
\hline & 2035 & & & & & & & & \\
\hline Ramp Entrance Crash Analysis & Year & & & & & & & & \\
\hline \multicolumn{2}{|l|}{ Overdispersion parameter $\left(\mathrm{k}_{\mathrm{sc}, \mathrm{EN}, \text { at,pdo }}\right)$ : } & 0.000 & & 0.000 & & 1.008 & & 0.510 & \\
\hline \multicolumn{2}{|l|}{ Observed crash count $\left(\mathrm{N}^{*}{ }_{0, s c, E N, a t, p d o}\right)$, crashes: } & 0 & & 0 & & 0 & & 0 & \\
\hline \multicolumn{2}{|l|}{ Reference year $(\mathrm{r})$ : } & 2012 & & 2012 & & 2012 & & 2012 & \\
\hline \multicolumn{2}{|c|}{ 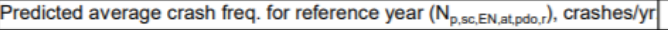 } & 0.000 & & 0.000 & & 1.777 & & 3.973 & \\
\hline Equivalent years associated with crash count $\left(\mathrm{C}_{\mathrm{b}, \mathrm{sc}, \mathrm{EN} \text {,at }}\right.$. & & 3.000 & & 3.000 & & 3.031 & & 3.031 & \\
\hline Expected average crash freq. for reference year given $\mathrm{N}^{*}$ 。 $\left(\mathrm{N}_{\text {2sc.ENat }} \mathrm{pc}\right.$ & & 0.000 & & 0.000 & & 0.276 & & 0.556 & \\
\hline Expected average crash frequency & 2012 & 0.000 & & 0.000 & & 0.276 & & 0.556 & \\
\hline$\left(\mathrm{N}_{\mathrm{e}, \mathrm{sc}, \mathrm{EN}, \mathrm{at}, \mathrm{pdo}}\right)$, crashes/yr: & 2013 & 0.000 & & 0.000 & & 0.276 & & 0.556 & \\
\hline & 2014 & 0.000 & & 0.000 & & 0.285 & & 0.573 & \\
\hline & 2015 & & & & & & & & \\
\hline & 2016 & & & & & & & & \\
\hline & 2017 & & & & & & & & \\
\hline & 2018 & & 0.000 & & 0.000 & & 0.285 & & 0.573 \\
\hline & 2019 & & 0.000 & & 0.000 & & 0.285 & & 0.573 \\
\hline & 2020 & & 0.000 & & 0.000 & & 0.285 & & 0.573 \\
\hline & 2021 & & & & & & & & \\
\hline & 2022 & & & & & & & & \\
\hline & 2023 & & & & & & & & \\
\hline & 2024 & & & & & & & & \\
\hline & 2025 & & & & & & & & \\
\hline & 2026 & & & & & & & & \\
\hline & 2027 & & & & & & & & \\
\hline & 2028 & & & & & & & & \\
\hline & 2029 & & & & & & & & \\
\hline & 2030 & & & & & & & & \\
\hline & 2031 & & & & & & & & \\
\hline & 2032 & & & & & & & & \\
\hline & 2033 & & & & & & & & \\
\hline & 2034 & & & & & & & & \\
\hline & 2035 & & & & & & & & \\
\hline Ramp Exit Crash Analysis & Year & & & & & & & & \\
\hline Overdispersion parameter $\left(k_{\mathrm{sc}, \mathrm{EX}, \mathrm{at}, \mathrm{pdo})}\right)$ : & & 0.000 & & 0.000 & & 0.000 & & 0.000 & \\
\hline Observed crash count $\left(\mathrm{N}_{0, \mathrm{sc}, \mathrm{EX}, \mathrm{at}, \mathrm{pdo} \mathrm{O}}^{*}\right.$, crashes: & & 0 & & 0 & & 0 & & 0 & \\
\hline Reference year $(r)$ : & & 2012 & & 2012 & & 2012 & & 2012 & \\
\hline Predicted average crash freq. for reference year $\left(\mathrm{N}_{\mathrm{p}, \mathrm{sc}, \mathrm{E}}\right.$ & ashes/yr & 0.000 & & 0.000 & & 0.000 & & 0.000 & \\
\hline Equivalent years associated with crash count $\left(\mathrm{C}_{\mathrm{b}, \mathrm{sc}, \mathrm{EX}, \mathrm{at}}\right.$ & & 3.000 & & 3.000 & & 3.000 & & 3.000 & \\
\hline 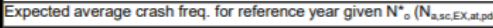 & & 0.000 & & 0.000 & & 0.000 & & 0.000 & \\
\hline Expected average crash frequency & 2012 & 0.000 & & 0.000 & & 0.000 & & 0.000 & \\
\hline$\left(\mathrm{N}_{\mathrm{e}, \mathrm{sc}, \mathrm{EX}, \mathrm{at}, \mathrm{pdo})}\right)$, crashes/yr: & 2013 & 0.000 & & 0.000 & & 0.000 & & 0.000 & \\
\hline & 2014 & 0.000 & & 0.000 & & 0.000 & & 0.000 & \\
\hline & 2015 & & & & & & & & \\
\hline & 2016 & & & & & & & & \\
\hline & 2017 & & & & & & & & \\
\hline & 2018 & & 0.000 & & 0.000 & & 0.000 & & 0.000 \\
\hline & 2019 & & 0.000 & & 0.000 & & 0.000 & & 0.000 \\
\hline & 2020 & & 0.000 & & 0.000 & & 0.000 & & 0.000 \\
\hline & 2021 & & & & & & & & \\
\hline & 2022 & & & & & & & & \\
\hline & 2023 & & & & & & & & \\
\hline & 2024 & & & & & & & & \\
\hline & 2025 & & & & & & & & \\
\hline & 2026 & & & & & & & & \\
\hline & 2027 & & & & & & & & \\
\hline & 2028 & & & & & & & & \\
\hline & 2029 & & & & & & & & \\
\hline & 2030 & & & & & & & & \\
\hline & 2031 & & & & & & & & \\
\hline & 2032 & & & & & & & & \\
\hline & 2033 & & & & & & & & \\
\hline & 2034 & & & & & & & & \\
\hline & 2035 & & & & & & & & \\
\hline $\begin{array}{l}\text { Crash Severity Distribution } \\
\text { (during Study Period) }\end{array}$ & & & & & & & & & \\
\hline Fatal crash frequency $\left(\mathrm{N}_{\mathrm{e}, \mathrm{w}, \mathrm{x}, \mathrm{at}, \mathrm{K}}\right)$, crashes: & & & 0.064 & & 0.028 & & 0.012 & & 0.114 \\
\hline Incapacitating injury crash freq. $\left(\mathrm{N}^{*}{ }_{e, w, x, a t, A}\right)$, crashes: & & & 0.220 & & 0.069 & & 0.031 & & 0.314 \\
\hline Non-incapacitating inj. crash freq. $\left(\mathrm{N}^{*}, w, x, a t, \mathrm{~B}\right)$, crashes: & & & 1.526 & & 0.510 & & 0.225 & & 2.270 \\
\hline Possible injury crash freq. $\left(\mathrm{N}^{*}{ }_{e, w, x, a t, C}\right)$, crashes: & & & 3.336 & & 1.051 & & 0.468 & & 4.763 \\
\hline 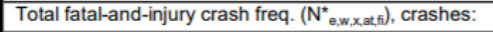 & & & 5.146 & & 1.658 & & 0.735 & & 7.462 \\
\hline Property-damage-only crash freq. $\left(\mathrm{N}^{*}\right.$ ewxatpos), crashes: & & & 6.589 & & 2.042 & & 1.539 & & 7.593 \\
\hline
\end{tabular}




\begin{tabular}{|c|c|c|c|c|c|c|c|c|c|}
\hline \multicolumn{2}{|l|}{ Total crash frequency $\left(\mathrm{N}^{*}\right.$ ew,w,at,as $)$, crashes: } & & 11.735 & & 3.700 & & 2.274 & & 15.056 \\
\hline \multicolumn{10}{|l|}{ Intermediate Results } \\
\hline \multicolumn{10}{|l|}{ Proportion of segment length with curve $1\left(P_{c, 1}\right)$ : } \\
\hline \multicolumn{10}{|l|}{ Proportion of segment length with curve $2\left(P_{c, 2}\right)$ : } \\
\hline \multicolumn{10}{|l|}{ Proportion of segment length with curve $3\left(\mathrm{P}_{\mathrm{c}, 3}\right)$ : } \\
\hline \multicolumn{2}{|l|}{ Distance from edge of inside shoulder to barrier face $\left(\mathrm{W}_{\text {icb }}\right)$, ft: } & 0.750 & 0.750 & 1.456 & 1.456 & 0.750 & 0.750 & 0.750 & 0.750 \\
\hline \multicolumn{2}{|l|}{ Proportion of segment length with barrier in the median $\left(\mathrm{P}_{\mathrm{ib}}\right)$ : } & 1.000 & 1.000 & 1.000 & 1.000 & 1.000 & 1.000 & 1.000 & 1.000 \\
\hline Proportion of segment length with rumble strips on outside shor & & 0.000 & 0.000 & 0.000 & 0.000 & 0.000 & 0.000 & 0.000 & 0.000 \\
\hline Proportion of segment length with rumble strips on inside shoul & & 0.000 & 0.000 & 0.000 & 0.000 & 0.000 & 0.000 & 0.000 & 0.000 \\
\hline Distance from edge of outside shoulder to barrier face (W & & 0.750 & 0.750 & 0.750 & 0.750 & 0.750 & 0.750 & 0.750 & 0.750 \\
\hline Proportion of segment length with barrier on the roadside & & 1.000 & 1.000 & 1.000 & 1.000 & 1.000 & 1.000 & 1.000 & 1.000 \\
\hline Proportion of segment length with Type B weaving, travel in increasing d & & 1.000 & 1.000 & 1.000 & 1.000 & 1.000 & 1.000 & 1.000 & 1.000 \\
\hline Proportion of segment length with Type B weaving, travel in decreasing & & 0.000 & 0.000 & 0.679 & 0.679 & 1.000 & 1.000 & 1.000 & 1.000 \\
\hline Traffic Data & Year & & & & & & & & \\
\hline Freeway Segment Data & 2012 & 198000 & & 198000 & & 198000 & & 198000 & \\
\hline Average daily traffic $\left(\mathrm{AADT}_{\mathrm{fs}}\right.$ ) by year, veh/d: & 2013 & 198000 & & 198000 & & 198000 & & 198000 & \\
\hline & 2014 & 203000 & & 203000 & & 203000 & & 203000 & \\
\hline & 2015 & 203000 & & 203000 & & 203000 & & 203000 & \\
\hline & 2016 & 203000 & & 203000 & & 203000 & & 203000 & \\
\hline & 2017 & 203000 & & 203000 & & 203000 & & 203000 & \\
\hline & 2018 & 203000 & & 203000 & & 203000 & & 203000 & \\
\hline & 2019 & 203000 & & 203000 & & 203000 & & 203000 & \\
\hline & 2020 & 203000 & & 203000 & & 203000 & & 203000 & \\
\hline & 2021 & 203000 & & 203000 & & 203000 & & 203000 & \\
\hline & 2022 & 203000 & & 203000 & & 203000 & & 203000 & \\
\hline & 2023 & 203000 & & 203000 & & 203000 & & 203000 & \\
\hline & 2024 & 203000 & & 203000 & & 203000 & & 203000 & \\
\hline & 2025 & 203000 & & 203000 & & 203000 & & 203000 & \\
\hline & 2026 & 203000 & & 203000 & & 203000 & & 203000 & \\
\hline & 2027 & 203000 & & 203000 & & 203000 & & 203000 & \\
\hline & 2028 & 203000 & & 203000 & & 203000 & & 203000 & \\
\hline & 2029 & 203000 & & 203000 & & 203000 & & 203000 & \\
\hline & 2030 & 203000 & & 203000 & & 203000 & & 203000 & \\
\hline & 2031 & 203000 & & 203000 & & 203000 & & 203000 & \\
\hline & 2032 & 203000 & & 203000 & & 203000 & & 203000 & \\
\hline & 2033 & 203000 & & 203000 & & 203000 & & 203000 & \\
\hline & 2034 & 203000 & & 203000 & & 203000 & & 203000 & \\
\hline & 2035 & 203000 & & 203000 & & 203000 & & 203000 & \\
\hline Entrance Ramp Data for Travel in Increasing Milepost Dir. & Year & & & & & & & & \\
\hline Average daily traffic (AADT $T_{b, e n t}$ ) by year, veh/d: & 2012 & 0 & & 0 & & 0 & & 0 & \\
\hline & 2013 & 0 & & 0 & & 0 & & 0 & \\
\hline & 2014 & 0 & & 0 & & 0 & & 0 & \\
\hline & 2015 & 0 & & 0 & & 0 & & 0 & \\
\hline & 2016 & 0 & & 0 & & 0 & & 0 & \\
\hline & 2017 & 0 & & 0 & & 0 & & 0 & \\
\hline & 2018 & 0 & & 0 & & 0 & & 0 & \\
\hline & 2019 & 0 & & 0 & & 0 & & 0 & \\
\hline & 2020 & 0 & & 0 & & 0 & & 0 & \\
\hline & 2021 & 0 & & 0 & & 0 & & 0 & \\
\hline & 2022 & 0 & & 0 & & 0 & & 0 & \\
\hline & 2023 & 0 & & 0 & & 0 & & 0 & \\
\hline & 2024 & 0 & & 0 & & 0 & & 0 & \\
\hline & 2025 & 0 & & 0 & & 0 & & 0 & \\
\hline & 2026 & 0 & & 0 & & 0 & & 0 & \\
\hline & 2027 & 0 & & 0 & & 0 & & 0 & \\
\hline & 2028 & 0 & & 0 & & 0 & & 0 & \\
\hline & 2029 & 0 & & 0 & & 0 & & 0 & \\
\hline & 2030 & 0 & & 0 & & 0 & & 0 & \\
\hline & 2031 & 0 & & 0 & & 0 & & 0 & \\
\hline & 2032 & 0 & & 0 & & 0 & & 0 & \\
\hline & 2033 & 0 & & 0 & & 0 & & 0 & \\
\hline & 2034 & 0 & & 0 & & 0 & & 0 & \\
\hline & 2035 & 0 & & 0 & & 0 & & 0 & \\
\hline Exit Ramp Data for Travel in Increasing Milepost Direction & Year & & & & & & & & \\
\hline Average daily traffic $\left(\mathrm{AADT}_{e, \mathrm{ext}}\right.$ ) by year, veh/d: & 2012 & 0 & & 0 & & 0 & & 0 & \\
\hline & 2013 & 0 & & 0 & & 0 & & 0 & \\
\hline & 2014 & 0 & & 0 & & 0 & & 0 & \\
\hline & 2015 & 0 & & 0 & & 0 & & 0 & \\
\hline & 2016 & 0 & & 0 & & 0 & & 0 & \\
\hline & 2017 & 0 & & 0 & & 0 & & 0 & \\
\hline & 2018 & 0 & & 0 & & 0 & & 0 & \\
\hline & 2019 & 0 & & 0 & & 0 & & 0 & \\
\hline & 2020 & 0 & & 0 & & 0 & & 0 & \\
\hline & 2021 & 0 & & 0 & & 0 & & 0 & \\
\hline
\end{tabular}




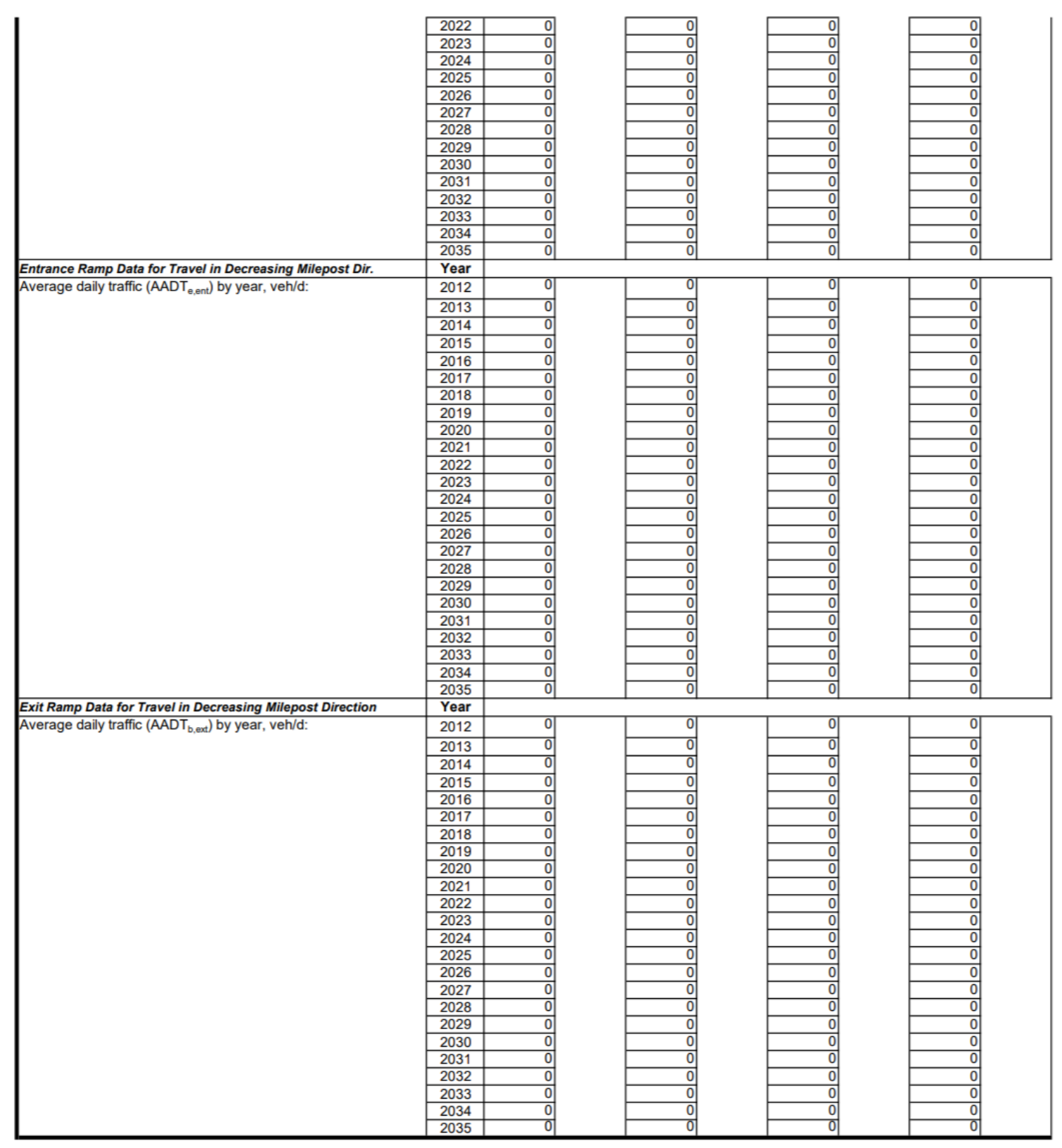




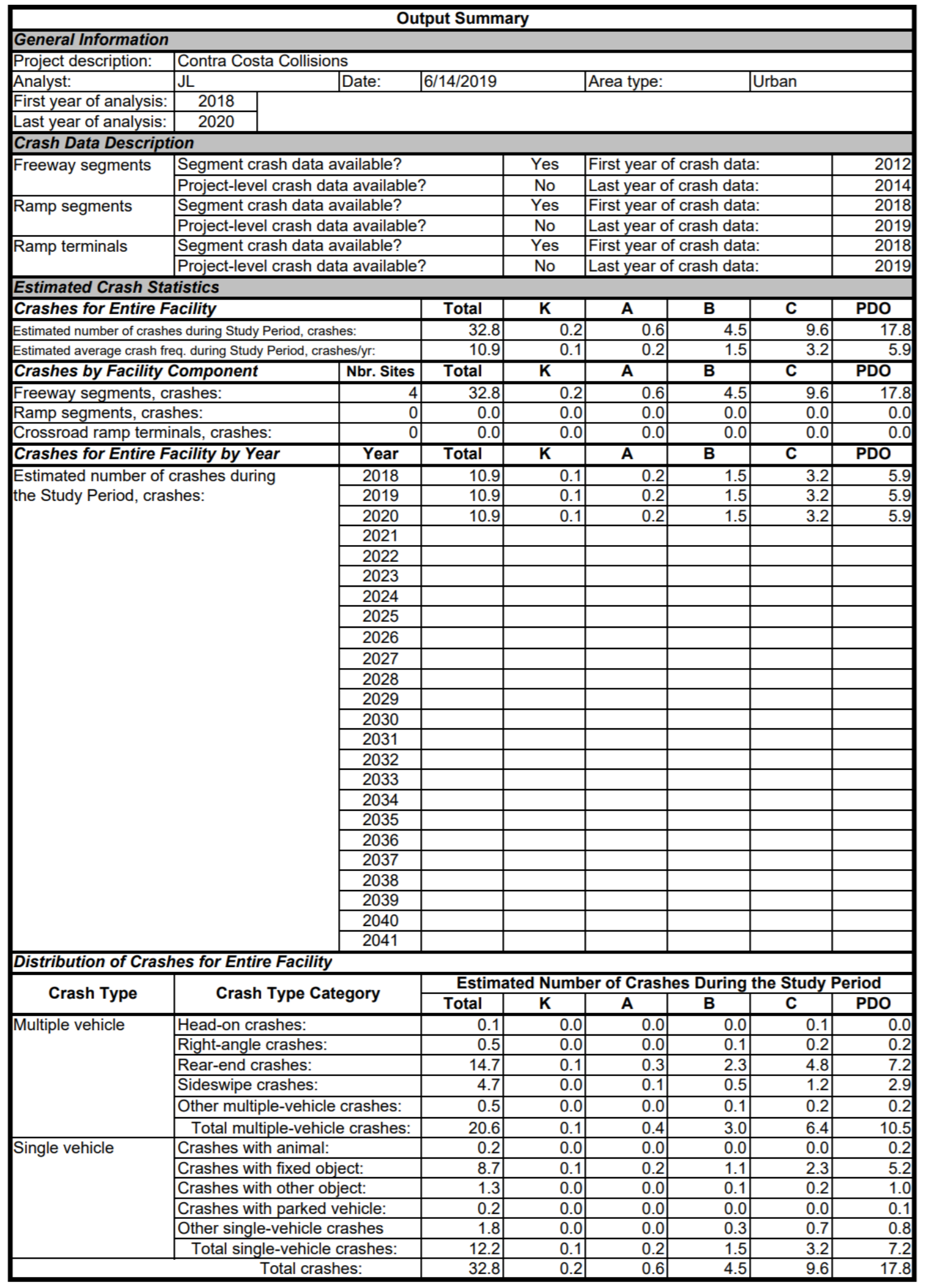




\begin{tabular}{|c|c|c|c|c|c|c|c|}
\hline \multicolumn{8}{|c|}{ Evaluation Site Summary } \\
\hline \multicolumn{8}{|c|}{ General Information } \\
\hline \multirow{2}{*}{\multicolumn{2}{|c|}{$\begin{array}{l}\text { Project description: } \\
\text { Analyst: }\end{array}$}} & \multicolumn{6}{|c|}{ Contra Costa Collisions } \\
\hline & & JL & Date: & $6 / 14 / 2019$ & & Area type: & \begin{tabular}{l|l} 
& Urban \\
\end{tabular} \\
\hline \multirow{2}{*}{\multicolumn{2}{|c|}{ First year of analysis: }} & 2018 & \multirow{2}{*}{\multicolumn{5}{|c|}{ Total length of freeway segments for Study Period (mi): }} \\
\hline & & 2020 & & & & & \\
\hline \multicolumn{8}{|c|}{ Site Description } \\
\hline \multicolumn{8}{|c|}{ Freeway Segments } \\
\hline Number & Lanes & \begin{tabular}{|c|} 
Study Period \\
Length (mi)
\end{tabular} & \multicolumn{3}{|c|}{ Crash Period Description } & \multicolumn{2}{|c|}{ Study Period Description } \\
\hline 1 & 5 & 0.190 & \multicolumn{3}{|l|}{ Seg1 } & \multicolumn{2}{|l|}{0} \\
\hline 2 & 6 & 0.060 & \multicolumn{3}{|l|}{ Seg2 } & \multicolumn{2}{|l|}{0} \\
\hline 3 & 7 & 0.040 & \multicolumn{3}{|l|}{ Seg3 } & \multicolumn{2}{|l|}{0} \\
\hline 4 & 6 & 0.210 & Seg4 & & & 0 & \\
\hline 5 & 0 & 0.000 & 0 & & & 0 & \\
\hline 6 & 0 & 0.000 & 0 & & & 0 & \\
\hline 7 & 0 & 0.000 & 0 & & & 0 & \\
\hline 8 & 0 & 0.000 & 0 & & & 0 & \\
\hline 9 & 0 & 0.000 & 0 & & & 0 & \\
\hline 10 & 0 & 0.000 & 0 & & & 0 & \\
\hline 11 & 0 & 0.000 & 0 & & & 0 & \\
\hline 12 & 0 & 0.000 & 0 & & & 0 & \\
\hline 13 & 0 & 0.000 & 0 & & & 0 & \\
\hline 14 & 0 & 0.000 & 0 & & & 0 & \\
\hline 15 & 0 & 0.000 & 0 & & & 0 & \\
\hline 16 & 0 & 0.000 & 0 & & & 0 & \\
\hline 17 & 0 & 0.000 & 0 & & & 0 & \\
\hline 18 & 0 & 0.000 & 0 & & & 0 & \\
\hline 19 & 0 & 0.000 & 0 & & & 0 & \\
\hline 20 & 0 & 0.000 & 0 & & & 0 & \\
\hline Ramp Seg & yments & & & & & & \\
\hline Number & $\begin{array}{l}\text { Crash Peri } \\
\text { Descriptior }\end{array}$ & & $\begin{array}{l}\text { Study Period } \\
\text { Description }\end{array}$ & Number & $\begin{array}{l}\text { Crash Peri } \\
\text { Descriptior }\end{array}$ & & \begin{tabular}{|l} 
Study Period \\
Description
\end{tabular} \\
\hline 1 & 0 & & 0 & 21 & 0 & & 0 \\
\hline 2 & 0 & & 0 & 22 & 0 & & 0 \\
\hline 3 & 0 & & 0 & 23 & 0 & & 0 \\
\hline 4 & 0 & & 0 & 24 & 0 & & 0 \\
\hline 5 & 0 & & 0 & 25 & 0 & & 0 \\
\hline 6 & 0 & & 0 & 26 & 0 & & 0 \\
\hline 7 & 0 & & 0 & 27 & 0 & & 0 \\
\hline 8 & 0 & & 0 & 28 & 0 & & 0 \\
\hline 9 & 0 & & 0 & 29 & 0 & & 0 \\
\hline 10 & 0 & & 0 & 30 & 0 & & 0 \\
\hline 11 & 0 & & 0 & 31 & 0 & & 0 \\
\hline 12 & 0 & & 0 & 32 & 0 & & 0 \\
\hline 13 & 0 & & 0 & 33 & 0 & & 0 \\
\hline 14 & 0 & & 0 & 34 & 0 & & 0 \\
\hline 15 & 0 & & 0 & 35 & 0 & & 0 \\
\hline 16 & 0 & & 0 & 36 & 0 & & 0 \\
\hline 17 & 0 & & 0 & 37 & 0 & & 0 \\
\hline 18 & 0 & & 0 & 38 & 0 & & 0 \\
\hline 19 & 0 & & 0 & 39 & 0 & & 0 \\
\hline 20 & 0 & & 0 & 40 & 0 & & 0 \\
\hline Crossroac & Ramp Tel & rminals & & & & & \\
\hline Number & Config. & Control & Crash Period Des & tion & & Study Peric & od Description \\
\hline 1 & 0 & 0 & 0 & & & 0 & \\
\hline 2 & 0 & 0 & 0 & & & 0 & \\
\hline 3 & 0 & 0 & 0 & & & 0 & \\
\hline 4 & 0 & 0 & 0 & & & 0 & \\
\hline 5 & 0 & 0 & 0 & & & 0 & \\
\hline 6 & 0 & 0 & 0 & & & 0 & \\
\hline
\end{tabular}

